Florida International University FIU Digital Commons

$11-4-2016$

\title{
Travel Education: A Phenomenological Study on Self-Directed Learning and Personal Enrichment Through Foreign Travel Experiences
}

Richard Jason Dapko

Florida International University, jasondapko@gmail.com

DOI: $10.25148 /$ etd.FIDC001259

Follow this and additional works at: https:// digitalcommons.fiu.edu/etd

Part of the Bilingual, Multilingual, and Multicultural Education Commons, Higher Education Commons, and the International and Comparative Education Commons

\section{Recommended Citation}

Dapko, Richard Jason, "Travel Education: A Phenomenological Study on Self-Directed Learning and Personal Enrichment Through Foreign Travel Experiences" (2016). FIU Electronic Theses and Dissertations. 2726.

https://digitalcommons.fiu.edu/etd/2726 


\section{FLORIDA INTERNATIONAL UNIVERSITY}

Miami, Florida

\section{TRAVEL EDUCATION: A PHENOMENOLOGICAL STUDY ON SELF-DIRECTED \\ LEARNING AND PERSONAL ENRICHMENT THROUGH FOREIGN TRAVEL EXPERIENCES}

A dissertation submitted in partial fulfillment of the

requirements for the degree of

DOCTOR OF EDUCATION

in

ADULT EDUCATION AND HUMAN RESOURCE DEVELOPMENT

by

Richard Jason Dapko 
To: Dean Michael R. Heithaus

College of Arts, Sciences and Education

This dissertation, written by Richard Jason Dapko and entitled Travel Education: A Phenomenological Study on Self-Directed Learning and Personal Enrichment Through Foreign Travel Experiences, having been approved in respect to style and intellectual content, is referred to you for judgment.

We have read this dissertation and recommend that it be approved.

Benjamin Baez

Eric S. Dwyer

Teresa Lucas

Thomas G. Reio, Jr., Major Professor

Date of Defense: November 4, 2016

The dissertation of Richard Jason Dapko is approved.

Dean Michael R. Heithaus

College of Arts, Sciences and Education

Andres G. Gil

Vice President for Research and Economic Development and Dean of the University Graduate School

Florida International University, 2016 
C Copyright 2016 by Richard Jason Dapko

All rights reserved. 


\section{DEDICATIONS}

My dedications are few, but mean the world to me. First, I thank God, in whom my faith has given me strength, patience, and peace. My own self-directed pursuits in life have given me incredible opportunities to grow as a person, see the world, understand others, and experience joy. The gifts from learning that I received through this process have been life changing, and for this, I am thankful. Second, to my mother and father for believing that I could do anything and for understanding that there was something important that I was looking for throughout my travel adventures. I dedicate this to you. Third, to my sister who had the courage to pursue a Ph.D. before me, I am proud of you; you inspired me to follow in your footsteps. Lastly, to the participants in this project, thank you for sharing your personal stories with me. My life is more interesting because I have heard them. 


\section{ACKNOWLEDGMENTS}

I want to gratefully acknowledge my major professor Dr. Thomas G. Reio, Jr. and my dissertation committee, including Dr. Benjamin Baez, Dr. Eric S. Dwyer, and Dr. Teresa Lucas, all of whom have experience traveling internationally and understand the educational value of it. Thank you for your support with this topic; I was deeply encouraged that you believed it to be interestingly unique and that you waited eagerly for its findings. Thank you for your time, suggestions, help, and genuine interest in a topic that was important to me. Each one of you has shown a professional care to help students, a personal belief in their potential, and a steadfast desire for their triumphs you are the definition of an educator. Thank you all for believing that I would return home, after traveling and living abroad during this project, with interesting findings and valuable contributions to my field of study. Knowing that you would be the first readers of my work made me want to raise my standards for quality in writing. Thank you Dr. Reio, for your periodic check-ins and supervision of my progress. I was happy that I was able to work with such a professional and scholar as my advisor. 


\begin{abstract}
OF THE DISSERTATION
TRAVEL EDUCATION: A PHENOMENOLOGICAL STUDY ON SELF-DIRECTED

LEARNING AND PERSONAL ENRICHMENT THROUGH FOREIGN TRAVEL EXPERIENCES

by
\end{abstract}

Richard Jason Dapko

Florida International University, 2016

Miami, Florida

Professor Thomas G. Reio, Jr., Major Professor

In the broad field of education, studies have been done to understand the ways in which adult learning, development, and transformation are fostered in travel contexts. Such studies mainly used the experiential learning and transformational learning theoretical frameworks to look at participants' lived learning experiences from travel. However, there is a void when one searches for studies that examine the intersection of self-directed learning and travel. This study used self-directed learning theory to explore the essence of learning from foreign travel experiences. The aim of this study was to understand the role of self-directed learning as a learning process that adults use to design and pursue learning and personal enrichment experiences in foreign travel contexts. This was about understanding the ways in which adults find joy in travel through creating their own learning environments. Qualitative interviews were gathered from participants who wished to share their experiences and conclusions were reported following a phenomenological framework. 
Today, becoming a self-directed learner is more important and prevalent than ever. Especially with the improved ease of use with technology to find and/or create learning opportunities and the availability of a multitude of travel options, information and experience-seekers have today a variety of ways to satisfy their hunger for personal enrichment. In an age when more adult learners are taking learning experiences into their own hands and looking to explore the foreign destinations that they might have only read about in books, or searched for online, it is important for travel-related providers and academic thought-leaders to understand the self-directed learning process as it relates to adult learners in foreign travel contexts. The findings of this study show that Knowles' self-directed learning theory can be an applicable and advantageous learning framework to be utilized during foreign travel experiences and that traveling with learning goals and strategies enhances such experiences. My personal goal with this project was to give readers a better understanding of how self-directed individuals learn through travel and an applicable construct with which to do so. 


\section{TABLE OF CONTENTS}

CHAPTER

PAGE

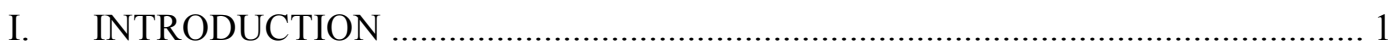

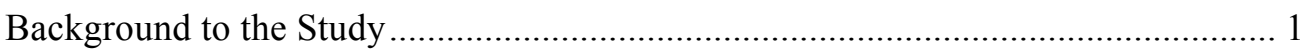

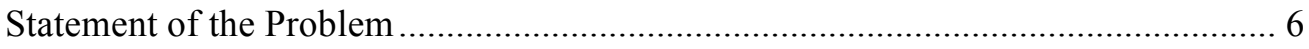

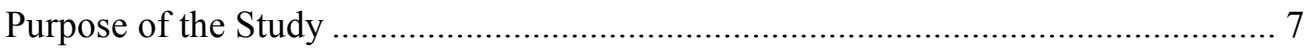

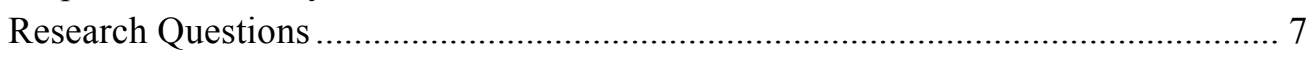

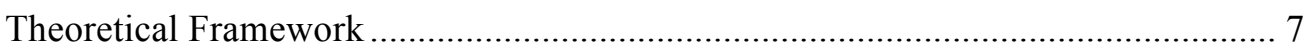

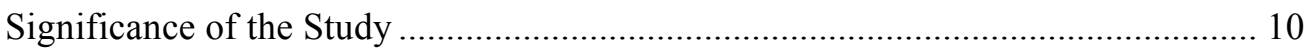

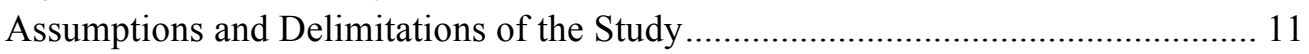

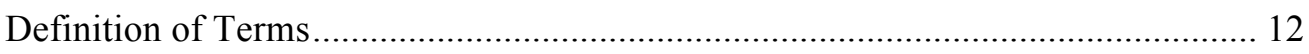

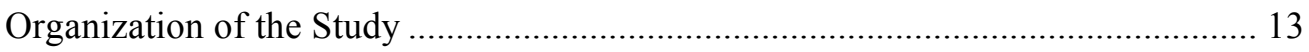

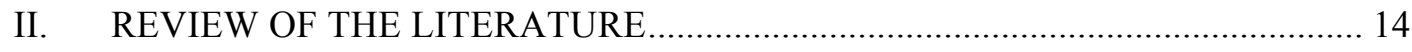

Adult Learning and Personal Enrichment .............................................................. 14

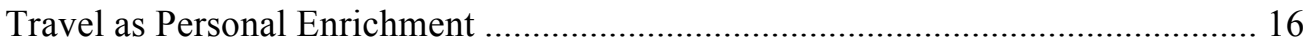

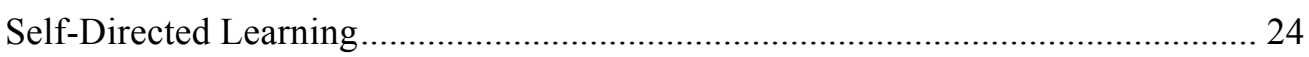

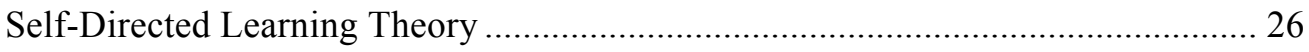

Application to the Adult Education Field ……........................................................ 40

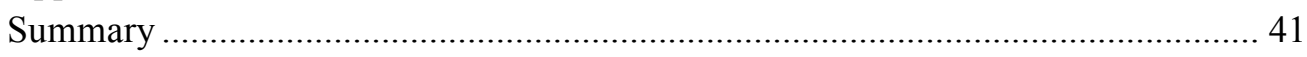

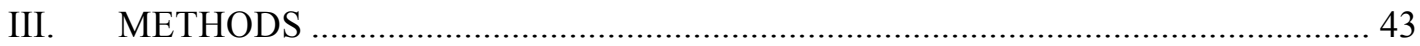

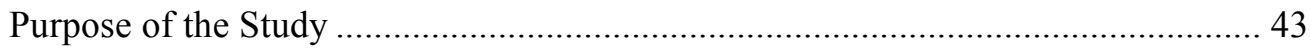

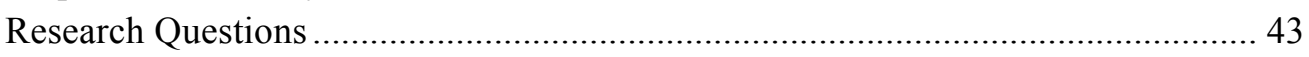

Phenomenological Framework ....................................................................... 44

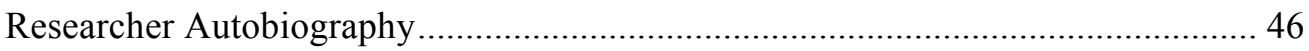

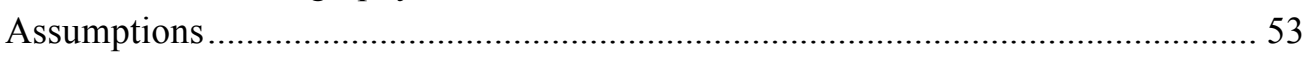

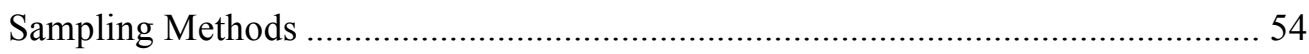

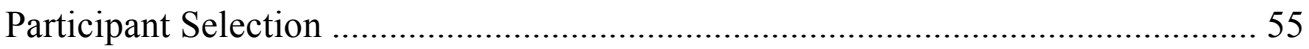

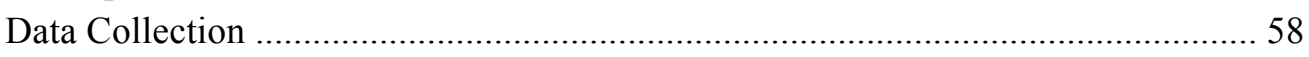

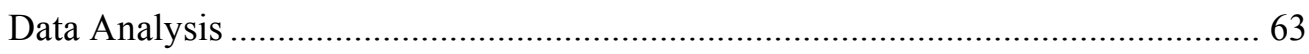

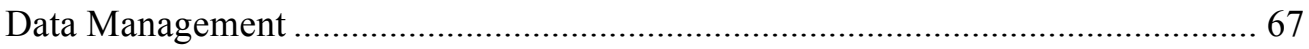

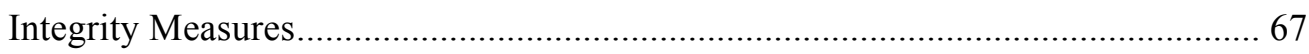

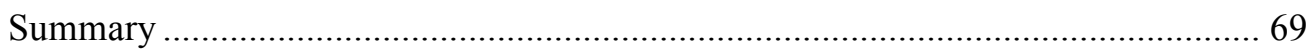

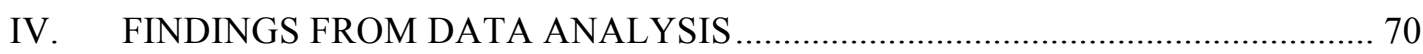

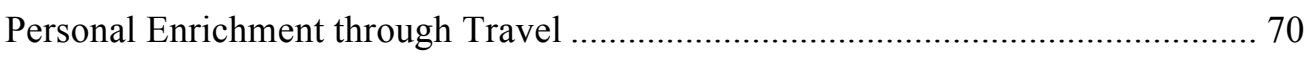

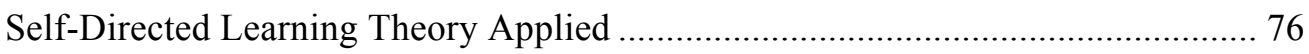

Identifying and Overcoming Challenges Along the Way ..................................... 114

Travel is Enhanced by Having Learning Goals and Strategies............................. 121 
Summary

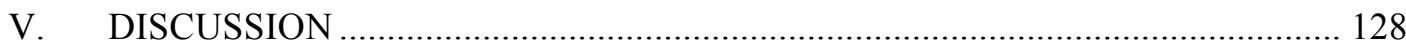

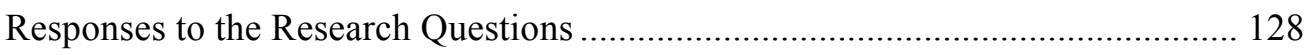

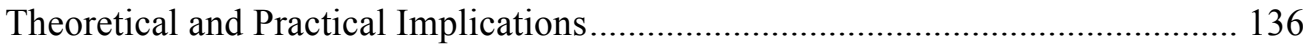

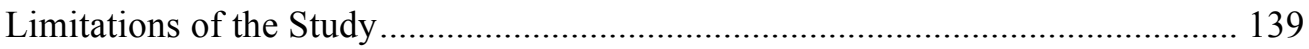

Recommendations for Future Research ......................................................... 140

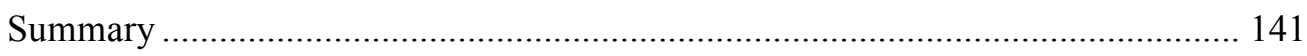

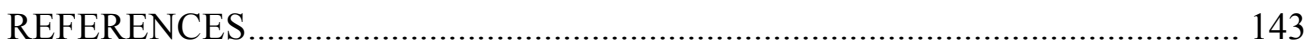

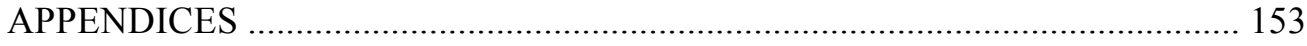

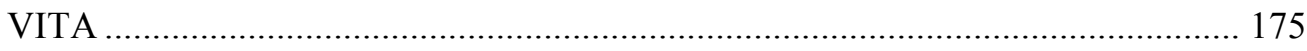


"The world is a book and those who do not travel read only a page."

-Saint Augustine

\section{CHAPTER I}

\section{INTRODUCTION}

The purpose of this phenomenological study was to understand the role of selfdirected learning as a learning process that adults use to design and pursue learning and personal enrichment experiences in foreign travel contexts.

This chapter begins with the background to the study, problem statement, purpose, and research questions. Next, the theoretical framework, significance of the research, assumptions and delimitations of the study, definition of terms, and organization of the study are discussed.

\section{Background to the Study}

People have been traveling to foreign destinations for various reasons long before Christopher Columbus "sailed the ocean blue." Today, travel is a large and growing industry; according to the World Travel and Tourism Council, travel and tourism accounted for over a $\$ 2$ trillion contribution to world GDP in 2012, up from $\$ 1.7$ trillion 5 years earlier in 2007 (WTTC, 2013). Business travel and tourism contributed over \$1 trillion to world GDP in 2012, up from $\$ 934$ billion in 2007 (WTTC, 2013). U.S. citizen traffic to overseas regions reached over 28 million passengers in 2012, which was a 5.5\% increase from the previous year (Office of Travel, 2013).

For many who travel, learning and personal enrichment are deliberate outcomes of their experience. Beside the 283,332 U.S. college students who were enrolled in study 
abroad programs for academic credit in 2011-2012 (Institute, 2013), adults of all ages participated in other forms of travel learning. There is a misconception among many college students that if they do not participate in study abroad programs during their undergraduate years, they might not have the opportunity again to enjoy learning experiences through foreign travel, unless they land a job that sends them to international locations or wait for retirement. On the contrary, there exists a variety of options for adult learners that wish to travel for the sake of learning and personal enrichment.

The notion that adults can continue to pursue learning experiences on their own time and terms points to an expression that is commonly heard in the adult education field: lifelong learning. In lifelong learning education, adults continue the process of further learning and continuous self-education throughout their lives. Lifelong learning also implies that learning occurs in many different settings and recognizes that many important learning influences are found outside the formal education system (Rubenson, 1998). This study focused on adult learning and personal enrichment gained through foreign travel, which in essence, was a study on lifelong learning.

\section{Learning through Travel}

Adult learners have various reasons for participating in formal and informal educational activities, travel notwithstanding. Mott (2000) pointed to some adult learners who participate "for the purpose of achieving some personal sense of fulfillment, for bringing about improvement in their lives, or even for the sake of leisure or recreation" (p. 335). An array of such formal and informal educational activities exists for the international traveler, including: enrolling in short or long-term language courses (total language immersion programs); volunteering; touring (historic sites, architectural works, 
natural wonders, national parks); adventure tourism (hiking, mountain climbing, rafting, etc.); attending professional conferences in foreign locations; participating in national celebrations, cultural festivals, or carnivals; and conducting international research, to name a few.

\section{Educational Programs for the Adult Traveler}

Adult learners quickly discover that there are a number of companies and organizations that provide educational experiences for the international traveler. One of the most well-known is Peace Corps, which provides a chance for selected applicants to see the world and immerse in a foreign culture while gaining international/intercultural experience, learning another language, and serving others (Peace Corps, 2012).

Worldwide, the Peace Corps Organization is currently serving 76 countries, including 8,073 volunteers and trainees (Peace Corps, 2012). The average age of volunteers is 28 , with 7\% being over age 50 (Peace Corps, 2012).

Other large, international organizations and companies have grown out of the demand for adult educational travel. International House World Organization (IH), Berlitz, and Amerispan offer foreign immersion with language and cross-cultural learning programs. IH also offers teacher training courses for adults interested in teaching their native language while traveling to foreign destinations (International House, 2012).

Touring can also create meaningful educational experiences (Rojek \& Urry, 1997). Companies such as Perillo Tours, National Geographic Expeditions, Education First, Deeper Africa, Kensington Tours, and Extraordinary Journeys, for example, provide travelers with structured and scheduled sightseeing tours and activity excursions. The programs offered from these companies vary greatly, but among them, the interested 
traveler will find opportunities, among others, to: follow guided tours through London, Amsterdam, Paris, Barcelona, and Madrid while learning about European history; experience food, wine, and museums of Italy; voyage on ship around Antarctica; safari through east Africa or climb Mount Kilimanjaro; participate in walking tours around Jerusalem while learning about major religions of the world; explore historical landmarks of ancient civilizations while learning about the cultures of indigenous people or ruins of Egypt or India, for example.

\section{Further Learning Opportunities for the Adult Traveler}

Formica and Uysal (1996), discussing foreign travel, suggested that "learning will be the leading motivation of the 21 st century; the learning concept is embedded in the desire to experience the history, the culture and the natural beauties of the host country" (p. 329).

Participating in national celebrations, carnivals, and festivals inherently create unique travel experiences, as they offer the traveler a real way to experience a country's history, arts, and culture (Yeoman, Robertson, Ali-Knight, Drummond, \& McMahonBeattie, 2011). Reasons for local communities to stage festivals include honoring national heroes or past events (Yeoman et al., 2011), religious traditions, local/cultural pride, and competitions; those who participate can have genuine learning experiences.

Some of the world's most well known carnivals and festivals include the parades of Rio de Janeiro (Brazil) and Trinidad and Tobago, the Running of the Bulls (Spain), Dancing with the Maya (Guatemala), Day of the Dead (Mexico), Chinese New Year (China), Raksha Bandhan (India), Oktoberfest (Germany), and the Olympic Games (host country is selected every four years). Host communities often offer such events to 
address issues of civic design, local pride and identity, heritage, conservation, urban renewal, employment generation, investment and economic development (Yeoman, et al., 2011). International travelers who design their travel plans with the intent of gaining historical or cultural understandings have the opportunity to learn first-hand about such local and national issues.

Additionally, attending international conferences, undertaking a foreign internship, or simply conducting research abroad are forms of travel for educational purposes and personal enrichment. These educational experiences can be seen as tools for enhancing career possibilities as well. Many organizations place a premium on job candidates' global competencies as such organizations strive to compete in an increasingly globally integrated marketplace (Vance, 2005).

Vance (2005) suggested that "individuals should seriously consider extended work experience [including internships] in a foreign business environment as very productive 'field learning' for building important global competencies" (p. 374). Various direct experiential learning approaches are being utilized to enhance learning outcomes in international education and global leadership competency development, including international internships, study abroad, cross-cultural virtual teams, and short travel study tours (Vance, et al., 2011).

Mitchell (2010) identified the "learning experience" as an important, motivating factor for travel (p. 177). Furthermore, if education was to be defined by consciously planned, sequential, and systematic learning procedures and learning outcomes, it would "ignore many of the informal and unplanned opportunities that potentially arise for learning within tourism" (Mitchell, 2010, p. 177). 
As we can see, there exists a large market for organized adult educational travel programs and lone-traveler experiences alike. It would, ultimately, serve the market makers and theorists as well, to have a closer look at the educational pursuits and experiences of participants. A greater understanding of educational travel could bring greater insight into why people travel at all (Mitchell, 1998). Exploring how adults learn from their foreign travel experiences will help us to understand their travel preferences and how, in fact, they choose to spend their recreation and leisure time, which for many adults, is limited.

\section{Statement of the Problem}

In the broad field of education, studies have been done (Arsenault, 1998; Brenner, 2014; Lindstrom, 2011; Sakkal, 2013; Stein, 2012) to understand the ways in which adult learning is fostered in travel contexts. Such studies mainly used the experiential learning and transformational learning theoretical frameworks to look at participants' lived learning experiences from travel.

There have also been done a range of studies on student learning in college study abroad programs (Couper, 2001; Kelly, 2010; Sanders \& Morgan, 2001; Swords \& Kiely, 2010; Tarrant \& Lyons, 2012; Tarrant \& Sessions, 2008). However, there is a void when one searches for studies that examine the intersection of adult self-directed learning and travel. This means looking at foreign travel experiences from the angle of lifelong learning (non-college-related) and personal enrichment, by using self-directed learning theory.

This theory has not been applied to the phenomenon of learning from foreign travel experiences. Exploring peoples' experiences of learning and personal enrichment 
derived from travel by using self-directed learning theory is a unique angle to look at such lived experiences. This examination looks at the process of self-directed learning as it is applied to learning from foreign travel experiences.

\section{Purpose of the Study}

The purpose of this phenomenological study was to understand the role of selfdirected learning as a learning process that adults use to design and pursue learning and personal enrichment experiences in foreign travel contexts.

\section{Research Questions}

The primary research question of this phenomenological study was: What is the essence of being a self-directed learner in foreign travel contexts? Secondary research questions included:

- How can Knowles' (1980) 6 components of self-directed learning be applied to learning and personal enrichment experiences in foreign travel contexts? For example, do learners include aspects of: (1) climate setting, (2) diagnosing learning needs, (3) formulating learning goals, (4) identifying human and material resources for learning, (5) choosing and implementing appropriate learning strategies, and (6) evaluating learning outcomes?

- How does being self-directed as a learner in foreign travel contexts serve to enhance the experience of foreign travel?

\section{Theoretical Framework}

The theoretical framework supporting this study will be briefly discussed here. The data gathered in this study concerning the learning and personal enrichment experiences of international travelers was analyzed using the contributions of Knowles 
(1980) theory of self-directed learning. The theory, along with an extensive discussion of comparable SDL models, will be presented in Chapter 2.

\section{Self-Directed Learning Theory}

Self-directed learning is one of the most important topics in adult education to be researched today, especially with its applicability to lifelong learning, online learning, and personal and professional development. Educational systems and the professions alike are recognizing the importance of developing practitioners to be lifelong learners and to pursue self-directed learning activities. With the focus on enhancing the ability of adults to be self-directed in their learning (Knowles, 1980), to take responsibility and initiative for planning, carrying out, and evaluating their own learning experiences, selfdirected learning theory is grounded in a humanist orientation to learning.

Humanist theories consider learning from the perspective of the human potential for growth; the emphasis is on human nature, human potential, human emotions, and affect (Merriam, et al., 2007). Theorists in this tradition believe that learning involves more than cognitive processes and overt behavior; it is a function of motivation and involves choice and responsibility (2007). In fact, Maslow (1970) and Rogers (1983) asserted that human beings control their own destiny; people are inherently good and will strive for a better world; people are free to act, and behavior is the consequence of human choice; and people possess unlimited potential for growth and development. Caffarella (1993) explained the humanist orientation of self-directed learning with the following statement:

The focus of learning is on the individual and self-development, with learners expected to assume primary responsibility for their own learning. The process of 
learning, which is centered on learner need, is seen as more important than the content. (p. 26)

Maslow's (1970) theory of human motivation, based on his famous hierarchy of needs, suggested at the highest level the need for self-actualization. This final need can be seen in a person's desire to become all that he or she is capable of becoming. The motivation to learn is intrinsic and thus emanates from the learner. Sahakian (1984) explained that learning itself is a form of self-actualization; among the growth motivations was found the need for cognition, the desire to know and to understand. Another interesting and important motivation of information-seeking and selfdirected learning is curiosity. Curiosity is increasingly being regarded as one of the important facets of human behavior (Reio, 2013). The desire to satisfy one's curiosity is one of the important factors motivating people to acquire new knowledge (Maslow, 1970). In fact, Reio (2013) suggested that further research be done to understand better how both cognitive and sensory types of curiosity stimulate development and learning. Traveling abroad, for the purposes of learning and personal enrichment, can certainly be regarded as a curiosity-driven activity. The compelling desire to explore what lies beyond one's national borders and then following that curiosity to foreign destinations might be frightening for many, but certainly has the potential to provide a rewarding adventure. Whatever the context of the participants' learning adventures happened to be, the focus of this study was on the learning process. From initial curiosity and preliminary travel plans and activity designs to the outcomes of learning and personal enrichment, the autonomous nature of adults taking learning experiences into their own hands was analyzed using Knowles' (1980) self-directed learning theory. 


\section{Significance of the Study}

The importance and implications of this research could affect the exchange of learning in the disciplines of adult education, travel \& tourism studies, lifelong learning, professional \& continuing education, psychology and self improvement, hospitality management, and international/intercultural education. In this study, the researcher aimed to make valuable contributions to the theoretical and practical applications of understanding the possibilities of adult learning and personal enrichment from foreign travel experiences.

At the academic level, this study extends the adult education and travel \& tourism research on educational travel by providing a phenomenological framework for comprehending self-directed travel learning experiences. The documentation and analysis of such self-directed pursuits was compared against Knowles' (1980) model of self-directed learning theory to provide an exploration of its practical application. Merriem (2001) remarked that there were numerous possibilities for how future research on self-directed learning might enrich adult education practice as well as contribute to theory in adult learning (p. 11).

At the firm level, this study could produce greater understanding of the learning motivations of those who purchase travel products/services and the outcomes from such purchases. Van Winkle and Lagay (2012) noted, "Tourism providers must develop a clear understanding of the learning experience tourists seek and the qualities of the experience that tourists value to ensure they can meet or exceed expectations" (p. 342). 


\section{Assumptions and Delimitations of the Study}

In this study, three assumptions are made. First, it is assumed that understanding the motivations of travelers, including those who travel for educational purposes, has an importance to the travel and tourism industry as well as adult learning fields. Second, it is assumed that individuals do, in fact, learn from foreign travel experiences. Third, it is assumed that individuals want to tell the story of their foreign learning and personal enrichment experience, and do so honestly. As a phenomenological study, it is important that participants be forthcoming and honest with information about their experiences.

There are three delimitations to this study. The first delimitation is looking at college study abroad participants' experiences. This study is concerned with adult learners, but not those who are traveling for college credit. Also, it is recognized that there are many reasons why one travels, that is, for business, vacation, visiting family/friends, religious reasons, etc. The second delimitation, then, is the focus on those who travel with the purposes of learning and gaining personal enrichment. As this study was guided by self-directed learning theory, it only looked at travelers who had these purposes in mind when preparing to travel; others were excluded.

The third delimitation addresses the fact that not everyone in the world has the access and opportunity to travel abroad for personal enrichment reasons. Those who do, have personally evaluated their financial and/ political situation, been granted travel permission by their home and host governments, and made the decision to spend their time and money on a travel experience. Due to the nature of the study, it cannot include asylum-seekers and refugees, for example, as their reasons for travel are due to a very different type of situation. 


\section{Definition of Terms}

For the purpose of this study the following terms were defined:

Adult learning (Andragogy), according to Knowles (1970), "learners see

education as a process of developing increased competence to achieve their full potential in life. They want to be able to apply whatever knowledge and skill they gain today to living more effectively tomorrow" (p. 44).

Lifelong learning, the notion that adults can continue to pursue learning experiences on their own time and terms, is the process of further learning and continuous self-education throughout their lives. Lifelong learning also implies that learning occurs in many different settings and recognizes that many important learning influences are found outside the formal education system (Rubenson, 1998).

Recreation \& Leisure, with parallels to the field of Tourism (Smith \& Godbey, 1991), is concerned with how individuals spend their free time.

Special interest tourism is concerned with the personal preferences people have while spending their recreation and leisure time on travel (Trauer, 2006).

Study Abroad refers to international academic programs for college credit pursued by U.S. students enrolled in higher education institutions (Institute, 2013).

Travel \& Tourism is one of the largest industries worldwide, and is defined by the World Tourism Organization as referring to traveling and staying in places outside one's usual environment for not more than one consecutive year for leisure, business, or other purposes (UNWTO, 1995). 


\section{Organization of the Study}

Chapter 1 addressed the background to the study and the problem statement. This chapter also described the purpose of the study, research questions, and theoretical

framework. The significance of the research, assumptions and delimitations of the study, and definitions of terms were also discussed.

In Chapter 2, a review of the literature relevant to self-directed learning theory and adult learning and personal enrichment are presented. In Chapter 3, the phenomenological framework is discussed, followed by this author's autobiography and assumptions related to the study. Then, sampling criteria and procedures for data collection, data analysis, and data management, and integrity measures are discussed. In Chapter 4, findings of the study are discussed, and the last chapter presents the implications and recommendations for future research. 


\section{CHAPTER II}

\section{REVIEW OF THE LITERATURE}

In this chapter, a review of the relevant literature on adult learning and personal enrichment through travel is presented and self-directed learning theory is explored. The purpose of the chapter is to review the academic literature regarding theory and previous empirical research that will explain the role of self-directed learning within the context of gaining personal enrichment through foreign travel experiences. The chapter is divided into main sections: Adult Learning and Personal Enrichment, Travel as Personal Enrichment, Self-Directed Learning, Self-Directed Learning Theory, Application to the Adult Education Field, and Summary.

\section{Adult Learning and Personal Enrichment}

Adult learners participate in many types of formal and informal educational activities. Some participate simply "for the purpose of achieving some personal sense of fulfillment, for bringing about improvement in their lives” (Mott, 2000, p. 335). Many adult learners pursue educational activities in their leisure time. Jarvis (2004) suggested that leisure time education is of "great importance since it provides opportunity for life enrichment and reflects a positive attitude on behalf of the learner to the acquisition of new knowledge and skills" (p. 32). He explained further:

If adult education can help people to relate more easily to contemporary culture, if it can help them to use their leisure time in a creative manner, if it can enrich the lives of many who undertake it [...] its provision will become even more important since more people are living longer and hence have more actual time in their lives to learn things. (2004, p. 32) 
Boshier (1991) suggested the following factors were applicable to the motivations of adult learners: communication improvement, social contact, professional advancement, improving relationships, social stimulation or escaping boredom, and cognitive interest or seeking knowledge for its own sake. The act of seeking knowledge for its own sake, cognitive interest, or simple curiosity can enrich an individual's life.

The simple pleasure that one feels in satisfying a curiosity is motivation enough for many information and experience seekers. Curiosity can be defined as a "desire to acquire new knowledge and new sensory experience that motivates exploratory behavior" (Litman \& Spielberger, 2003, p. 75). According to Opdall (2001), curiosity is, indeed, a legitimate motive to undertake exploration, described as a "confident and focused interest to find something out" (p. 331). Reio (2012) defined curiosity as:

A state of increased arousal response promoted by a stimulus high in uncertainty and lacking in information [...] There are two basic types of curiosity: cognitive and sensory. Cognitive curiosity is the desire for new information, while sensory curiosity is the desire for new sensations and thrills. (p. 894)

Being able to pursue such motivational interests for learning, seeing, experiencing, and doing, arguably leads to a sense of personal enrichment. The term personal enrichment here is defined by its qualifying synonyms: advancement, enhancement, development, or improvement, of the self. Therefore, personal enrichment activities are those that provide a positive benefit to the life of the learner.

Hansman and Mott (2010) explained: "adults may engage in less formal and more self-directed activities to enhance their personal or spiritual growth, to take on hobbies, or to learn skills that may improve their daily lives" (p. 16). Penland's (1979) study found that almost 80 percent of the population of eighteen years and over perceived 
themselves as continuing learners, whether in self-planned or formal courses and of the designated categories of his study, personal development and home and family ranked highest in popularity, followed by hobbies and recreation, general education, job, religion, voluntary activity, public affairs, and agriculture or technology (Penland, 1979).

The term personal enrichment is used in adult education, specifically when referring to lifelong learning. The concept of lifelong learning is constructed on the idea that learners have the control of making decisions about the goals and means for learning throughout their lifetime. Because the process continues throughout one's life, it cannot be identified with any specific age group. According to King (2010), the list of lifelong learning skills that could enrich one's life include: self-directed learning, problem solving, creativity, flexibility, critical thinking, coping strategies, research strategies, analysis, interpretation, independence, initiative, collaboration, multiple literacies, and goal setting (p. 425). She advised, "Helping learners of all ages to see the possibilities for learning in the world around them $[\ldots]$ can unleash new generative power that will add to personal fulfillment and success" (p. 425).

\section{Travel as Personal Enrichment}

Travel is frequently listed as a good choice among lifelong learning opportunities (MacNeil, 1998; Arsenault \& Anderson, 1998; Roberson, 2005). Boyatzis (1995) explained that "people learn most effectively when they are in control of the learning process and can choose developmental activities best suited to their personal situation" (p. 51). Foreign travel, especially when designed to be a learning activity, can foster personal enrichment and development of lifelong learning skills. A similar advantage of travel is that it provides an outlet for curious and exploratory behavior, a path to new 
information, adventure, and thrills. Bodger (1998) suggested that traveling for educational purposes "provides an immediate and personal experience of an event, place, or issue that cannot be duplicated" (p. 28). He further explained that learning experiences through travel "fall naturally within the continuum of lifelong learning" (p. 29).

Lindstrom (2011) discussed the various ways in which travel can offer personal enrichment. First, through "pilgrimage travel," he explained:

For thousands of years, numerous believers from Islamic communities, Christian enclaves, and other religious traditions have pursued enlightenment through pilgrimages to their sacred religious sites. Travelers past and present face and overcome various challenges to visit places of inspiration where they can pause to study and reflect upon their life [...] Modern day pilgrims continue searching for solace and enlightenment, inspired by a wide variety of historical, cultural, and spiritual figures, locations, and causes. (p. 5)

Cousineau (1998) agreed, suggesting that pilgrims take strength from the mere belief that the journey itself will return them as a changed person — no longer themselvesimproved in an undiscovered yet significant way.

Adventure travel can also provide educational experiences and personal enrichment (Lindstrom, 2011). The world has always been considered something that needed to be explored and conquered (2011). Civilizations such as the ancient Greeks, Romans, Chinese, Vikings, Polynesians, English, and Spanish all have recorded histories of sending brave explorers to discover new territories; one can reasonably assume that few if any adventure travelers of the early history era returned from their voyages as the same person who had departed (2011). Today, the adventure traveler has many options to explore the world while backpacking through the Andes mountains, train-hopping through Europe, white-water rafting in Costa Rica, kayaking on rivers in Africa, walking 
along the Great Wall of China, wilderness-trekking in the Australian outback, crossing the Sahara on camelback, etc.

Lindstrom (2011) also mentioned tourism and sojourner travel as means to gaining new information and experiences. Tourism travel, which pertains to vacation and leisure, can certainly be educational for the experience-seeker. Fussel (1987) explained that travel has long been an accepted means of enhancing one's knowledge and education, whether performed formally or purely for leisure. Van Winkle and Lagay (2012) concluded:

Learning during tourism is an engaging process of exploring one's self, relationships, other people, cultures and places where reflection about the self, relationships, past experiences and differences between one's own experience that the experience of others forms the basis of a learning experience that allows people to confirm or dis-confirm pre-existing knowledge by freely engaging in activities, with people and in spaces outside of the usual environment. (p. 350)

In their study (Van Winkle \& Lagay, 2012), fun, enjoyment, and engagement were commonly noted as features of the learning experience during tourism, which confirmed their thoughts that tourists seek opportunities for fun learning experiences that enhance their engagement with what they are learning about. Furthermore, Packer (2006) noted that exploration tends to be a key ingredient for learning during travel; through tourism, people have the freedom to explore and 'play with new ideas.'

Unlike tourism travelers, "sojourners" tend to relocate to new locations, thus giving them more of an extended opportunity to experience new lands, cultures, and to form new relationships (Lindstrom, 2011). Sojourners are often presented with an opportunity to learn a foreign language and the potential of learning to appreciate a culture different than their own (2011). Extended stays in a culture that is not one's own 
can also result in personally challenging situations that are likely to develop lifelong learning skills.

\section{Travel as Personal Enrichment through its Challenges}

The potential for personal growth through challenging cross-cultural encounters has historically been hypothesized by numerous psychologists, and labeled "culture shock." Hirschorn and Hefferon (2013) created an experimental design to analyze the motivations and personal enrichment outcomes of ten participants who had the experience of leaving a career to undertake independent foreign travel. They explained:

Three main themes emerged: an existential yearning to travel, "jumping off the ledge" (courage), and discovering authenticity. Personal growth occurred via adversity within the travel experience itself, but also at the pre-travel stage of departure, where leaving security and venturing uncertainty was experienced with "milestone" significance and, for some, as a seismic event akin to trauma.

(Hirschorn \& Hefferon, 2013, p. 283)

The processes by which growth is posited to occur include challenge to perceptions of self and own culture, release from routine and conformity, gathering of social and cultural capital, and necessary adaptation when living abroad (Hirschorn \& Hefferon, 2013). The researchers concluded that it is the close cultural engagement of the extended independent travel experience that is crucial to this process (2013). The shock of contrast and exposure to cultural and linguistic difference in culturally engaging travel can act as a trigger for personal growth.

Lyons (2010) discussed the notion of adversity and exposure to difference as precursors to personal growth, by arguing that some forms of travel offer an opportunity for personal transformation. Lyons (2010) presented the construct of "autonomous crosscultural hardship travel" (ACHT, p. 286), that is, foreign travel characterized by intense 
cross-cultural engagement, challenging conditions, and extended periods of movement. According to Lyons (2010), one not only encounters adversity as a facilitator to growth but also the loss of the home culture's supports, cues, and roles, which can force sudden recognition of one's identity as socially constructed and allow space for the emergence of the rudimentary "truer, more basic, deeper self” (p. 294). Lyons (2010) further concluded that the desire to pursue challenging long-term solo travel may embody Maslow's self-actualization impulse for travelers.

The three main themes that emerged from Hirschorn and Hefferon's (2013) study corroborate Lyon's position on personal development via foreign travel. First, participants' existential yearning to travel, also referred to as "a calling to something more," was defined by motivations for travel such as challenge and freedom; most participants described an elusive, long-standing need for something “more," "bigger," “wider," "potential," "possibility," and "to feel alive" (2013, p. 291). Participants described a long-standing desire to autonomously explore the world, following deep reflection on the purpose of their existence and nagging sense of discovering a life meaning (2013). This yearning for something more resulted in anxieties around reflections of the passage of time, finiteness of existence, one's mortality, and imagining later life regrets of not having taken advantage of a unique opportunity of the present moment (2013).

The second theme that emerged was referred to as "jumping off the ledge" (Hirschorn \& Hefferon, 2013) and was characterized by an urge to travel that was so compelling that some participants sold their cars and homes and left significant relationships, provoking extreme anxiety and feelings of trauma. Beyond overcoming 
pre-travel anxieties, participants also described mid-travel feelings of culture shock, fear of personal attack, prejudice, shyness, and daily uncertainty. However, by facing and overcoming such challenges, participants described personal growth by learning life lessons about the value of courage (2013). Previously living life as if to "play it safe," participants described a new life perspective full of vitality, self-efficacy, and meaning (2013).

Finally, the third emerging theme in Hirschorn and Hefferon's (2013) study was discovering authenticity, meaning, that participants experienced vitality by connecting with their "true self." Through self-determined activity, exposure to difference, and the experience of anonymity, traveling offered participants opportunities to connect with a sense of "true" self, vitality, fulfillment, and presence (2013). Participants described experiences of connecting to a "core" self within their travel experiences, which altered their outlook and priorities in life upon return. Travel experiences that result in an altered view of one's self can lead to real personal decisions about the direction of life and career paths.

\section{Travel as Personal Enrichment through Career Development}

Traveling with the intention of personal development and developing lifelong learning skills can result in acquiring and/or improving abilities that transfer over to the world of work and offer learners career growth potential. Inkson and Myers (2003) concluded that overseas travel in the pursuit of personal development and professional skill development is common among young adults. This is because "the characteristics of 'overseas experience' travel- boundarylessness, autonomy, independence, adaptability, transience, self-directed learning, and multiculturalism- are increasingly requirements of 
careers" (2003, p. 172). They suggested that human resource managers should be aware of the potential value of self-directed overseas experience in prospective employees when searching for corporate talent (2003).

As companies recruit, select, train, and promote on a global scale from a global labor pool, workers need, in addition to a set of skills, a global mindset (Rhinesmith 1992). People with global mindsets have the ability to look at the broader context, accept contradiction and ambiguity, trust processes rather than structure, value diversity and teamwork, view change as opportunity, and strive for continuous self-development (Kerka, 1993).

Even if they do not themselves relocate, workers will likely deal with people from other nations in their own workplaces or electronically. Dealing with other people in a diverse local as well as international context requires intercultural communication, teamwork, negotiation, and conflict resolution. In order to work with diverse teams, for example, workers need awareness of different values, cultural norms, and worldviews. Foreign language skills are becoming essential career skills as well.

Traditionally, issues of career choice, work preparation, and occupational information have been addressed in a national context (Herr 1990). However, the shift to a global context changes the content and focus of career education and development. Employment security is becoming "employability security" (Kanter 1991, p. 9) - the knowledge that one has the competencies demanded in the new economy and the ability to expand and adjust those competencies as requirements change. Furthermore, the ability to take self-directed, personal responsibility for one's career development is essential in today's world. 
In Orahood, Kruze, and Pearson's (2004) study, it was found that students who had foreign experience were more open to internationalizing their careers. These students, due to the skills that they acquired while abroad, are the types of professionals that employers seek for international assignments and even for domestic assignments that require a degree of cross-cultural competency (2004). Further, it was reported that:

The most illustrative findings were that $96 \%$ of study abroad respondents indicated that it affected their career plans and $94 \%$ are at least interested in working for a U.S. company with an international focus. Whereas $82 \%$ of respondents express an interest in working abroad, only $51 \%$ of non-study abroad respondents hold a similar interest. Another revealing finding is that $58 \%$ of the respondents stated that they are actively pursuing positions in foreign countries. (2004, p. 125)

It is clear that job-seekers are pursuing experiences that can enhance their competitiveness in a global market. Employers, as well, acknowledge the value of international experiences and are showing greater interest in candidates that can demonstrate what is being learned through their foreign travels. According to a study done by Trooboff, Vande Berg, and Rayman (2008):

Employers value some personal qualities, and an even greater numbers of skills, that derive from the "intercultural/global competence" criteria they were asked to rank. They especially value "listening and observing well," "adapting well to change," "working well under pressure," "analyzing, evaluating and interpreting well," and "working effectively outside one's comfort zone." (p. 29)

Murray (1999) also predicted a set of selection criteria that he believed would be important to employers in the future. These included a multicultural criterion, defined as a global understanding or mindset, and diversity, as the ability to be diplomatic and to possess an understanding of cultural differences and different ways of thinking (1999). Thomas and Inkson (2009) explained that cultural intelligence involves understanding the fundamentals of intercultural interaction, developing a mindful 
approach to intercultural interactions, and finally building adaptive skills and a repertoire

of behaviors so that one is effective in different intercultural situations. In essence, interacting effectively across cultures is now a fundamental requirement in today's global business environment (2009).

Essentially, the literature on experiencing learning and personal enrichment through foreign travel is there, and there are a multitude of learning experiences that are to be had through travel. Furthermore, understanding the role of self-directed learning as learning process that adults use to design and pursue such learning and personal enrichment experiences in foreign travel contexts was an new angle that needed to be studied.

\section{Self-Directed Learning}

Throughout ancient and modern history inquiring minds have set out to answer important questions through independent study, meditation, reflection, inquiry, and travel. Formal education, as we know it today, did not always exist. Educating the masses in a common curriculum was not always thought of as the best way to educate leaders and citizenry alike. In fact, some of the first schools that were developed in ancient times were based on self-directed learning.

Plato formed the Academy in 387 B.C. on the model of Socrates' dialogic method of teaching, with its emphasis on tutoring and mentoring. The Academy, often thought of as the first university in the Western world, was informal, consisting of an area set aside in Athens where students and teachers could meet to discuss ideas. This model incorporated two essential elements of the self-directed learning approach: (a) the teacher as mentor or facilitator rather than dispenser of knowledge to be committed to memory, 
and (b) the learner as a thinker and creator of knowledge rather than a passive recipient of the knowledge of others.

In modern times, there have been many masters, legends, and savants who, in lieu of formal education, pursued more independent learning projects, became self-taught in their arts, and made enormous contributions to the world. This notable list includes the likes of:

- Playwright George Bernard Shaw, who had very little formal education, educated himself through intensive reading, lecturing and participation in debates. Shaw was awarded the Nobel Prize for literature in 1925. His social comments are still quoted by contemporary writers.

- American novelist Ernest Hemingway, one of America's most celebrated literary giants. Author of For Whom the Bells Toll, The Sun Also Rises, and the Old Man and the Sea among others, he decided to skip college in order to learn from the experience of living. In 1954, he received the Nobel Prize for Literature.

- Acclaimed Mexican painter Frida Kahlo, after abandoning the study of medicine, began to learn and develop the artistic abilities that would make her name known throughout the world. Her interest in painting began as a hobby to help pass the time as she recovered from a terrible bus accident.

- Alexander Graham Bell, self-taught inventor of the telephone and telegraph. His college experience consisted only of attending a few lectures.

- Renowned architect Frank Lloyd Wright, America's most famous architect, developed his own methods himself before the field of architecture became a formal discipline. He designed over 800 buildings of which over 300 were actually built. His style, which he called "organic architecture," is still the object of study today.

- Andrew Carnegie, American industrialist and the richest man in the world of his time. He received his education not through school but through work and eventually became one of the world's greatest philanthropists.

- Sir Richard Branson, British billionaire and owner of Virgin Records and Virgin Airways. He chose to pursue business ventures instead of college. 
- American journalist Walter Cronkite, one of America's most celebrated journalists and longtime CBS news anchor, Cronkite dropped out of college to work for the Houston Post in 1935.

- Thomas A. Edison. Thought by some of his teachers to be too stupid for school, Edison was taught at home by his mother in his early years. Eventually this selftaught scientist would pioneer such technology as the electric light and the phonograph, and hold more than 1000 patents of invention.

- Bill Gates, arguably the richest and most famous college dropout in the world. Gates, co-founder of Microsoft, whose own self-directed learning included designing and building one of the most advanced computing software systems in the world from his garage, is exemplar of success through self-directed and lifelong learning.

Today, more recent trends in adult education demonstrate that even formal, classroom environments should cater towards students' individual self-directed needs, goals, and interests. This model adopts the idea of inquiry-based learning where students are presented with scenarios to identify their own research, questions, and knowledge regarding the area. As a form of discovery learning, students today are being provided with more opportunity to "experience and interact" with knowledge, which has its roots in self-directed learning.

\section{Self-Directed Learning Theory}

While certainly adults have always learned on their own, serious study of this phenomenon is relatively recent in comparison with other aspects of learning. There has, however, been a great deal of scholarly interest in autonomous and self-directed learning in adult education. The theory was chosen for this study because adults, in fact, experience personal enrichment through self-directed learning activities. Effectively, self-directed learning offers a path to increased life satisfaction (Guglielmino, 2008). 
Tough $(1967,1971)$ coined the term self-planned learning while providing the first comprehensive description of self-directed learning as a form of adult study. He described how adults craft their own plans for learning new things as he used the term "adult learning projects." The emphasis in this early work was on understanding how adults do, in fact, learn on their own and what the goals of self-directed learning should be. Scholars also debated about the goals of self-directed learning and began exploring the characteristics of those who are self-directed in their learning (Brookfield, 1986; Collins, 1988; Mezirow, 1985).

Around the same time, Knowles proposed that one of the basic assumptions of adult learning is that learners become increasingly self-directed as they mature (Knowles, 1970, 1980). In this model, importance is given to the adult's self-concept as a responsible decision maker and to their ability to take responsibility for their own learning. In defining what self-directed learning means, Knowles (1975) explained:

In its broadest meaning, 'self-directed learning' describes a process by which individuals take the initiative, with our without the assistance of others, in diagnosing their learning needs, formulating learning goals, identify human and material resources for learning, choosing and implementing appropriate learning strategies, and evaluating learning outcomes. (p. 18)

An important focus in the research literature on self-directed learning has been to look at "self-directedness" as a personal characteristic inherent in the learner. Following the assumption that learning in adulthood means becoming more self-directed and autonomous, Knowles (1980, p. 43) explained: "adults have a deep psychological need to be generally self-directing." Furthermore, the development of the skill of being a selfdirected learner is a high priority, especially as we live in an ever-changing world. 
Knowles' (1975) thoughts on the subject could have been written by a present-day author:

The "why" of self-directed learning is survival- your own survival as an individual, and also the survival of the human race. Clearly, we are not talking here about something that would be nice or desirable... We are talking about a basic human competence- the ability to learn on one's own- that has suddenly become a prerequisite for living in this new world. (pp. 16-17)

Guglielmino's $(1977,1997)$ studies on self-directed learning posited that "readiness," as an internal psychological state, is an important factor to look at when examining self-directed learners. She identified the psychological qualities involved in readiness for self-directed learning as initiative, independence, and persistence in learning; a high degree of curiosity; a strong ability to learn independently; enjoyment of learning; a tendency to be goal oriented; and a tendency to view problems as challenges rather than obstacles. These qualities form the cornerstones of her Self-Directed Learning Readiness Scale (SDLRS), which is the most frequently used quantitative measure in studies of self-directed learning. The measure scale has been used in a multitude of studies, including ones like Reio (2004). Shokar et al. (2002) showed a positive correlation among SDLRS scores and the clinical performance of medical students in their study. Effectively, those who scored higher in readiness for self-directed learning comparatively outperformed those who scored lower.

Guglielmino (1978) explained that "self-direction in learning can occur in a wide variety of situations [...including] self-planned and self-conducted learning projects developed in response to personal or workplace interests" (p. 34). She argued that "selfdirection in learning exists along a continuum; it is present in each person to some degree" (1978, p. 34). Further, to answer the question of why we ought to research it, 
promote it, support and foster it, she responded, "Perhaps the most basic reason lies in the fact that it is our most natural way to learn [...] Self-directed learning is our most basic, natural response to newness, problems, or challenges in our environment" (Guglielmino, 2008, p. 2).

Chene (1983) described the autonomous learner as independent, able to make choices and critical judgements, and capable of articulating the norms and limits of a learning society. Other scholars (Brockett \& Hiemstra, 1991; Garrison, 1992; Tennant \& Pogson, 1995) have agreed with the concepts of autonomous and independent thinking, self-responsibility, and control over learning when discussing self-directed learning in adult education.

However, the literature also suggests that autonomy is not context-free; that a person will exercise autonomy in certain situations and not in others. Knowles (1975, 1980) certainly expressed the importance of context with his explanations of andragogy. A learner's autonomy is likely to vary from one context to another, just as variables such as the learner's technical skills in learning, their familiarity with the subject matter, their sense of competence, and their commitment to learning will vary from situation to situation (Merriam, et al., 2007). Although there is some variance of autonomy across contexts, it can be said without reservation that the applicability of self-directed learning in adult education and the value in studying it are credible.

\section{Models of the Theory}

Self-directed learning has been studied with different approaches, including cognitive/ constructivist, social learning, and humanist approaches; the importance of individual experiences, the relationship between social/environmental aspects and 
individual learning, the degree of transfer occurring among different areas of learning, and views of human nature itself are all related to different perspectives of SDL (Ainoda, et al., 2005). It is, therefore, important to pay attention to the theoretical background in order to discuss SDL effectively, and to understand others' differences or sameness of views.

Houle (1961), as a pioneer in adult education, broke ground with his qualitative study focusing away from the teacher and onto the exploratory activities of the learner. His conclusions reported similarities in the learning process among 22 interview participants and thus he was able to identify three types of learners based on learners' perceptions of their reasons for pursuing lifelong learning.

The first learner type in Houle's (1961) study was goal-oriented. This type of learner sought to accomplish specific goals when faced with a need, interest, or problem. New knowledge or skill was pursued by the learner when the need or interest was perceived. Learning tended to be episodic rather than occurring as a constant flow of experiences.

The second learner type was activity-oriented (Houle, 1961). These learners found meaning in the pursuit of new knowledge or skill without a stated reason for the activity. Thus, the enjoyment of being involved in the activity was reason alone to pursue it.

Finally, the third learner type was learning-oriented, those who sought knowledge for its own sake (Houle, 1961). Most of these learners began their pursuit for knowledge in childhood, as enthusiastic readers. Their desire to learn is what drove them to join organizations or enroll in classes; it was for the value and enjoyment of learning in itself. 
Houle (1961) found that learners did not necessarily fit into just one type of learning, but that there was overlapping between the three types. The learner and their learning needs together formed a complicated intersection of motivations and interests. Ultimately, though, Houle (1961) believed that independent, self-directed learning was the chief method of learning for most individuals; furthermore, learning over a lifetime is essential to maintaining competence in the professions after formal education ceases.

Tough $(1967,1971)$, building upon the work of Houle, was at the forefront of describing self-directed learning; a concept which he named self-planned learning. He posited that adults create learning plans to carry out projects for themselves and he named such projects "adult learning projects." He defined learning projects as "a highly deliberate effort to gain and retain certain definite knowledge and skill, or to change in some other way" (Tough, 1978, p. 250). While Houle (1961) found that individuals learn for the love of it, Tough (1979) found the love of learning itself was seldom sufficient for embarking on a learning project. For Tough, learners worked on projects to prepare for a job or to keep up with the desired skills required at the time.

Within his investigations, Tough found that learners went through thirteen steps to accomplish their projects, including deciding about what, where, and when to learn along with selecting learning resources, identifying challenges, and so on. Learners move through steps to reach their learning goals, from one to the next, in a rather straight line. These thirteen steps can be categorized into four areas: (1) the learner oversees the entire process, (2) the learner regularly reflects on his or her progress, (3) the learner plans the next step in the learning process, and (4) the learner assesses the success of choices made (Tough, 1979). Specifically, the thirteen steps were as follows: 
- Deciding what detailed knowledge and skill to learn;

- Deciding the specific activities, methods, resources, or equipment needed for learning;

- Deciding where to learn;

- Setting specific deadlines or intermediate targets;

- Deciding when to begin a learning episode;

- Deciding the place at which to proceed during a learning episode;

- Estimating the current level of one's knowledge and skill or one's progress in gaining the desired knowledge and skill;

- Detecting any factor that has been hindering learning or discovering in efficiency aspect of the current procedures;

- Obtaining the desired resources or equipment or reaching the desired place or resource;

- Preparing or adapting a room for learning or arranging certain other physical conditions in preparation for learning;

- Saving or obtaining the money necessary for the use of certain human or nonhuman resources;

- $\quad$ Finding time for the learning; and

- Taking steps to increase the motivation for certain learning episode. (Tough, 1967)

These ideas formed a foundation for Tough's work, which confirmed the importance of self-directed learning in adults' lives.

Malcolm Knowles, a student of Houle, introduced the concept of andragogy to the United States in the 1970's, which was defined as the art and science of helping adults learn, in contrast to pedagogy as the art and science of teaching children. He explained: 
But something dramatic happens to their self-concepts when people define themselves as adults. They begin to see their normal role in life no longer as being full-time learners. They see themselves increasingly as producers or doers. Their chief sources of self-fulfillment are now their performances as workers, spouses, parents, and citizens. Adults acquire a new status, in their own eyes and in the eyes of others, from these noneducational responsibilities. Their selfconcept becomes that of a self-directing personality. They see themselves as being able to make their own decisions and face the consequences, to manage their own lives. In fact, the psychological definition of adulthood is the point at which individuals perceive themselves to be essentially self-directing. At this point people also develop a deep psychological need to be seen by others as being self-directing. (Knowles, 1970, pp. 45-46)

Knowles's (1975) model of self-directed learning included six major steps:

climate setting, (2) diagnosing learning needs, (3) formulating learning goals, (4) identifying human and material resources for learning, (5) choosing and implementing appropriate learning strategies, and (6) evaluating learning outcomes. Like Tough's model, Knowles proposed that learners move through steps, quite linearly, from one to the next. His model was based on his original assumptions that he used to describe adult learning, which were:

1. As a person matures, his or her self-concept moves from that of a dependent personality toward one of a self-directing human being.

2. An adult accumulates a growing reservoir of experience, which is a rich resource for learning.

3. The readiness of an adult to learn is closely related to the developmental tasks of his or her social role.

4. There is a change in time perspective as people mature- from future application of knowledge to immediacy of application. Thus, an adult is more problem centered than subject centered in learning. (Knowles, 1980, pp. 44-45)

It is clear that Knowles used his assumptions as foundational to designing, implementing, and evaluating learning activities for adults, including self-directed 
activities. To Knowles, being self-directed meant that adult learners could participate in the diagnosis of their learning needs, the planning and implementation of the learning experiences, and the evaluation of those experiences. In andragogy, great emphasis is placed on the involvement of adult learners in the process of self-diagnosis of needs for learning, translating those diagnosed needs into specific educational objectives, designing and conducting learning experiences to achieve the objectives, and evaluating the extent to which the objectives have been accomplished (Knowles, 1970).

Another important aspect of andragogy is the understanding that adults define themselves largely by their experience. In fact, they define who they are in terms of the accumulation of their unique sets of experience and if you ask adults who they are, they are likely to identify themselves by describing what their occupations are, where they have worked, where they have traveled, what their training and experience have equipped them to do, and what their achievements have been (Knowles, 1970). The implication here is that adults value their experiences and the learning lessons derived from them. Knowles (1970) explained further that:

The central dynamic of the learning process is thus perceived to be the experience of the learners; experience being defined as the interaction between individuals and their environment. The quality and amount of learning is therefore clearly influenced by the quality and amount of interaction between the learners and their environment and by the educative potency of the environment." (p. 56)

It is important to note that these self-directed learning models are systematic in their approach. The ultimate goal of SDL is to transition the responsibility of learning from the teacher to the learner, allowing the learner to assume control and establish independence in setting learning goals and monitoring their progress. Both Knowles and Tough — pioneers in the field of modern self-directed learning — stated that the primary 
goal of the self-directed learning model is to develop the learner's capacity to be selfdirected (Knowles, 1975; Tough, 1967).

Spear and Mocker (1984) suggested the notion of organizing circumstance, in that learners sometimes use a single resource as a guide for self-direction that is readily available to them in the immediate environment. They found that if a book was selected as the tool for learning, it was either in the learner's possession already or was borrowed from someone nearby, although it may not have been the best resource for the learning project. The implication is that self-directed learners engage in projects which are structured primarily by the limited choices in their immediate environment.

Spear and Mocker (1984) thus identified three essential elements that defined the learning process: (1) the learner's expectations, (2) the learner's skills and knowledge, and (3) the resources found in the environment. Since each learner created a unique learning environment, self-directed learning outcomes produced seemingly varied results. Their (1984) conclusions were that: (1) a change in personal circumstances is the trigger for self-directed learning, (2) the new circumstance provides limited learning options to the learner, (3) the circumstances dictate most of the learning conditions, and (4) the circumstances facilitate the movement from one learning episode to subsequent ones.

Consequently, Spear's (1988) model of self-directed learning was based on three elements: the opportunities that people find in their own environments, past or new knowledge, and chance occurrences. He suggested that self-directed learning projects are composed of sets or clusters of those elements; information gathered through one set of activities (a cluster) is stored until it fits in with other ideas and resources on the same topic having to do with other clusters of activities. 
For Spear, successful self-directed learning outcomes are those in which the learner can engage in a sufficient number of clusters of learning activities and later assemble the clusters into a meaningful whole. Spear (1988) explained: "the learner is perhaps in greatest control when the assembling of the clusters begins and decisions are made regarding what knowledge is of most and least importance" (p. 217). Some learners favor using multiple approaches to learning activities and concluding results after information is gathered. Some prefer trial-and-error learning, while others rather guide themselves by information seeking, making sense of random events, and moving to new levels of learning. Ultimately, the learner is the decision maker in deciding what new learned knowledge is most important.

Brockett and Hiemstra's (1991) model of self-directed learning was a two-part model, including: instructional method processes and personality characteristics of the individual learner. Under instructional processes, learners assume primary responsibility for planning, implementing, and evaluating their learning experiences. An "educational agent" or "resource" often plays a role in the learning process; there is an emphasis on the interaction between teaching and learning in this model.

The authors' second part of the model, personality characteristics of the learner, had to do with the learner's desire or preference toward assuming responsibility for learning. The importance of the notion of personal responsibility is what has given the model attention and distinction from others. In terms of learning, explained Hiemstra (1994):

It is the ability or willingness of individuals to take control that determines any potential for self-direction. This means that learners have choices about the 
directions they pursue. Along with this goes responsibility for accepting any consequences of one's thoughts and actions as a learner. (p. 13)

Garrison's (1997) model of self-directed learning was three-dimensional: selfmanagement, self-monitoring, and motivation. The model stated that the learner would take control of shaping the conditions required to reach their goals and objectives, which is "self-management." The responsibility of seeking out and using learning materials lay with the individual. Self-monitoring has to do with metacognitive processes, meaning their ability to think critically, so that a purposeful meaning can be constructed. The individual might think about their learning strategies and evaluate whether or not they are reaching their goals. Motivation, in this model, involves what influences people to participate or enter into a self-directed learning activity and what keeps them participating in the activity. Motivation influences both self-management and selfmonitoring in this model.

Other models of self-directed learning can be found in studies of specific populations, like Cavaiere's (1992) case study of the Wright brothers, Valente's (2005) study on older adults and health care, and Roberson and Merriam's (2005) study of rural older adults. Effectively, qualitative studies of adults have detailed a wide number of life-enriching activities that individuals pursue through self-directed learning (Guglielmino, 2008). Nevertheless, there currently does not exist a self-directed learning model that is specific to understanding peoples' experiences of learning and personal enrichment derived from foreign travel. 


\section{Goals of the Theory}

What is more essential for the continuous, lifelong learning that is required in today's world of pervasive and ever-increasing change than self-directed learning? Guglielmino (2008) answered this question by suggesting that "in a world of unprecedented proliferation of information and technology, instant worldwide communications, and intense global competition, lifelong self-directed learning is now, more than ever, a necessity for survival" (p. 4).

The goal of self-directed learning is to enhance the ability of adults to be selfdirected in their learning, whether it be in formal or informal learning settings, the workplace, pursuing interests or leisure activities, or in our everyday lives. Merriam, et al. (2007) explained:

Within this goal, the assumption is that part of the job of educators of adults is to help learners, whether they are learning on their own or in formal learning programs, to be able to plan, carry out, and evaluate their own learning. (p. 107)

Knowles (1973) believed that one should not wait until adulthood to begin developing self-directedness. As much as it is a lifelong learning skill, it should be practiced as early as primary education. Knowles (1973) further elaborated:

As an individual matures, his need and capacity to be self-directing, to utilize his experience in learning, to identify his own readiness to learn, and to organize his learning around life problems, increases steadily from infancy to pre-adolescence, and then increasingly rapidly during adolescence [...The] rate of natural maturation is represented as a decrease in dependency. (p. 43)

The skill practice of being self-directed begins in childhood. Later, the point at which the individual "achieves the self-concept of essential self-direction" is the point at which "he psychologically becomes an adult" (Knowles, 1973, p. 45). Self-directed learning is our most basic, natural response to newness, problems, or challenges in our 
environment (Guglielmino, 2008). It is an inherent ability that allows us to seek the answers to our own questions and should be practiced and improved throughout the individual's lifetime. The question is, how does one know if it is, in fact, being improved?

To realize an improvement, one must suspect that a change has occurred. Merriam, et al. (2007) explained that the second goal of self-directed learning is to foster transformational learning, based on the work of Mezirow and Brookfield.

Transformational learning has to do with adults making meaning of their experiences and concluding with changes in perspectives (Mezirow, 1990). "Transformative learning involves a particular function of reflection: reassessing the presuppositions on which our beliefs are based and acting on insights derived from the transformed meaning perspective that results from such reassessments" (1990, p. 18). The process of meaningmaking is one of the most vital types of self-directed learning adults engage in (Guglielmino, 2008). She (2008) explained:

By confronting and reflecting on the learning moments in their lives, they are able to arrive at new understandings. Based on those understandings, they may decide to rewrite their stories. Adults' reflections on their lives often lead to the visualization of a new future and the actualization of it. (p. 8)

Knowles (1973), with his theory of andragogy, also emphasized the importance of adult learners to reflect on their experiences. He (1973) instructed that "in the technology of andragogy there is decreasing emphasis on transmittal techniques of traditional teaching and increasing emphasis on experiential techniques which tap the experience of the learners and involve them in analyzing their experience (p. 46). 
Ultimately, adults need to reflect critically and have an understanding of the reasons for their needs, wants, and interests (Merriam, et al., 2007). Brookfield (1986) explained: "the most complete form of self-directed learning occurs when process and reflection are married in the adult's pursuit of meaning" (p. 38). Thus, the only way for an individual to notice a change in perspective and a heightened level of self-directedness is through critical reflection. In fact, it is common for learners to be unconscious to the fact that learning has occurred. Learning, many times, is a side effect of the activities one undertakes (Simons, 2000). For that reason, the qualitative nature and interview-based design of this study provided a natural space for participants to reflect on their foreign experiences, the self-directed learning process, their changes in perspective, and the personal enrichment that occurred from their travel pursuits.

\section{Application to the Adult Education Field}

Self-directed learning theory has been one of the major advances and greatest contributions to the adult education field (Brookfield, 1984; Houle, 1961). However, Bulik and Romero (2000) suggested that further research is needed to develop effective applications of self-directed learning processes and advance adult learning theories. Furthermore, Merriam, et al. (2007) exclaimed that "research and theory building in selfdirected learning is in need of fresh questions" (p. 127). They (2007) listed suggested areas to be investigated, to expand our understanding of adult learning through self-directed learning, including:

- To what extent is self-directed learning situational or cultural?

- How do cultural and contextual factors shape self-directed learning? 
- Does being self-directed as a learner have an impact on one's own instructional and planning activities?

This study was designed to develop such application of the self-directed learning models and advance the adult education body of knowledge. To that end, this author believed that it was appropriate to use self-directed learning theory as a tool to explore adult learners' autonomous and self-directed natures in the unique learning contexts of foreign travel. Lindstrom (2011) suggested: "those who engage in a more self-directed and reflective approach to travel will gain insight into their personal limitations as well as their tremendous potential for tremendous growth and independence” (p. 238).

This study has the potential to help understand andragogy theory as well. Knowles (1983) theory of andragogy was defined as "the art and science of helping adults learn" (p. 55) and claims that "as a person matures, his or her self-concept moves from that of a dependent personality toward one of a self-directing human being" (Knowles, 1980, p. 44-45). Exploring the travel experiences of adults who set out to travel for the purpose of learning and gaining a measure of personal enrichment could affirm the value and application of self-directed learning in a new and unique context: foreign travel. Guglielmino (2008) suggested, “As researchers, it is our responsibility to learn all we can about the process of self-directed learning and the best ways to facilitate the skills and attitudes of self-direction in learning [...] There is much that remains to be discovered" (p. 10).

\section{Summary}

In this chapter, self-directed learning and adult personal enrichment through travel were discussed. First, adult learning and personal enrichment were explained, using the 
contexts of lifelong learning and foreign travel. Next, self-directed learning and selfdirected learning theory were defined and models and goals of the theory were presented. Finally, this study's application to the adult education field was highlighted. Chapter 3 explains the phenomenological method of this study. Chapter 4 describes the findings and Chapter 5 discusses the responses to the research questions, implications, and recommendations for future research. 


\section{CHAPTER III}

\section{METHODS}

This chapter begins with the purpose of the study and the research questions. The phenomenological framework is discussed, followed by this researcher's autobiography and assumptions related to the study. Next, sampling methods and procedures for data collection, data analysis, and data management are described. The chapter concludes with a discussion of integrity measures and a chapter summary.

\section{Purpose of the Study}

The purpose of this phenomenological study was to understand the role of selfdirected learning as a learning process that adults use to design and pursue learning experiences in foreign travel contexts.

\section{Research Questions}

The primary research question of this phenomenological study was: What is the essence of being a self-directed learner in foreign travel contexts? Secondary research questions included:

- How can Knowles' (1980) 6 components of self-directed learning be applied to learning and personal enrichment experiences in foreign travel contexts? For example, do learners include aspects of: (1) climate setting, (2) diagnosing learning needs, (3) formulating learning goals, (4) identifying human and material resources for learning, (5) choosing and implementing appropriate learning strategies, and (6) evaluating learning outcomes? 
- How does being self-directed as a learner in foreign travel contexts serve to enhance the experience of foreign travel?

\section{Phenomenological Framework}

This study used a phenomenological framework to gather and understand research data and answer the research questions. According to Moustakas (1994), phenomenological methods: recognize the value of qualitative designs and methodologies, as studies of human experiences are not approachable through quantitative approaches; they focus on the wholeness of experience rather than solely on its objects or parts; they search for meanings and essences of experience rather than measurements and explanations; they obtain descriptions of experience through firstperson accounts in informal and formal conversations and interviews; they regard the data of experience as imperative in understanding human behavior and as evidence for scientific investigations; they formulate questions and problems that reflect interest, involvement, and personal commitment of the researcher (p. 21).

The foundational question of a phenomenological study is: What is the meaning, structure, and essence of the lived experience of this phenomenon by an individual or by many individuals (Johnson \& Christensen, 2008)? The purpose of phenomenological research was to obtain a view into the research participants' lived experiences and to understand their personal meanings (2008). We understand that events and experiences can mean different things to different people; however, phenomenologists generally assume that there is some commonality in human experience, and the quest is to understand this commonality. The commonality of experience is known as the essence of the experience (2008). 


\section{The Essence}

In philosophy, essence is the attribute or set of attributes that make an entity or substance what it fundamentally is, and which it has by necessity, and without which it loses its identity. Essence is contrasted with accident: a property that the entity or substance has contingency, without which the substance can still retain its identity. The concept originated with Aristotle, who used the Greek expression literally meaning, "the what it was to be." This phrase presented such difficulties for its Latin translators that they coined the word essentia (English "essence") to represent the whole expression.

The search for the essence of a phenomenon is the defining characteristic of phenomenology as a research technique (Johnson \& Christensen 2008). An essence is an essential characteristic of an experience (2008) and it is universal in particular occurrences of a phenomenon. A phenomenological point of view requires a set of assumptions that are different from those used when human behavior is approached with the purpose of finding "facts" and "causes" (Bogdan \& Biklen, 2007). Researchers strive, rather, to have their writing be consistent with the data they collect-not that they claim their assertions are "true," but that they are plausible given the data (2007). Further, they believe that the qualitative research tradition produces an interpretation of reality that is useful in understanding the human condition. Phenomenology provides a critical reflection upon the essential nature of experience, the necessary foundation for research, theory, and practice in education (Bolton, 1979).

Phenomenology was an ideal framework for this study due to its focus on the essence (commonality) of human experience. Understanding the common characteristics of the experiences of this study's research participants could benefit the development of 
self-directed learning theory and provide useful application to the field of adult education.

\section{Researcher Autobiography}

The importance of documenting the researcher's own lived experiences, as they relate to the context of the study, is inherent, as it can reveal their understanding of the subject, empathy toward participants, and relate-ability to similar experiences. Further, understanding these experiences gives insight into why the researcher chose the topic, their assumptions, and personal challenges with it. This is my story.

\section{My Lived Experiences Learning through Travel}

I have been traveling and learning about the world and its people, cultures, and histories through a very real, hands-on approach since I was an eighteen-year-old, recent high school graduate. See, during high school, I had no plans of going to college. All I knew was that I wanted to keep studying Spanish, my favorite subject. Consequently, when my twelfth-grade Spanish teacher recommended that I go to Costa Rica to fully immerse in the language and culture, a plan developed in my mind. Graduation was in June, and in August, as soon as I turned eighteen, I was off to Central America to live with a cultural exchange family. In hindsight, I can see clearly that I was motivated by my own self-directed learning plans- to experience a culture different from my own and improve second-language skills that I would use for the rest of my life.

After living in Costa Rica for about one year, I returned to the United States and my life, and my life's direction, had changed forever. I was "bitten by the travel bug," meaning that I knew that I was destined to be a lifetime traveler; consequently, whenever I would get the chance, and the money saved, I would plan foreign adventures. 
"Adventures," for me, meant learning trips; my fascination with how others lived and how cultures developed only grew with time. I would end up going back to school for a college degree, graduating with a major in International Studies, because it was the most relevant major for learning about the world.

In college, rather than becoming involved in athletics or fraternity life, I joined cultural groups and made friends with students from the English Language Center so that I could practice my Spanish and learn about foreign cultures. It was my way to stay connected to a world that existed outside of my own country. People would ask me all the time what it was, exactly, that I wanted to do once I graduated. I said that I wanted to travel.

Later, in my twenties, after having saved enough money to be able to travel and live abroad for a few months before graduate school, I left a professional government position to go live in the Dominican Republic and teach English at a small private institute. I was there for a semester, living and teaching, and was challenged in many ways, including culture shock and lifestyle differences. However, through challenge, I learned many valuable lessons. For example, I suspect that not too many Americans know what it is like to have a daily routine without the luxury of lights, electricity, and running water during certain hours of the day. But, in essence, one becomes more resourceful from those types of situations. It was my dream to live in such a unique and dynamic place, and teach English as a foreign language.

I ended up in Miami for graduate school, to pursue a Master's degree in education. Studying higher education administration, I thought, would open a door for me to work with international students and help them along their journey in a foreign 
country and education system just like others helped me during my travel journeys. So, that is what I did, for about seven years.

Further down the road, in my thirties, after holding a professional position at Florida International University and having completed all the coursework for my doctoral studies, I decided it was once again time to have a travel experience and immerse myself into a different culture for an extended period of time. I had a new dream; I wanted to be a traveling writer, at least for a little while. I had the idea of using my doctoral dissertation and another writing project to be the reason for traveling and dedicating fulltime effort toward something productive and beneficial. It was the opportunity of a lifetime. So, I ended the lease on my apartment, sold my car and furniture, donated clothing to Salvation Army, put some important things in storage and bought a one-way ticket to South America. It might sound crazy, but I saw it as a call to adventure another learning adventure.

I began writing this dissertation in Miami, where I was encouraged to begin the process of writing before finishing the degree's coursework. Once all courses were passed, I was free to leave Miami and travel while I wrote. So, I decided that Medellin, Colombia, a city with 360-degree views of the Andes Mountains would be an inspiring place to continue writing, and it was. I met other travelers that also thought Medellin was a fascinating place to visit or live and I had frequent opportunities to chat about the focus of my dissertation and receive valuable feedback from fellow travelers. See, as a traveler, I have always wondered if other travelers had similar experiences, especially when it came to learning and personal enrichment. I wondered what others were learning through 
travel, and I wanted to hear about their experiences. I found that there was a large expat community in Medellin, actually.

I initially chose Medellin to be my home while I wrote about a year before I relocated, after my first weekend get-away trip to the city. I was enamored with the genuine kindness that the "Paisa" people are known for (paisa is the term for people who live in and around Medellin). It is not the type of hospitality that you expect from a 5star resort hotel in the Caribbean somewhere. Actually, it is more humble and unpretentious; it feels as if locals simply enjoy being friendly, kind, and warm toward each other. And if you are an outsider, you immediately feel it hit you when you arrive. There is a sense that it has come to be their tradition, formed over centuries of inhabiting a secluded valley surrounded by mountains, in which people must learn to be patient and cooperative with each other. Out of this sense grew a custom of care for one another. As a matter of fact, before I had arrived, Colombia was named the world's happiest country, as mentioned in the Huffington Post and the Washington Post. The Huffington Post said:

The survey polled 66,040 people from 68 countries across the globe between September 2015 and December 2015, and asked respondents: "In general, do you personally feel very happy, happy, neither happy nor unhappy, unhappy or very, unhappy about your life?" According to the survey, 87 percent of Colombians polled said they were happy, and only 2 percent said they were unhappy, giving them a "net happiness score" of 85 percent - twenty points above the global average and nearly double the score of the United States.

The Washington Post explained:

There is always something dubious about attempts to quantify happiness, as with the latest WIN/Gallup International's annual global End of Year survey, which awarded Colombia a score of 85 percent "net happiness." But Colombia consistently ranks near the top of happiness polls no matter how these surveys frame their questions, and it's worth asking why... To most Colombians, nothing is more important than family, friends and fun... there is joy in the small things in life. 
This process, for me, of living abroad and writing, I referred to as my "Ernest Hemingway Experience.” See, Hemingway, an American novelist who received both the Pulitzer Prize for Fiction (1953) and the Nobel Prize in Literature (1954) spent much of his writing career abroad, living in exotic locations such as Paris (1920s) and Cuba (1930s and 1940s). It seems Hemingway produced some of his most notable works while immersed in inspiring foreign locations. Again, this might have been an unconventional career move for me, but a dream fulfilled nonetheless. And I perceive the saying, "Not all who wander are lost," as very fitting here.

I also considered this path that I took to be a part of my "hero's journey," so to speak. American mythologist, writer, and lecturer Joseph Campbell, most recognizable for his motto, "follow your bliss," documented world mythologies and culminated them into a single recognizable theme: the hero's journey. He wrote:

The hero's journey always begins with the call. One way or another a guide must come and say 'look, you're in Sleepy Land. Wake, and come on a trip.' And so it starts. The hero's journey is one of the universal patterns through which that radiance shows brightly. What I think is that a good life is one hero's journey after another. Over and over again, you are called to the realm of adventure, you are called to new horizons. Each time, there is the same problem: do I dare? And then if you do dare, the dangers are there, and the help also, and the fulfillment or the fiasco. There's always the possibility of fiasco. But there's also the possibility of bliss. (Campbell, 2004)

I believe that foreign travel gives us a way to go off into the unknown and redefine ourselves, even if only temporarily, into the hero of our own story - to open our eyes in a new way and discover something about the world or ourselves that transforms us for the better. And thus we return forever changed. This theme was explored with participants, the idea that travel enriches one's life. 
As an educator and someone who has dedicated his career to the field of education and development, this was $m y$ journey- to become a better educator by being a student who goes deeper into the lessons of his study. The journey was to find the lessons that travel had for me, while I wrote about and understood the lessons that travel had for others.

After 1 year in Colombia and traveling throughout the country a bit, I left. It was an amazing experience, but I felt that I needed to contrast my Colombian experience with yet another country and culture that would have even more lessons for my journey. I had mastered a level of fluency with Spanish and understood many of the unique nuances of a Latin-American culture. I needed to go somewhere that I had no previous experience with the language or culture, so that I could feel a sort of disorientation that so many travelers feel while abroad. I decided that I would go to French Canada, specifically, Montreal. Although it is in a majority English-speaking country, Montreal, and its province Quebec, are predominantly Francophone. All street signs, transportation signs, advertisements, product descriptions, announcements, and conversations on the street are done in French. I should add that I do not know French and I found it quite challenging to understand anything. But I found that I loved the experience because after a couple of months, I understood better the process of adapting to this type of situation, how a traveler must overcome certain uncomfortable situations and learn to "survive" culturally in a foreign environment. I must add that Montreal is a very diverse city and I found most people to be at least bilingual (French and English), if not trilingual; however, French is the language of instruction in schools and the preferred mother tongue of the local people. I was fascinated by a culture with which I had no previous experience. 
Montreal was my home while I concluded this study and finished the project. Spending a substantial amount of time in Colombia and Quebec was the perfect way for me to understand the experience of living in completely different cultures.

I mention my living situation over the past year and a half to reveal that I was, indeed, living some of the same experiences that my participants have lived. In this way, I did not need to try to gain access, as a researcher, into a "traveler" culture in which I was unfamiliar. In fact, my familiarity with this subject was what helped to establish stronger rapport with my participants. As a result, when it came to concluding the findings in this study, participants felt that I, as a fellow traveler, had been an understanding and trustworthy conveyer of the thoughts, opinions, and meanings that they had made of their experiences.

In fact, my experiences traveling have been a large part of what makes me who I am. From an eighteen year-old leaving the U.S. to live in Costa Rica for a year and thinking that college simply was not for him- to a doctoral candidate living in South America and French Quebec, writing a dissertation on the topic of travel and learning, life has brought me to some amazing places. For example, besides Costa Rica, Dominican Republic, Colombia, and Canada, which have been mentioned, my travels have also included parts of Spain, France, England, Portugal, Venezuela, Panama, Puerto Rico, and the Bahamas. As so, I have learned something about each destination and about the world, whether it has been cultural or linguistic, geographical or historical, or more of a hands-on learning from watching others do something differently. I like to relate my lessons to the famous poem by writer/poet Robert Frost (1874-1963), titled "The Road not Taken:" 
Two roads diverged in a yellow wood, And sorry I could not travel both And be one traveler, long I stood And looked down one as far as I could To where it bent in the undergrowth;

Then took the other, as just as fair And having perhaps the better claim, Because it was grassy and wanted wear; Though as for that the passing there Had worn them really about the same,

And both that morning equally lay In leaves no step had trodden black. Oh, I kept the first for another day! Yet knowing how way leads on to way, I doubted if I should ever come back.

I shall be telling this with a sigh Somewhere ages and ages hence:

Two roads diverged in a wood, and I I took the one less traveled by, And that has made all the difference.

I too, have taken the road less traveled, and it has made all the difference. Consequently, my own learning experiences bring certain assumptions that I have about the learning experiences of others. Next, I will discuss those assumptions.

\section{Assumptions}

Upon critical personal reflection, I realize that the assumptions that I have had toward the process of learning through travel experiences include the following:

1. There are, in fact, a multitude of learning/personal enrichment outcomes to be gained through foreign travel.

2. Learning/ personal enrichment experiences through travel can be life changing. In fact, I believe that people are forever changed by the enriching experiences that 
they have during foreign travel. Further, overcoming the challenges that one faces while abroad is highly educational and enriching as well. One must learn to be open-minded toward new experiences, and adapt to the unexpected.

3. Those who design travel plans with the intention of learning something new usually are not aware that they are applying any component of self-directed learning theory. In this study, it was my job as researcher to understand their learning process.

4. Awareness that learning or personal enrichment has occurred sometimes only happens upon personal reflection, after the experience is over. It was my job as researcher to elicit such reflection and probe the participant's descriptions.

\section{Sampling Methods}

One of the main issues that researchers deal with when conducting a study is locating information-rich individuals who are available, accessible, and appropriate to be potential participants (Johnson \& Christensen, 2008). In this case, however, because I have been traveling for many years and meeting fellow travelers along the way, I had the opportunity to create a list of potential interviewees for this study. Many of them have agreed to participate beforehand, making them a convenience sample. Researchers use convenience sampling when they include in their sample people who are available or volunteer or can be easily recruited and are willing to participate in the research study (Johnson \& Christensen, 2008). The researcher selects individuals who can be "conveniently selected." In fact, the majority of researchers do not select random samples; rather, they tend to use convenience samples (Johnson \& Christensen, 2008). 
Convenience sampling did not bring as many participants as needed, however. It provided me with only nine. There were nine people who I knew previous to this study that had experience with traveling for educational purposes in a self-directed manner. To find more participants, purposive sampling was employed. In purposive sampling, the researcher specifies the characteristics of a population of interest and then tries to locate individuals who have those characteristics (Johnson \& Christensen, 2008). I found four more participants that fit my criteria while I was traveling. In fact, three of them were housemates with whom I shared temporary accommodations and one was a neighbor in an apartment building where I rented an apartment. The website that I used to find housing while I was abroad was "airbnb.com." Although it is a site that is used worldwide to find accommodations in virtually any region of the world, I found that it was a resource mainly for travelers visiting foreign countries. That is to say that in Colombia, I did not meet any Colombians that used it locally, although I met plenty of Americans, Europeans, and Australians who did. The website was a resource for me, through which I met three participants in Colombia who were willing to talk about their travel experiences and one while I was in Canada. The next section will discuss the characteristics that I looked for in potential participants and my selection criteria.

\section{Participant Selection}

One concern with participant selection is, "how do I identify knowledgeable subjects?" For this study, subjects were not asked to participate simply based on the fact that they have traveled. This study was not based on what someone did during a foreign travel experience; the study was undertaken to better understand what and how someone learned during a foreign travel experience. Thus, selection criteria was based on the 
following: (1) the participant traveled outside of their home country, which could have been for a short-term stay (my minimum requirement was 1 week), (2) there was something to be learned or an experience to be had that would bring personal enrichment. Traveling outside of one's home country also meant that they would be leaving their own culture, as there are no two countries that are alike in this world. Being immersed in another culture brings a host of learning opportunities in itself. In this study, many participants were U.S. citizens who have traveled abroad; however, I included citizens of other nations as participants as well. Further, the reason for traveling needed to include a learning/ personal enrichment experience, so that I could explore participants' learning plans and strategies to see if any or all components of Knowles' (1980) self-directed learning theory could be applicable in this context. With respect to age and gender, my goal was to have a diverse set of data samples, therefore, "adult learners" in this study meant man or woman, 18 years of age and older. In fact, this definition could have included one who traveled for the first time at 18 , or a retiree who has traveled their entire life.

Another concern with participant selection is, "how many subjects should be selected so that adequate exposure to the field can be reached?" To answer this question, it is important to recognize that the phenomenological approach to research can be applied to a single case or to multiple selected samples. While single-case studies are able to identify issues which illustrate discrepancies and system failures - and to illuminate or draw attention to 'different' situations - positive inferences are less easy to make without a small sample of participants. In multiple-participant research, the strength 
of inference which can be made increases rapidly once factors start to recur with more than one participant.

However, samples for qualitative studies are generally much smaller than those used in quantitative studies. Qualitative samples must be large enough to assure that most or all of the perceptions that might be important are uncovered, but at the same time if the sample is too large data becomes repetitive and, eventually, superfluous. If a researcher remains faithful to the principles of qualitative research, sample size in the majority of qualitative studies should generally follow the concept of saturation (Glaser $\&$ Strauss, 1967), as the study goes on more data does not necessarily lead to more information. Although researchers generally use saturation as a guiding principle during their data collection, I found the following practical estimated ranges to be helpful in gauging my own research milestones and timelines: for phenomenological studies, Creswell (1998, p.64) suggested five to 25 samples of data; Morse (1994, p.225) suggested at least six samples. It was my expectation then that 10-12 samples would provide sufficient data for the purposes of exploring the essence of this study, and I ended with 13 overall. See Table 1, it shows that participants had substantial personal experience with foreign travel and thus would be able to provide valuable points of view according to their extensive background with it. Further, this table shows the diversity of national heritage among the participants, which provided diversity of experiences. 
Table 1

Participant Information

\begin{tabular}{lcllcc}
\hline Pseudonym & Gender & Age & Nationality & Age First Traveled & Travel Experience \\
\hline Jorge & M & 33 & U.S. (Colombian) & 4 & 19 countries \\
Daniel & M & 50 & U.S. & 8 & 17 countries \\
Kamal & M & 29 & Indian & 2 & 19 countries \\
Gabrielle & F & 32 & French & 5 & 7 countries \\
Evelyn & F & 34 & Australian & 17 & 16 countries \\
Eric & M & 50 & U.S. & 20 & 17 countries \\
Logan & M & 32 & U.S. & 16 & 15 countries \\
Viktorya & F & 23 & Moldovan & 4 & 11 countries \\
Marie-Anne & F & 25 & Haitian & 7 & 13 countries \\
Jean Claude & M & 45 & Canadian (French) & 10 & 33 countries \\
Darrell & $\mathrm{M}$ & 48 & Bahamian & 15 & 30 countries \\
Eduardo & $\mathrm{M}$ & 43 & U.S. (Puerto Rican) & 6 & 15 countries \\
Ken & $\mathrm{M}$ & 45 & U.S. & 11 & 37 countries \\
\hline
\end{tabular}

\section{Data Collection}

In a typical phenomenological research study, the data are usually collected through in-depth interviews (Johnson \& Christensen, 2008). Using the interview data, the researcher attempts to reduce the statements to the common core or essence of the experience as described by the research participants (2008). The data collection method for this study was in-depth qualitative interviews, which Rubin and Rubin (2011) defined as having the following characteristics: 
1. The researcher is looking for rich and detailed information, not for yes-or-no, agree-or-disagree responses. He or she is looking for examples, for experiences, for narratives and stories.

2. The interviewer does not give the interviewee specific answer categories; rather, the questions are open ended, meaning that the interviewee can respond any way he or she chooses, elaborating upon answers, disagreeing with the question, or raising new issues.

3. The questions that are asked are not fixed. The interviewer does not have to stick to a given set of questions or ask them in a given order; he or she can change wording or skip questions if they don't make sense at the time, or make up new questions on the spot to follow up new insights. He or she can pose a separate set of questions to different interviewees. (p. 29)

Bogdan and Biklen (2007) described interviewing as a process so familiar that we do it without thinking (p. 103); it is simply a purposeful conversation. The interview is, in essence, used to gather descriptive data in the subject's own words, so that the researcher can develop insights on how subjects interpret some piece of the world (2007).

\section{Process}

The two main types of in-depth qualitative interviews are semistructured and unstructured interviews. Because I intended to use a more directed approach to the interviews, they had a semistructured design, simply meaning that the researcher has a specific topic to learn about, prepares a limited number of questions in advance, and plans to ask follow-up questions (Rubin \& Rubin, 2011). In semistructured interviews, the researcher tries to focus more narrowly on the planned items that speak to the research question (Rubin \& Rubin, 2011). Qualitative interviews offer the interviewer considerable latitude to pursue a range of topics and offer the subject a chance to shape the content of the interview (Rubin \& Rubin, 2011). Further, good interviews tend to be those in which the subjects are at ease and talk freely about their points of view; they 
produce rich data filled with words that reveal the respondents' perspectives (Rubin \& Rubin, 2011).

According to Johnson and Christensen (2008), one effective strategy for eliciting data from participants is to tell each participant to recall a specific experience he or she has had, to think about that specific experience carefully, and then to describe that experience to the researcher (p. 398). The researchers suggested that participant responses can be in the form of written narratives, as well as in-person interviews. This is important to note, as I requested written narratives from certain participants who either felt more comfortable with it than in-person interviewing or were geographically located in a foreign country at the time of data collection.

The goal was to get participants to think about their specific experience and to describe it in rich detail. "Richness" means that the interviews elicit numerous themes that can be explored; richness is obtained by asking for extended descriptions, long stories, and narratives, which often contain multiple themes (Rubin \& Rubin, 2011). It can also be defined as depth and detail, which can be obtained by exploring the themes that the interviewee discusses. I framed a few of my interview questions to be answered in the form of a personal account, or story. I believe that stories are, in fact, more interesting and enlightening than explanations. They are richer and provide a more personal connection between two people, may it be the storyteller and the reader, than mere matter-of-fact accounts can provide.

Furthermore, I felt that using academic and profession-specific terms that we use in the education fields, like "learning needs," "performance measures," "learning outcomes," "evaluation metrics," and "reflection and analysis" might have created a level 
of misunderstanding between participants and myself. Therefore, engaging the participants in a sort of storytelling about their experiences was the direction that I took.

For example, instead of asking, "How were you prompted to travel by your perceived learning need?" I asked, "Was there something going on in your life that triggered your desire to travel?" Instead of asking, "In what ways did you monitor or reflect on your learning process?" I asked, "What did you learn from your experience?" Instead of saying, "How were you able to locate and utilize the resources that you would need to facilitate the learning experience?" I asked, "How did you find help along the way?” American author Joseph Campbell said, “I don't believe people are looking for the meaning of life as much as they are looking for the experiences of being alive" (The Power of Myth, 1988, Episode 2, Chapter 4). The purpose of these interviews, then, was to capture those experiences.

\section{Responsive Interviewing}

Responsive interviewing, as the style of interviewing that I employed, is based on the importance of building a relationship of trust between interviewer and interviewee that leads to more give-and-take in the conversation (Rubin \& Rubin, 2011, p. 36). Responsive interviewing emphasizes searching for context and richness while accepting the complexity and ambiguity of real life. Other characteristics of responsive interviewing include: the understanding that the personalities of both interviewer and conversational partner impact the questioning; interviewing is an exchange that occurs within a meaningful (albeit sometimes temporary) relationship between interviewer and interviewee; and the design remains flexible, from the first formulation of the research topic to the last bit of analysis of the data (Rubin \& Rubin, 2011). 
Responsive interviews are built around main questions, follow-up questions, and probes that together elicit the rich data that speak to the research question (Rubin \& Rubin, 2011). Main questions begin a discussion about each separate part of the research question and they ensure that the research question is answered from the perspective of the conversational partner. Follow-up questions seek detailed information on the themes, concepts, or events that the interviews produce; they explore the interviewee's answers to obtain further depth and detail and to ask for clarifying examples. Probes help manage the conversation by keeping it on topic, signaling the desired level of depth, and asking for examples or clarification. Probes can be short comments or gestures, for example, "Go on..." or "Can you give an example?"

The interviews were recorded on my iPhone, which had an excellent recording application. The device was tested with a pilot study that was done for this research undertaking, in a previous doctoral class, which turned out very successful and confirmed my interest in this subject. The recordings were then transcribed professionally by a reputable service online called rev.com and returned to me for review of accuracy. In the case that a participant preferred to send me a written narrative following my questions, a review was done to make sure that they understood the questions and to see if there were any necessary follow-up questions. In addition, a written conversational guide accompanied me during the interviews, which was simply an outline of the questions that I wanted to ask, the themes that I want to touch upon, and a checklist of goals to be accomplished. As with any natural conversational flow, I expected the unexpected. However, the conversations were guided by interview themes that gave insight to the 
research questions. The majority of interviews were approximately 1 hour in length and provided approximately 15-20 pages of transcribed data, each.

\section{Interview Themes}

Interview themes included the following: (1) background information setting up the discussion of the travel experience, (2) an explanation of how learning and/or personal enrichment was gained through foreign travel, (3) an exploration into their personal process of self-directed learning strategy; in other words, the cognitive process and steps that the participant took to consciously plan, execute, and reflect upon a travel experience in which learning and/or personal enrichment was gained.

Background information included why the participant chose a particular foreign destination- what they wanted to see, do, learn at the location- and what led them to being interested in the destination in the first place. Next, the discussions lead to what exactly was the learning and/or personal enrichment experience for the participant. Finally, I probed the participant's own design plans and strategies for learning while traveling and explored how they might have helped to enhance the overall travel experience.

\section{Data Analysis}

During data analysis, the researcher searches for significant statements, ones that have particular relevance to the phenomenon being studied (Johnson \& Christensen, 2008). The researcher might want to ask themself, "Does the statement seem to have meaning to the participant in describing his or her experience? Is the statement descriptive of the experience?" The core part of early data analysis is to recognize and identify concepts, themes, events, and examples and then mark them in the text (Rubin \& 
Rubin, 2011). The researcher then chooses to code the ones that they think will give them a better understanding of the research problem.

Statements that touched on research themes were coded with an organized system that this researcher developed. Developing a coding system involves several steps: searching through data for regularities and patterns as well as for topics the data cover, then writing down words and phrases to represent these topics and patterns (Bogdan \& Biklen, 2007). The authors (2007) suggested "coding families," as a tool to develop coding categories and to help in sorting out data (p. 174). Coding families include: setting/context codes, process codes, activity codes, event codes, strategy codes, relationship codes, methods codes, and more (2007). Bogdan and Biklen (2007) advised to develop a coding system with a limited number of codes, about 30-50, that encompass topics that the researcher wants to explore. Codes are developed to label important statements and themes that emerge from the data, and this researcher utilized 10 major theme codes based on what emerged from the data that pertained to personal enrichment through travel, Knowles SDL model, travel being enhanced through learning, and travel challenges - themes that might help to understand the phenomenological context of the study. Further, another 20 codes were labeled as specific items to be analyzed, that fell under the 10 major code themes. See Appendix B.

\section{Data Analysis and Computer Software}

There exists today a variety of computer assisted qualitative data analysis software (CAQDAS) to help researchers be more efficient with their increasing amount of data. Programs offer assistance in terms of transcription analysis, coding and text interpretation, recursive abstraction, content analysis, and discourse analysis. Such 
programs include: Atlas Ti, NVIVO, RQDA, LibreQDA, FreeQDA, Coding Analysis Toolkit (CAT), and Computer Aided Textual Markup \& Analysis (CATMA), to name a few.

The advantages of using this software include saving time, managing huge amounts of qualitative data, having increased flexibility, having improved validity and auditability of qualitative research, and being freed from manual and clerical tasks (John \& Johnson, 2000). Concerns include increasingly deterministic and rigid processes, privileging of coding, and retrieval methods; reification of data, increased pressure on researchers to focus on volume and breadth rather than on depth and meaning, time and energy spent learning to use computer packages, increased commercialism, and distraction from the real work of analysis (John \& Johnson, 2000).

I mention my understanding of available software programs to make it clear that I weighed my options. However, for this researcher, Microsoft Word worked just fine, files were created to store documents and they were labeled and organized within larger files. Every document and file was labeled with a clear description. One file, labeled "Interviews," held all of my collected data; another file, "Researcher Journal," contained my ongoing journaling notes; there was another file for "Codes list" and another for "Research Questions." These files were stored within a larger file, which held other important documents for my doctoral program, including memos, forms, IRB approval, and other completed dissertations to use as writing examples. I found it very easy to search for a specific file and, consequently, specific words, codes, or phrases within documents by using the search feature at the top of each Word document. Interview data were coded by utilizing the [Insert > Comment] feature at the top of the screen; this adds 
a comment to the right side of all text on the page, this is how I underlined the words, phrases, and statements as a code theme and added the name of the code to the comment area at the right of the page. Later, these codes could be retrievable at an instant by using the search feature at the top of the Word document.

\section{Reporting of the Analysis}

The phenomenological researcher is usually most interested in describing the fundamental structure of the experience- the essence- for the total group (Johnson \& Christensen, 2008). Thus, as my coding system emerged and consistent similarities among participants' experiences showed themselves as an essence, the common structure formed, and is described in Chapter 5. In fact, it was my role as a phenomenology researcher to describe the fundamental features of the experience that are experienced in common by virtually all the participants (Johnson \& Christensen, 2008).

The final report in a typical phenomenological study is a narrative that includes a description of the participants in the study and the methods used to obtain the information from the participants (usually interviews), a rich description of the fundamental structure of the experience, and a discussion of the findings (Johnson \& Christensen, 2008). Johnson and Christensen (2008) described a well-written report as producing a "vicarious experience," meaning that it is so highly descriptive of the participants' experience of the phenomenon that it will elicit in the readers a feeling that they understand what it would be like to experience the phenomenon themselves (p. 399). This was my aim with the final narrative.

During the time that I was writing the final conclusions, I revisited my researcher journal to compare my own thoughts with data from the interviews. I kept personal notes 
on all interviews and all stages of this research process. This review was helpful to me while I reported findings and formulated into words the phenomenological essence of learning through travel that was shared among the participants. My journal entries discussed how I personally knew each participant, what I felt each participant was trying to say with their explanations, and reasons why I coded certain themes in the data the way that I did. It was important for me to keep an ongoing journal because I wanted to maintain a high level of integrity with expressing the findings- consistent with how each participant described their experiences.

\section{Data Management}

The data that was collected from this study was in two forms: recorded and transcribed. Data management, then, refers to how the data was recorded, collected, organized, and protected. The audio recordings were saved as audio files, with password protection. The transcriptions were saved as Word documents in individual files and given pseudonyms for the protection of the participants. Further, all electronic data files were stored and secured on my password-protected Macbook. Upon transcription of the interviews, every document had a file name and archived under a larger file, which held pertinent doctoral program materials. Microsoft Word was the software used to open, edit, and save documents. This was a simple, yet organized way to organize, retrieve, and visualize the data.

\section{Integrity Measures}

The integrity of a research study has to do with its trustworthiness and credibility. Integrity is "honesty and probity within the conduct of qualitative research and underpins ethical practice in all the activities that comprise data collection and analysis" (Watts, 
2008, p. 440). It is characterized by openness and wholeness on the part of the researcher and can be understood as a type of "straightforwardness" or "moral uprightness" that rejects intentional duplicity and deceit. Integrity is central to ethical research principles that focus on the responsibility of researchers to do no harm, to gain informed consent from participants and to represent respondents' views as accurately as possible, as part of the epistemological process (Watts, 2008). Integrity within empirical research is not an abstract concern; it directly informs the choice of methods as part of legitimizing knowledge production within an 'appropriate' theoretical framework (Watts, 2008).

These methods, in my case, included in-depth interviews and written narratives, which require ethical rigor in their execution that is based on taking participants' accounts seriously. To establish a high level of truthfulness and accuracy of the data, I utilized a system of member checking as a validity check whenever possible in the process, meaning that I had the participants review the interpretations and descriptions of the experience, especially the statement of the fundamental structure of the experience. In addition, a number of participants wanted me to send them the audio file of their interview following our discussion, which I did, and they saw no concern with the quality or accuracy of recording.

Watts (2008) further noted that the collection of qualitative data that describes meaning and experience is rooted in a subjective paradigm that is not value-free and is inextricably linked to the goals of the researcher who may not be emotionally detached from the topic of enquiry. In this sense, qualitative research is not neutral or objective and acknowledgement of the values and assumptions that frame research is an important feature of integrity (2008). For this reason, I kept a researcher journal of my own 
thoughts, opinions, value-judgments, and perceptions about the process, during the process. Additionally, I utilized the technique of writing field notes while interviewing participants so that I was able to document and critique my own subjective perspectives. It was my intention to be as transparent as possible as a researcher and as thorough and open as I could be with this study, as to increase the trustworthiness and credibility of the study. See Appendix C for the participation consent form.

\section{Summary}

This chapter outlined the phenomenological research design that was used in this study. Adult learners who have traveled abroad with the intention of gaining an educational/ personal enrichment experience were selected to participate in this study. The focus was on the process that they used to design and carry out their educational objectives. This was compared with Knowles' (1980) self-directed learning theory to see if learners do actually apply structured processes when it comes to their travel plans and to find out how useful the theory could be for understanding the essence of participants' experiences. Semi-structured interviews were conducted and all interviews were recorded and transcribed verbatim. Exception to this was when a participant either felt uncomfortable with a recorded interview or they were in a foreign location at the time of data collection. Those participants submitted written narratives in lieu of a recorded interview. Analysis was applied to the data with the intention of finding an essence among participants' descriptions. Integrity measures were an important aspect to this study and were applied at every step along the way. The findings from the data collection and analysis are discussed in the next chapter. 


\section{CHAPTER IV}

\section{FINDINGS FROM DATA ANALYSIS}

The purpose of this phenomenological study was to understand the role of selfdirected learning as a learning process that adults use to design and pursue learning and personal enrichment experiences in foreign travel contexts. This chapter reveals the findings from the analysis of participant interviews. This chapter begins with the participants' explanations of how travel has brought personal enrichment to them. Next, the six stages of Knowles' (1980) theory of self-directed learning are applied to participant responses to research questions, to understand how the model is applicable in travel contexts. Finally, an exploration is given of how participants identified and overcame challenges along their learning journey, and how, in fact, travel is enhanced by having learning goals and strategies.

\section{Personal Enrichment through Travel}

In Chapter 2 of this study, the term "personal enrichment" was defined and an explanation was given as to how it relates to adult lifelong learning, and further, how the experiences of international travel bring personal enrichment. Participants in this study had many examples to give of how this is so. In fact, an overwhelming number of participants revealed that travel had made them a better person, or that it had contributed positively to their personality or helped to build their character. Daniel explained:

I think that a big part of the person that I am today has to do with the fact that I'm relatively well-traveled... It has made me more curious and inquisitive... In conversation, it has enriched my knowledge; there's always something to talk about... It has made me more open-minded; I certainly have learned a lot... I think that travel has absolutely been a part of who I am. 
When I asked Ken if he thought travel had enriched his life in some way, he

responded by saying:

Absolutely! For starters, I'm proficient, although not yet fluent, in Spanish...Learning a second language opens up an entire new world to someone...Living abroad better enables you to appreciate the positives and negatives of one's home country... The life experiences I've had along the way are priceless. New friends new cuisines, new chapters of world history that I previously was unaware of, etc. I would highly encourage everyone, and I do mean everyone, to spend at least one year outside of their home country if possible.

I probed Ken further by asking him if he felt like he had been forever changed by his

travel experiences. He exclaimed:

Absolutely! I have been changed for the better. My view on life is now more horizontal and not just longitudinal. My tolerance for and understanding of other cultures and points of view has grown in ways that were a previously unrecognized blind spot for me. I've also realized that the amount of money it takes to make me happy, pre-and-post-retirement, is considerably less than what it was before I began this adventure. I'm more conscious of responsibly utilizing our natural resources, like water, and oddly enough, learning a new language has increased my understanding of my maternal language- English.

For Eric, travel had always been a lifelong dream. For him, travel is a way to

experience moments of adventure and thrill. He showed his excitement for adventure

with his enthusiastic explanation:

I've always traveled for the sake of the experience itself. I definitely experience a sense of adventure and an expanded self-reliance with each trip. There's something I find very enriching about always learning to adapt through an unfamiliar location and culture, with ever diminishing stress...I've always enjoyed the logistics of planning a trip and the sense of being "in motion" on a trip. Being in an airport always conjures a sense of excitement. Even though I always have a ticket for a trip, there is the opportunity of stepping up to a counter and buying a ticket to begin a trip to literally anywhere in the world. Just knowing that always brings on a subtle little thrill.

When I asked Eric to describe how one of his travel experiences had enriched his

life, he discussed his trip to Colombia. He had felt a personal satisfaction and 
accomplishment in reaching his goals of (1) learning Spanish by immersing himself in a Spanish-speaking country and (2) learning to paraglide in the Andes Mountains. For him, these were skills that he would be able to bring back to the U.S. and use for the rest of his life. He explained:

My Colombia trip enriched my life not only through my acquiring enough Spanish to get around comfortably in a Spanish speaking country, but through a sense of accomplishment at having made significant progress toward a goal I had set for myself. A significant difference in the realm of enrichment regarding that trip is that I was in one place long enough to make friends, with whom I still keep in touch in Spanish. I've never made that type of enduring connection as a result of travel, and I'm thrilled to feel I'm maintaining a connection at some level with a country that I very much enjoyed, and which I feel further shaped who I am as a person. I also learned to paraglide while in Colombia and continue to enjoy that sport now that I'm back in the States. Learning a new and complex sport provided a unique set of experiences and cultural interaction that I would not have known otherwise.

Beyond acquiring new skills and an exciting new hobby, I was exposed to a "subculture" within a culture, and saw tourist locations and places off the beaten path through an entirely different perspective than if I'd simply visited those places to see the sight or experience the location. And I know having an activity in which I can participate in almost any country I visited, quickly plugging myself into a local community that will expose me to their culture and country in ways I'd otherwise never be exposed to. I highly recommend learning a sport or other nonlanguage skill for anyone with the time to do so in another country.

Jean-Claude said that travel had enriched his life in ways that brought him closer

to nature and humanity. He said that it has helped him forge a more patient character.

He explained:

Practically, how all those experiences enriched my life would be by being closer to humanity and nature, more grounded to what is most important and thereby less superficial - more patient, having more compassion, dealing better with stress and creating new friendships. I realized no matter where I go that we're all human beings, maybe superficially we differ from each other, different skin color, beliefs, habits, but deep down, we are all the same - have the same basic needs: a shelter, eating, and loving. When I smile to someone, no matter where he is from on this planet, I usually get a smile back. 
Marie-Anne also felt like travel had enriched her life for the better. I asked her if she had been changed by travel; she said, "One-hundred and ten percent! I think I am a more welcoming person because of travel; I also feel more independent.”

Kamal, having roots in India and extensive experience living abroad in Dubai and the U.S., not to mention European travel, affirmed that travel helps to develop one's character. He noted, 'I'm more inclusive of people... I don't judge people anymore, not completely...You become more inclusive of people once you travel and see different cultures and how people are in different cultures."

Viktorya agreed that travel is, indeed, impactful to the life of the traveler. About her experience moving to Miami from Moldova to do an international internship, she said, "travel changes us a lot and this experience has marked an important chapter in my life." Travelers do, in fact, tend to be transformed by their experiences, forever. She said that even years later she was still realizing things that she had learned from her trip.

I asked Darrell if exploring other cultures helped him to learn more about himself and he did not hesitate in saying that it did. Born and raised in the Bahamas and later living in the U.S. and traveling throughout Europe and Latin America, he explained:

It removed certain preconceived notions that I had about people and places and the difference in people. I've learned that there are some differences but more in common than different. It's amazing that some places I went that people had certain upbringings similar to what I would have experienced. I would think, you're in a country with a totally different ethnicity and everything, [like] language, but your similarity and the way you were brought up is so similar to mine. So, yes, it really made me learn so much about myself and the similarity I have with other people and cultures. 
I probed Darrell further and asked how travel enriches one's life, exactly. Examining his response, it seems that for him, enrichment happens as a result of learning new things; he said,

Because I've returned with an additional knowledge of culture, history, people, that I didn't have before. I'm more in tune, I'm smarter about this place than I was before. Think about it, you go to a place and you learn things about it that you never knew and when you come back, you're never going to lose that, because it's knowledge that you have gained. So you've learned something. For me, it's always an enhancement.

Jorge said that his experiences traveling had made him feel more like a "global

citizen." He mentioned that his experience traveling from Miami to Greece: "gave me a perspective that no destination on the globe is too far to visit." Jorge said that he was proud of himself for making travel a priority in his life and visiting so many unique places. In fact, it helped him to learn that he is a leader and someone that others look to for travel guidance. He explained:

I learned that I'm a leader. I'm someone that people trust in making decisions on their behalf when it comes to travel plans. I didn't know that then, but reflecting back, I recall now times when people would lean on me for tips and plans on what to visit and see when travelling.

I asked Gabrielle if she could see how her experience of traveling from France to

live in the U.S. had enriched her life. Her response was:

Definitely it enriched my life in so many ways. I thought I was an experienced traveler having traveled to many different countries, but traveling by myself and spending an extended period of time in a country proved to be quite an interesting experience. I got to experience the "real" America, outside of hotels and postcards.

Not only had Gabrielle felt enriched by her travel experiences, she felt changed, and left with new perspectives and enduring memories. She explained: 
It did change me. Once I was back home, I realized that I was missing a place that I had called home for a long time. I also realized that I was not totally French anymore. Culture is not set in stone, it evolves as we come into contact with other cultures, or spend a long time immersed in another culture. When I was back home, I missed speaking English or going to my favorite place in town. I found myself dreaming and thinking in English, reminiscing places I had visited.

When I asked Eduardo if he thought that he had become a better person through

travel, he responded with a story, a personal account that he wanted to share to make his point. I asked, "Do you feel like you were changed as a person through this experience?" Eduardo replied:

Oh yeah. I'll give you a story. My work ethic has changed dramatically. When I was in Turkey, when I was in Diyarbakir, our team hired a contractor who happened to be Kurdish. He was a very successful contractor, although I've heard and personally seen how the Turkish treat the Kurds, a lot of discrimination, but this guy was very, very, very successful. What I learned from that experience is that even in the face of adversity, if you work hard and you have an established reputation, you can be successful. That meant a lot to me, only because I told myself right then and there, if this could happen in this country, this could definitely happen in the United States, and that changed me. That empowered me more so than ever. That empowered me.

When I asked Eduardo if he felt like he was a better person through traveling, he did not hesitate to answer:

Absolutely. Absolutely. I've learned in life that you have to be humble. I've leaned in life that unless you're very, very fortunate, you have to work for what you want in life. You have to go out and get it. I've learned in life to be respectful. You can't hold grudges. You can't hold grudges. I've learned in life to never hold grudges and just keep on moving, keep on trucking, keep on pressing forward to that finish line.

Jean-Claude explained how he views personal enrichment through foreign travel experiences with the following: "If we consider the nature of life as impermanent, things in constant change, the inevitability of death, what defines our lives is what we 
experience, it's not enough to read a book, to watch a movie, or listen to someone, we need to experience it directly - and traveling gives you all kind of experiences."

\section{Self-Directed Learning Theory Applied}

Participants were asked various questions that pointed toward answering the research question: How can Knowles' (1980) 6 components of self-directed learning be applied to learning and personal enrichment experiences in foreign travel contexts? This researcher presupposed that some, or all, of the components of SDL could be used to look at this study and understand the essence of participants' experiences of learning through travel. Further, I wanted to understand which components are utilized, and in what ways, for example, do learners include aspects of: (1) climate setting, (2) diagnosing learning needs, (3) formulating learning goals, (4) identifying human and material resources for learning, (5) choosing and implementing appropriate learning strategies, and (6) evaluating learning outcomes? See Figure 1. 


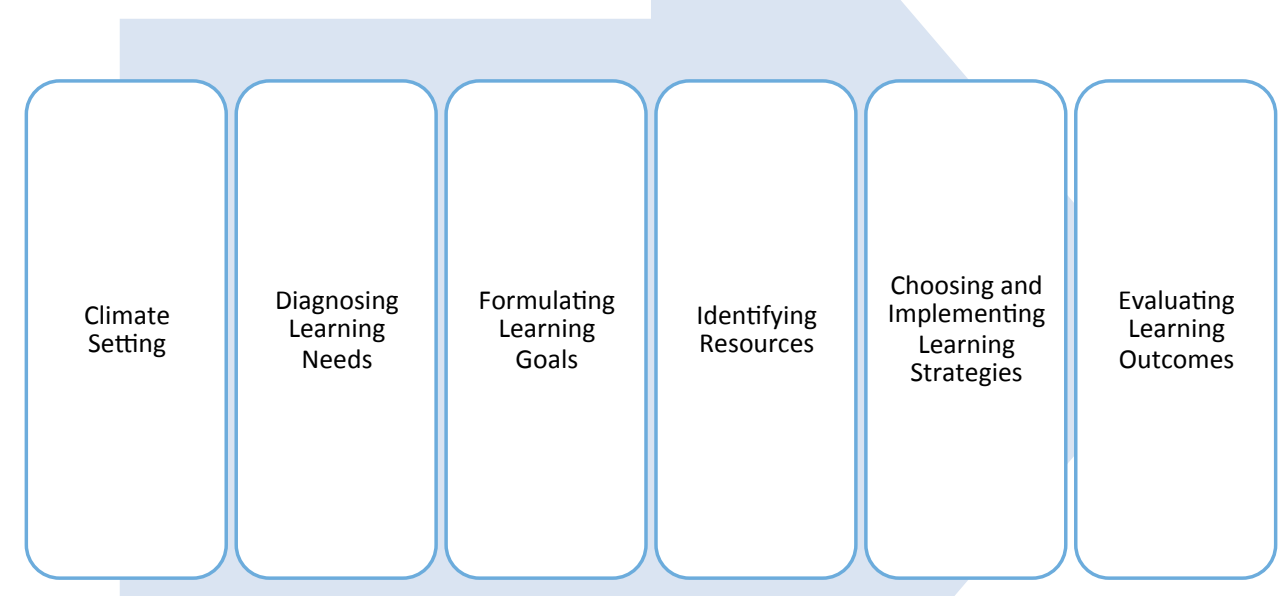

Figure 1. Knowles 6 Components of Self-Directed Learning

This section shows the evidence, in the words of the participants, that Knowles (1980) theory of SDL is applicable in the context of learning through foreign travel, and how each component can be understood.

\section{Climate Setting}

Climate setting, the first component in Knowles' (1980) learning theory, refers to the way in which the learner establishes a supportive learning environment, also defined as a healthy psychological climate. According to Knowles, this learning environment 
shows the characteristics of respect, collaboration, trust, supportiveness, openness, authenticity, pleasure, and humaneness. Knowles considered these characteristics to be more important than the physical environment, itself. Setting a climate for learning is an important component to SDL, and is especially significant to travelers. Almost as if he were speaking to the context of this study, Knowles (1984) exclaimed:

Learning should be one of the most pleasant and gratifying experiences in life; for, after all, it is the way people can become what they are capable of being achieving their full potential. It should be an adventure, spiced with the excitement of discovery. It should be fun. (p. 16)

In travel, the learning environment, many times, is not just the destination, but also the entire journey to arrive there. It includes all of the places that one must pass through and the people that one encounters along the way that add to the learning experience. It is also the attitude and perspective of the traveler that contribute to an adventure of discovery. It is the learner who sets their own climate for learning.

Knowles further explained that the central dynamic of the learning process is perceived to be the experience of the learners; "experience" being defined as the interaction between individuals and their environment (Knowles, 1980, p. 56). He said, "The quality and amount of learning is therefore clearly influenced by the quality and amount of interaction between the learners and their environment and by the educative potency of the environment" (1980, p. 56). Participants in this study explained how foreign travel provided them with rich environments for engaging in new learning experiences.

Climate setting was an important aspect for learning during Eduardo's travels. When I asked him if he was a "planner" in regard to his trips, he said: 
Yeah...The thing is, I look at the sense of security, only because I have a fear of getting robbed. I want to have a good time. I want to go to a place where it's safe. The outcome of the trip is to have a good time, learn, and then come back home to tell your kids, your friends, whatever the case may be.

Eduardo also understood that for him, the size of the tour group mattered, when planning any trips. I asked him if he preferred to travel alone or with a tour group, and he said, "I would say a limited tourist group, specifically three or four people. The reason being is because with a smaller group, there's more interaction. With a smaller group, people are more prone to convey whatever they're seeing."

When asked about a time that he planned a foreign trip, Eduardo indirectly mentioned how he sets a climate for learning. He described what he thought would be an ideal learning environment for him. He recounted a story:

I went to Barcelona, Spain. I always wanted to go to Barcelona. I had heard really good things about Barcelona. The purpose of me going to Barcelona, Spain was to know a little bit more of why does that region... why is it drawing so many popular people? Not popular people, but people from all over the world. Why is it popular? Prior to going, I did a little bit of research. I learned that they have famous buildings by an artist known as Gaudi. They have a park. Also, Barcelonians, in general, they're very outgoing social people. It's a city called "City by the Sea," a city filled with a lot of culture, a lot of activity. I was like I want to be part of that. I want to experience that.

Eduardo did, in fact, learn from his Spain trip, and being in the ideal learning environment for him helped him to reach his learning goals. He wanted to be around people who were known for being outgoing and social, in a place that was full of culture and action. Eduardo explained the outcome of his trip in this way:

I learned about the history. I learned about the Sagrada Familia. I went to the actual church. I had papitas [chips]... What I learned after the overall trip is that you have to enjoy life. The common theme that I learned there is that you have to be social, you have to be outgoing. You'd be surprised the experiences life would give you if you choose to be social and outgoing naturally and with anyone. 
When Gabrielle was in the planning stage of her trip to immerse herself in an English-speaking culture, she thought carefully about the learning environment that she would need to accomplish her goals. For her, the learning environment and setting did have to do with a specific location. She needed to travel to the United States. To Gabrielle, the U.S. provided the ideal climate for learning. She explained:

I went there because I wanted to learn to speak English better. I could read English but I was really bad at speaking or understanding English. I wanted to become an English teacher. However, I did not want to be like those teachers I had in school who could barely speak the language because they had a formal education in it and a better grasp at grammar than at speaking the language. I wanted to be a well-rounded teacher. I could have gone to Great Britain. But strangely, I was never attracted to the UK; I guess it was so close and everybody who wanted to learn English would go there to learn English. And I was curious about America. I really wanted to see if it was different or similar to the movies. I wanted to go visit landmarks such as the Empire State Building or the White House. I also wanted to see if I could be by myself and manage it on my own.

When it came to setting a climate for learning, Eric shared with me that he had a

list of requirements that he needed to be met, including: geography (central location), topography (mountain setting), ability to understand the local dialect (neutral Spanish), positive reviews of the local lifestyle, friendliness of the people, and year-round pleasant weather. Once he narrowed down places that would match his criteria, he finally settled on Colombia. He explained:

I selected [Colombia] from among Spanish-speaking countries because one of my travel objectives was to obtain proficiency in foreign languages through extended stays and immersion studies. I wanted to learn a South American Spanish and it's said that Colombia has the most "neutral" pronunciation of Spanish, although I quickly learned that Spanish varies widely even within a single country. Colombia, and Medellin, in particular, became interesting to me because of the positive things I'd heard about the lifestyle and people. I enjoy living in or near mountains, and Medellin fit the bill there, as well as being a modern city with spring-like weather year round, and an excellent jumping off point to visit other parts of Colombia and South America. I never made it to other parts of South America on that trip, but part of the plan was to allow the plan to change...My 
mission was to gain proficiency in Spanish through immersion. Living in-country was important to me because I feel that being able to absorb culture and regional perspective is essential to the type of proficiency I was seeking. I selected Colombia based on its somewhat central location in South America, and Medellin for what I'd heard about its weather and friendly culture.

Darrell also wanted to learn Spanish, but he knew that his ideal learning environment would be in Spain. Spain would provide a climate for learning the things that he was interested in, like Spanish history and culture. Darrell visited Spain for the first time as part of an organized trip, but returned later to live for over a year due to his fascination and genuine interest in what Spain had to offer. Darrell always felt that he would work in a professional position that might require intercultural and bilingual skills. So, he was determined to learn Spanish. He explained:

I always knew that I wanted to work in some sort of environment that I am working in now, luckily. Spain was going to be important, and I knew Spanish was going to be the language that I wanted to learn, and I also wanted to go behind the language and learn about the culture and history and why we have countries of the world, and so many other things. What other place to go? I could have gone to Mexico, all these other places to learn, but I chose to go to Spain.

For Darrell, the actual place or location is, in fact, important when it comes to setting a climate for learning. He affirmed:

When I traveled, it's always about the place. I try to take myself personally out of it, and then I think naturally I get immersed into it. So I go there with a view that I'm going to absorb what's there, and I'm going to put myself there, I'm going to take what's there and bring it into me...I'm trying to immerse myself into that culture.

Logan also used climate setting as a way to determine a location fit to help him with his goals of learning Spanish, learning to surf, and volunteering with a Christian organization. But unlike Darrell's desire to absorb all that the local culture could offer to him, Logan wanted to be of some kind of service to the local culture. For him, Venezuela 
was a match as an environment in which he could accomplish all three of his goals. He

described his experience with the following:

My first experience living in another country was in Caracas, Venezuela. Before moving there, I had long wanted to learn to surf. So I decided that I wanted to go somewhere to learn to surf while at the same time working with an organization that I could help in the process. Since I am a Christian, I thought it would be cool to work with a Christian organization. I reached out to a group called Christian Surfers International and after sending emails to a few countries, Venezuela seemed like the best choice for helping...I knew that I wanted to learn Spanish and knew that was never going to happen by staying in the USA or even for that matter, traveling and living with English speakers. I had to live and breathe solely in Spanish. There is a quote from Charlemagne that goes, "to have another language is to possess a second soul." When I speak and live in Spanish, I literally feel myself transform into the Latin culture - rather than just seeing it as a tourist. You learn so much by becoming a part of a culture rather than just passing through. The experience becomes less about what you get out of it for you and more about how you can positively build up others around you.

For Viktorya, when choosing a location to do her professional internship, it was important to be in a place that was fun, had an enjoyable climate, and a unique culture. For her, this combination would create an ideal learning environment. She discussed her process of climate setting with the following:

When choosing a place for my internship, I said it's going to be Miami because it was a very attractive destination, vibrant, and with a Latin American touch. And I love Latin American people, big cosmopolitan cities, and of course nice weather and palm trees year round. It seemed to be a fun and amazing place which I really wanted to travel to.

Jorge mentioned that while planning his trip to Greece, his intention was to take it slow and create a leisure-style environment for learning. He said that he did not want to “jump around Europe," but have a more relaxed experience, while absorbing the culture at his own pace. He explained:

I visited Greece for two weeks. I'll be honest, my initial intrigue on visiting Greece was to sit on a balcony and watch the Mediterranean Sea go by. Not knowing a single person in my life who had been there, I wanted to take in the 
Greek culture and history and not jump around Europe like so many do...I simply wanted to take in everything Greece had in store for me - from a cultural perspective, but also a self-discovery standpoint. I had no knowledge of the Greek language and little exposure to Greek people. Plus, historically there may not be another culture more fascinating since they go way back.

Marie-Anne also envisioned in her mind what it would be like to be in an ideal learning environment, before she left for her European trip. With her fascination for Italian culture, she knew that it would be found when she arrived in Italy. She explained:

My trip really started once I landed in Venice. So, to start off, I have a love for Italy like no other. I love the culture, the people, the food, and the feeling I get when I am there. Venice was exactly what I expected: romantic, passionate, and authentic. I ended up staying there for four days. Originally, I was thinking I would be there around two days, since that's all you really need to see the city, but I couldn't leave. I ended up staying four days before deciding to take a trip to Milan for a day then a flight to Amsterdam.

Marie-Anne set the climate for her own learning experience by choosing the destination that brings her joy, and subsequently, she had an enriching time.

For Daniel, setting a climate for learning was also important. He admitted that lying on a beach for a week, for example, would do nothing for his sense of personal development. He enjoys traveling for enriching experiences, through cultural exchange and language immersion. Being in challenging situations, like being forced to speak another language when it is difficult, is where Daniel feels personal growth. He sets his own climate for learning by choosing those types of learning experiences. He explained ("we" refers to Daniel and his partner):

There's only so much "laying on the beach" type vacation we can do. I absolutely love that, but I can't...I don't want to just go, lay on the beach, run and see Buckingham Palace and that's it. I want to immerse [myself] and enjoy it...It's very little pool time... we love art, we love parts of world history, love people, cultures, languages. We do try. We suck at French, but every time we go somewhere in France, we try, and they appreciate that. Our Spanish is a little 
better. German, I speak German, so that's fine. Italian, not so hard, because it's similar to Spanish, so we get by there. We always try.

While we discussed the notion of being enriched through travel and cultural immersion, and indirectly talked about climate setting, Daniel said, in jest:

Learning doesn't have to be, I go to class, I get a textbook and a syllabus and I spew it back out on a test. It really can be, I went to a Broadway show. It could be, I went to Barcelona for three days and studied Gaudi architecture, and if you don't walk away feeling like you learned something from that, you probably should be going to McDonalds and sitting on the beach.

\section{Diagnosing Learning Needs}

The second component of Knowles' (1980) self-directed learning theory is the identification of a learning need. There must be a learning need, or a desire to experience something new, that motivates the learner in their pursuits. For many of the participants in this study, it could be explained as satisfying a curiosity, experiencing a feeling of discovery, being transformed by a new experience, gaining a feeling of accomplishment, or the desire to continue traveling more and more as a life passion - also known as "wanderlust." Wanderlust can be defined as a strong desire or impulse to wander or travel and explore the world. In psychology, wanderlust may reflect an intense urge for self-development by experiencing the unknown, confronting unforeseen challenges, getting to know unfamiliar cultures, ways of life, and behaviors.

The data also revealed that some participants traveled with a sense of urgency. While they were evaluating their learning needs, they had the realization that time is of the essence, so to speak, and if they did not take the trip in that moment of their life, it might never happen. They said things like "life is fleeting," "you only live once," and "it was on my bucket list" (which is a list of things that one wants to accomplish before they 
die). This sense of urgency seemed to add to the learner's motivation and make their need stronger. This section will present participant descriptions of how they diagnosed their own learning needs.

Jean-Claude mentioned that he has a strong desire to explore other regions of the world and has had a sense of adventure for travel since he was a child. These things have helped to develop his personality and create learning needs. He explained:

In my case, the taste for traveling started as a young kid and I remember that my main interest was to go see other places - this fear but also curiosity of the unknown and probably as well as the need of becoming more independent and a way of building my confidence to be on my own. As my life unfolded, I became more and more interested in discovering new regions of the world, always having this sense for adventure, the fact that you never really know what you're going to experience, all the people you will meet on your journey, the difference of culture, mentality, food, habits, and so on.

Darrell was quite clear about his learning needs; he is motivated by gaining a

sense of discovery from his travels. Darrell wants to learn, see, and experience new

things. He calls these moments during travel his "wow" moments. He said:

I'm always traveling with the intent of finding something new. I think it's subconsciously I'm absorbing this new culture, this new history. But I'm in search of seeing that moment, that "wow" moment. I'm always in search of the "wow" factor...Enlightenment. So if I go to a place, I'm going to go find the "wow" factor in that place... Usually it's completely different in every country. In fact, it could be different in every city in every country...The truth is, when we travel, we're going for that moment. We may even have multiple moments, but it's that one life-changing moment on that trip, in that place, at that time, that you are searching for.

To gain an understanding of Ken's learning needs and motivations for travel, I asked him if there was something specific going on in his life that might have triggered his desire to travel. He explained that living abroad and learning Spanish was something that he had always wanted to do. For him, it would be the fulfillment of a lifelong dream. 
Further, at his age and point in his career, he felt a sense of urgency to fulfill his dream with immediacy. He said:

There were multiple triggers for me. My age was a determining factor. I'm 45 now and I was 43 when I quit my job to travel full-time, and I had always wanted to live abroad and try to learn Spanish. Another trigger was the death of someone that I ran track with in high school. The final trigger had to do with the fact that I had recently begun a new job with a new company and I thought that it would be better to leave at the beginning of the start of a new career with a new company versus waiting two to three years after I had invested that much more of my time and capital with this new employer.

Gabrielle also mentioned a sense of urgency associated with her desire to

experience the culture in the United States. Her learning needs were fueled with the

motivation to travel with immediacy as well as Ken. She recounted:

I was always fascinated [by the U.S.] and the vision I had of it because of all the movies and the great influence of American culture on the world. I wanted to see for myself what people talked about when they talked about the American dream and the land of the free. There is another reason as well, a weird one maybe, but well. I remember when I was 18 , I was in this watch repair shop with my mother. The TV was on and I looked up mechanically without really understanding what was going on. I saw the planes crashed into the Twin Towers. I could not believe such a thing could ever happen in America. I had a strange thought at that moment, I thought "I have to hurry up to go to America before all the landmarks disappear." I wanted to make sure I saw it before it no longer existed. Strangely, I still have that thought. I want to go to certain places because I fear they will not be there in the future. I want to be able to see with my own eyes before it becomes a mere mention in a history book.

As I interviewed Eduardo, I realized that he has a keen sense of self; he

understands his own personality and his learning needs and motivations. The following shows the type of mindset that has motivated Eduardo to travel:

I'm very adventurous by nature. I'm the type of person that likes to learn things. I like to just go out and experience it. I don't consider myself an introvert. The burning desire, the fuel that makes me like that, is you only live one time. Also, I am a war veteran. I've been on missions with Turkish people in those six months, also with the Air Force I've seen some things I didn't like. Life is short, the world is big. Appreciate it. Get to know it. Live in it. Learn it, because you 
know what? There's going to be a point in life that you're going to be like I wish I did this, I wish I did that. I want to be like hey, at least I did it, or at least I tried.

Eduardo mentioned more about his learning needs, like gaining the sense of accomplishment when one can check off a place from their "bucket list." He also needs to feel like he learned something from the local culture, and that he felt safe while traveling. For these reasons, Eduardo makes it a priority to thoroughly plan his travels. He explained:

I've always had a bucket list. There are some things that I actually want to see. I still have a bucket list. There's some things that I feel I haven't done. What motivates me is that I'm going to die. That's what really motivates me. Before I die, I want to experience this. Sometimes it doesn't happen the way I imagine it in my mind, but however when I get to that place I'm there, so, I make the best of it. That's why I plan. I don't go off the cusp only because there's that fear of uncertainty. I don't want to be a victim of uncertainty. I just want to go there, have a good time, learn the history. It sounds a little bit stereotypical, because that's what most tours do. However, being on a limited budget and not having that sense of security, that's me.

Jorge also mentioned that his trip to Greece had always been on his "personal bucket list." For him, it was a trip that needed to be accomplished, a life goal to be fulfilled before he dies. Kamal, as well, referenced this notion of death being imminent and travel as a priority before it comes. He said, "The thing is, though, you have a short time on this planet to grow and really experience what is there to experience...Y You got to push yourself to actually go out and see what's out there in the world because otherwise you're just limiting yourself."

It is the personal gratification that one feels from accomplishing the goal that motivates many to travel. Another major learning need, or motivation, is curiosity. It appears that curiosity, for many, grows with time and each travel adventure. This concept is known as "wanderlust," and many of the participants in this study showed the 
defining characteristics of those who experience it. Wanderlust is a strong desire - or need - to travel and explore many different places. Participants described this desire as a learning need, albeit in different ways.

Evelyn had the desire to continue traveling and exploring the world after her first travel experience to Spain from her home in Australia. She recalled, "After living in Spain with a Spanish host family for a year the desire to learn other cultures, languages, and experience the un-comfortableness that comes with being out of the place you call home has always sparked my interest to travel whenever possible."

Jorge exclaimed that travel is good for his soul, or rather, the personal enrichment that comes from travel experiences brings him joy. He said, "I look back and realize that in order for me to be internally happy forever, the more I travel, the better it is for my soul and overall mood." When I asked Jorge if he had been successful in reaching his learning goal through travel, he said:

My goal hasn't been attained yet and it may never be. Travel is a never-ending passage that has no end. There is no way to fully visit every corner of the world, so I believe that I have been successful in traveling a good amount which has enriched my life tremendously and I will continue to make short term travel goals to fulfill my bucket list needs. However, I don't believe the "end goal" is ever reached, at least not my goal of seeing the entire world.

I asked Darrell if traveling were a lifelong dream for him; he responded by saying that even though he had been to many parts of the world, there were still some places that he expects to visit. For one who has the wanderlust desire, travel is never finished. He explained in his own words, "Fortunately, I could say that it's no longer a dream, because I've been to almost all parts of the world except the Middle East. The other places that I haven't gone, is going to be because of curiosity." 
Eric, in his own words, describes exactly how the concept of wanderlust satisfies

a learning/ personal enrichment need that he feels. He explained:

Over the years I've noticed a sense of wanting to "get up and go somewhere" from time-to-time. I may be happily living in one location, working and generally having a "settled life," but a sense of needing motion bubbles up. In the past, I've not been able to act on every instance of that urge, but I'd often at least take a road trip to feed that urge, and sometimes a longer international trip. That may be a sign of many things about me, but certainly that travel meets some internal urge or need.

Eric said that he had been traveling for many years; in fact, about 10 years ago he dedicated himself to creating a lifestyle based on generating income from rental properties so that he could pursue full-time travel. Eric has been keenly aware of his own learning needs and how they are met through travel. When I asked him if he felt like he was called to some sort of adventure or discover something new through travel, he responded:

I definitely felt called to adventure...I almost always have an underlying urge to "go on the road." I was very much motivated by the urge to experience something new and different, and to learn a language. I believe that travel brings me back to a state that is more child-like, in the sense that I'm overwhelmed by the unfamiliar and by being conscious about dropping my learned cultural filters I can, to some degree, build up new filters as part of my learning processes... Add language learning to that experience and the joy of learning and "mindexpansion" is multiplied many times over. It is this "learning of a perspective" that I believe is one of the key underlying motivations for most of my travel.

Marie-Anne also described her desire to keep traveling as an urge or need. When thinking about the learning experiences and personal enrichment that she has found through travel, it appears that she has, in fact, diagnosed her own learning needs. She explained, "Travel is my restart button. Every few weeks I am searching the web to see where my next stop will be. Every few months I'm on a plane headed some place - and it's amazing." When I asked her if travel fulfilled some need for her, like satisfying a 
curiosity or lifelong dream, she said, "Travel is not a dream, at least not anymore. Travel is a necessity for me. It's part of how I mentally reconnect with myself; it's how I ground myself." When I asked her if she had been successful with her learning goals through travel, she said, “I don't think I will ever reach my goal. There is always someplace to go and more to see.”

\section{Formulating Learning Goals}

According to self-directed learning theory, the learner is responsible for setting his or her own learning goals. These goals, or objectives, specify what the learner will learn, not what will be done to learn them. In the case of learning through travel, the target goal might be to learn a new language; see a historical landmark; participate in a cultural festival; gain intercultural understanding; satisfy a curiosity; or achieve a feeling of discovery, adventure, or accomplishment, for example. Knowles (1980) explained:

Learning is described psychologically as a process of need-meeting and goalstriving by the learners. This is to say that individuals are motivated to engage in learning to the extent that they feel a need to learn and perceive a personal goal that learning will help to achieve. (p. 56)

Participants, did, in fact, have learning goals for their international trips. The goals that they set for themselves helped to satisfy their learning needs. For example, a participant might have had a need to travel every few months, to explore other cultures, and feel the excitement of adventure. The goal would be the thing that they wanted to achieve along the way. This section explores some of the learning goals that participants had during their travels and shows that travelers do, in fact, travel with learning goals in mind.

Ken clearly defined the goals that he had for his extended stays in Colombia and Spain. He explained: 
My main goal was to become as fluent in Spanish as I could, given my time parameters, combined with my desire to travel around South America. In addition, a secondary goal was to explore other business opportunities outside of my previous career industry in the States - healthcare, I'm a medical doctor who was working for a medical device company.

Viktorya was also clear about the learning objectives that she had for the internship that she set up in Miami; she said:

I did travel with both the purpose of learning and discovering new things. Since the main purpose of my travel was to do my internship, I intended to learn first, the way of operating a hotel in U.S. at an international hotel chain as Accor. Second, I was very curious about the way of living and the lifestyle in Miami: arts, people and culture; it is a famous location as well with a very cool nightlife.

One of Marie-Anne's learning goals when she travels is to discover new points of view; in fact, she is fascinated by different perspectives held by people of other cultures. In her own words, the explained:

When I travel, most of the time I want something from [the local people], I want to learn more about how they think and how their thoughts, ideas, and views may have been molded by their environment. That's what I want to learn when I travel. I want to learn how people see the world and how their views influence their interactions with others.

Kamal also wanted to discover a different perspective, or way of life, when he traveled to Sri Lanka. He became fascinated by the culture and how people live, which was different from his life in India and Dubai. He said that he wanted to see how people "lived" and what made them happy. For him, those were his learning goals. He explained:

I went to Sri Lanka in 2009, right before I came to Miami. That was because I learned so much about Sri Lanka in my history lessons and whatnot and how one of [the] emperors of India pushed Buddhism there. I wanted to see how they lived and what kept them happy because they had no possessions. Like I said, they have no attachments to anything. They have no worldly attachments... That's one of the trips I really researched on because I actually wanted to meet people and different kinds of people. It was a lot of war going on in Sri Lanka before that 
between the Tamils and the Sri Lankans...Then, there were these people who were completely at peace in the middle of all that revolution and whatever was going on there...I wanted to see both sides.

Logan, as well, wanted to experience something different, discover new ways of thinking, and see how others lived in different parts of the world. Logan wanted to escape the routine and explore exotic locations, and learn about the world around him. He said, "My intention for traveling was to simply explore. I had no expectations...I think my goals with traveling really came down to knowing that there is more to this life on Earth than just waking up, going to work, going to the gym, going home and eating, going to bed, and repeating." Logan wanted to learn what "more" there was to life.

Eric said that his trip to Colombia included the learning goals of learning Spanish and learning to paraglide. Paragliding, or "parapente" in Spanish, is actually a popular form of recreation around the Medellin/ Antioquia area of Colombia, which is known for its high altitude and steep mountain ranges. Eric discussed his learning goals by saying:

The idea that having structure around my learning goal helped me achieve a sense of "daily life" which was valuable in helping me feel settled more quickly, but the goal of learning Spanish was essential in keeping me engaged in a process of learning and discovery, not jut of the language, but of the culture, geography, politics, and most every facet of life in Colombia and South America.

Paragliding, as an activity that I picked up while in Colombia, [gave] me a great and unique exposure to a "subculture" of Colombian life, and also gave me a portable activity which will offer me a built-in social opportunity in almost any country I travel to.

Gabrielle also knew exactly what her goal was when she traveled to the U.S. She was clear about her learning goal, and had a plan for achieving it. She explained:

I had a goal. I was not just traveling for the purpose of traveling. I specifically wanted to learn a language. I knew I needed to immerse myself in order to learn what I could not learn at school. I had to be around other English speakers. I had 
to go out there and be open to different people and a different culture, which was difficult to do at first.

Eduardo admitted that one of the learning goals that he had on a recent trip was to explore business practices in other countries. He wanted to see how successful businesses operate compared to what he knows of business practices in the U.S. He explained that once he retires from the military, he would like to set up a franchise business, so he is pursuing experiences that could put him in the right places to learn business management and operations strategy that he will be able to apply when the time is right to go into business for himself. Eduardo recounted:

My specific goal right now is all about what I do currently. Afterwards, my goal is going to be working on a franchise. What I do in my travels sometimes, I look at other businesses. Why are they successful here? These are completely different people, but you know what? They have a venue that's very successful, so mentally, I take notes. I see the food is good, or maybe not. That helps me with formulating something long-term... When I went to Colombia... when we went in the food court, I was looking at the food courts. Why is this one popular or this makes " $\mathrm{X}$ " amount of money...In terms of business, I look at that... Why is it successful and how could I apply it to a business that I'm going to open in the future?

Daniel mentioned that during the course of many years traveling, he has had various learning goals, but that in fact, he has always had learning goals. He said, "I think every trip probably has had a subconscious or otherwise learning goal out of it." Daniel may not have always written down specific learning goals to be accomplished from his trips, but he admitted that at some unconscious level, he thought about it. When we discussed having learning goals in mind before and/or during travel, he said:

I think I'll be honest, it's not like I sat down and said, "Here's the five things I want to learn on this trip." I would say, let's call it subconsciously, if you will...The little bit of research, slash, five things you want to see, those little bits that we did subconsciously were a goal because...the [Sagrada Familia] is Gaudi's church in Barcelona. I'm not religious. Churches are not my 
thing... [however] I wanted to see that. It was a learning goal. I was fascinated by how he constructed it and the different ways that he was approaching that and the fact that it's still going on today, and how it influenced other parts of the city. Subconsciously, yeah, that was a goal. Did I write it down and say, "Here are my learning goals." I would have not said that until we were talking and thinking about it.

\section{Identifying Human and Material Resources for Learning}

The fourth component of Knowles' (1980) self-directed learning theory is identifying resources for learning, both human resources and material. It is acknowledged that even though the learner is in charge of his or her own learning experience, assistance is often needed. This assistance comes in many forms. Travelers, for example, might find travel agents, travel websites, or tour guides helpful. They might ask friends, family, or acquaintances who have personal knowledge of the location and/or local culture for travel advice. Other helpful human resources for learning could be teachers, medical professionals, locals, or fellow travelers. Material resources for learning, in this context, includes books, manuals, brochures, maps, guides, up-to-date information found on official websites, and other helpful internet resources like suggestions for travel and tourism, statistics, warnings, weather, and resources for accommodation/transportation arrangements. This section explores the variety of resources that participants utilized in their self-directed learning experience through travel. Note that all participants did, in fact, admit to using some form of learning resource during the travel experiences that they discussed.

Daniel admitted that he tends to use a variety of resources for learning during his travels. He uses books, brochures, maps, country websites, and prefers to ask either locals or others that have gone to " $\mathrm{X}$ " country for advice on things like where to eat. 
Looking at a list of possible resources that could be used during travel (see Appendix A),

Daniel mentioned which ones he did, in fact, use as a helpful resource. He said:

Travel agent, probably not, tour guide, once. [I] probably would ask questions if I knew you had gone, I'd ask you questions about, "Hey, what was your favorite restaurant?" Or something like that. No teachers, nope. Locals, I would ask locals, definitely, I can give examples of that. Books, brochures, maps. At a period of time, yes, I probably carried a "Fodor's" some places. Definitely maps because we drove. Yep, I'll do some research on my own. Personal intuition a lot...I typically would look at the country's website, or the city's website and just see what the top things are. We're going to Barcelona, you want to see what to do. The Gaudi church...the thing we probably search the most would be a major architectural site, that probably either has a ticket involved or a line, so that's a little prep. More so, though, where to eat. We eat locally, we don't eat at McDonald's, we don't look for Ruby Tuesday's or whatever. We look, like, "Where is the best place to go get seafood in Barcelona?" Because you're on the ocean. We found this tiny little thing of a dump, that you would not go in if you looked at it, the most amazing seafood I've ever had.

Evelyn described clearly the resources that she found most useful during her

travels in Colombia. She said:

Locals are my biggest resources, however, it's a little difficult if there are language barriers. In Colombia, I was fortunate enough to know the language, making relationships with locals was a huge bonus for me. Language and local connections aside, expats are a great wealth of knowledge with many forums available in each country or city you go to. Facebook groups are a superb wealth of knowledge. I use them consistently to understand anything from banking and transferring of money, visa, medical, or doctor requirements, where to find the best "empanada." I found answers to all of my questions from fellow expats who had been in the same situation as me and they're always willing to help out.

Jorge mentioned that although he wanted to plan almost his entire Greece trip on

his own, to fit his personal tastes and preferences, he did, in fact, contract a travel agent

for help. He explained, "I booked the trip separately but with the guidance from a

prominent Greek travel agent who was generous enough to share tips with me; however, I

booked everything myself as I believe I have the best taste in maximizing a travel experience." 
Viktorya also mentioned that she found resources helpful during her internship in Miami, both pre-and post-arrival. She listed her internship placement agency, the human resource department at the hotel, friends that she met in Miami, and the Internet as important resources for her learning experience. Further, she was able to utilize an internship manual, which likely saved her valuable time learning her duties. She said, "In terms of planning, I did have a training manual that guided me to learn about my job and guest relations department in general, the main purpose of the internship."

Jean-Claude admitted that one of the most useful resources that he acquired during one of his international trips was a language phrase book. It helped him to unlock the door to interact with others and allowed him to enjoy the process of language learning. He recounted:

The first time I went to Indonesia, I bought a phrase book and dictionary and was putting some time in it almost everyday. I found a good way to learn is by talking directly to the locals and also kids, usually kids use basic words and are more patient - but not always. Even though you sound terrible, they love that at least you try, and of course, if you don't try, you don't learn. After already a few weeks, I could get basic conversations and locals start to see you not just like a tourist, but a tourist that is trying to speak their language. After several trips to the same country, I kept learning bit by bit to improve and I can say it helped me a lot overall, to get to places and interact with people. Looking back, I am quite satisfied that I took the time to learn, I enjoyed the whole process plus it paid off.

Marie-Anne prefers to use online resources, travel websites and airline webpages.

For example, she named Spirit Airlines as one of her favorite low-cost airlines, and regularly checks their website for deals. She said, "It allows me to travel to a lot of the Caribbean and the Americas for minimal cost. I also use CheapCaribbean.com for some last minute beach-type trips. Otherwise, I just search the web for deals." For suggestions on what to see and do at a specific travel destination, Marie-Anne mentioned 
that she uses online resources as well, she said, "I use 'TripAdvisor' to get ideas of some landmarks to see. Otherwise, I don't know my plan until I get to my destination."

Logan also used an Internet search to find an organization that would turn out to be a valuable resource for him in his quest to travel, learn Spanish, volunteer, and surf. He said, "I found Christian Surfers International (CSI) by simply typing in 'surf missions trips' into Google. Whatever you want, Google can provide... Since working with CSI, I have traveled throughout South America, including Colombia, Peru, Brazil, and soon to be Argentina - as I am moving there in about one month.”

Gabrielle admitted that resources for learning were helpful for her when she traveled to the U.S. She mentioned that a friend that had previously been to New York and knew English served as a type of guide, initially. She continued, "The internet was also a great source to find housing, places to eat, places to visit, but also to help with transportation and where to go. Along the way, we met so many people who would make suggestions on where to go to eat the best food in town, what landmark was worth seeing, where to have fun, etc." Gabrielle also used maps as a learning resource. Transportation, in fact, can be complicated and very different from place to place, country to country. Maps are vital to travelers and tourists; they provide direction and help with one of the most important lessons to learn while abroad: how to get around. Gabrielle said, "I also made sure that I had the transportation maps readily available because that's my way to discover things. I like taking public transportation; however, I did not realize that public transportation would be different."

Ken agreed that books and Internet searches provide helpful information and serve as valuable resources for learning, but for him, first-hand accounts from others who 
had been to his places of interest were crucial in his quest to choose a location to learn Spanish. Likewise, taking a quick trip to his travel destinations before longer-term stays turned out to be most helpful during his investigation and planning process. $\mathrm{He}$ explained:

At the beginning of my adventure, I employed the usual tools like the Internet and books. Those resources are certainly helpful to get you out of the gate and start in the right direction for your journey. However, what I've found to be equally helpful has been the old-fashioned method of "footwork/ pounding the pavement." And by this, I mean actually talking to people who have been where you want to go. And for me, the most beneficial thing that I did prior to traveling full-time was to do a brief scouting visit to the places that I was considering moving to. This to me is the absolute best way to investigate your potential new surroundings because you can then see first-hand neighborhoods/ schools and other things that you've read about and then make your own informed decision.

When I showed Kamal a list of learning resources that could potentially be utilized during travels (see Appendix A), he said "yes" to many of them. Kamal tends to use a variety of learning resources for his trips. He explained:

Books, manuals, brochures, maps, for sure. Internet, absolutely. Medical professionals, it depends on where I'm traveling to. Say, if I'm traveling to India, I got to get some shots depending on what part of India I'm traveling. Say if I'm traveling to Mumbai, I'm fine, but if I'm traveling to, say, Agartala, that's northeast corner. I need to get some shots. [Also] friends, family. Friends always because I always try to see if I have someone or if I know someone in the city I'm traveling to. [It] always helps because they would give you an actual opinion instead of people trying to sell you something. I've used tour guides in the past, like once [when] we are on travels like Egypt, because it's a completely different country. You don't speak the language.

While Eric was planning his trip to Colombia, he utilized many resources for his own learning. He wanted to plan many things so that his experience would be meaningful, yet remain flexible to unexpected experiences that might arise. While he was still in Denver, he researched on the Internet and sought advice from Colombians who lived in his area. Once he arrived to Colombia, and seeking local support, he 
decided to stay in a hostel owned by an American so that he would have a friend who

knew the city. In his own words, he explained:

I tried to make use of as many resources as possible without setting myself up on an organized trip or planning with too much detail. I wanted to be very flexible in where I lived in town and what trips I took throughout the country, in order to let my experiences shape the course of my trip. Examples of resources I made use of included a friend in Denver who is from Colombia and even a guy I met at a retail store who was Colombian. The Internet was probably the resource that I employed more than any other when I was trying to identify which country and city I'd live in, and once I'd selected those, it was critical in identifying lodging and language school options... I wanted some level of local support when I first arrived, and I organized that in the form of staying at a hostel that had an American owner who was being very helpful with advice even before I'd arrived. Once I was there, he was very helpful in helping me quickly get to know the city.

\section{Choosing and Implementing Appropriate Learning Strategies}

In this study of self-directed learning, participants were responsible to design and implement their own learning experience, including planning and participating in activities and utilizing resources that would facilitate the acquisition of knowledge or skills that they sought. This is the essence of self-directedness and is the fifth component of Knowles' (1980) theory, which is also known as "conducting learning experiences" (Knowles, 1980, p. 48). Participants described the strategies that they employed in their learning endeavors, each one unique in their own way. This section will highlight those strategies.

For Evelyn, pursuing a learning experience that would combine more than one interest is the ideal strategy. She explained that her desire to learn Spanish was combined with going to a destination of interest where they spoke Spanish. She would be able to improve second-language skills and immerse herself into the culture. Another example 
that she gave was finding a job that interested her and being able to live in a foreign country that also interested her. In her own words, she said:

I think it's always important to learn new things and plan accordingly, for example, if you loved Yoga, then maybe traveling to India would combine two things of interest: firstly, travel, and secondly, traveling to the home of something you love. This principle could be used over and over again. Want to learn Spanish? Go to Colombia as they speak a very clean dialect. Personally, I always wanted to work abroad, so living in the place we [Evelyn and husband] wanted to work was key and I was able to enjoy discovering the idiosyncrasies of the country.

Logan, as well, traveled with the learning strategy of combing more than one interest into his travel experience. As mentioned previously, he traveled to Venezuela to learn Spanish and learn to surf, while being able to volunteer with a Christian organization abroad.

Jean-Claude said that he uses the same strategy - combining his passion for travel with other passions which he can practice and improve while abroad. He explained, "Then I started traveling to surf or rock climb, two passions that made me go places I would probably never [have] gone otherwise - so considering that, I usually pick a destination where I can practice one of these passions.”

Eric also had the strategy of combining more than one interest into his learning experience abroad: learning Spanish and learning to paraglide. He thought that this would be the ideal strategy for multiple reasons. First, it would give him a sense of routine, Spanish lessons in the morning, and flying in the afternoon. For him, this was a productive use of time. Second, taking paragliding lessons would make him feel more involved with the local community. Because only foreigners take Spanish classes in Colombia, Eric needed an activity that would help him to socialize more with locals and 
to immerse deeper into the local culture - paragliding provided it. And third, Eric felt that learning a new skill while abroad would equip him with an ability that he would be able to take anywhere in the world. Discussing his strategy for learning Spanish, he explained:

Another conscious element of my planning was to create a sense of structure for my stay, at least initially. I chose to do that in the form of taking Spanish classes at a well-organized and accredited university in the city of Medellin. I felt that, for me, it would be important to have structure in the form of classes and metrics to gauge progress, but possibly more importantly in providing structure to create a sense of "daily life" while I was based in one city. Of course, I took many trips to other parts of the country and engaged in plenty of spontaneous events and developed a social life, but the class work and schedule allowed me to quickly settle into an initial daily routine. I found that was extremely helpful in giving me a strong sense of focus and purpose while I was acclimating and formulating additional ad hoc plans for my stay, possibly avoiding a sense of aimlessness, although I believe strongly that some aimless wandering is important as well.

Eric had a strategy for using and expanding his Spanish vocabulary outside of the

classroom as well. He said:

Additionally, it was valuable to do "normal" things, which I'd typically not do on a shorter trip, such as getting haircuts and going to the dentist. Experiences like those further expanded vocabulary and provide another opportunity for social interaction that I'd not normally have on a shorter trip.

Discussing his strategy for adding paragliding lessons to his Colombian experience, Eric explained:

It was interesting in that I was able to build on my existing love of flying airplanes and ad hoc learn a new activity in a foreign country. Additionally, it was another thing that added some structure, both social and learning, to my life while in Medellin. I think it is a pattern for me, that I like to learn new things in a structured environment. I put that inclination to use both in the paragliding and in selecting formal university classes for my Spanish learning...I've never really thought about it before, but that seems to be a pattern for me. I really think that learning a new skill in a foreign country is an excellent way to expose myself to learning in a different context and to see a view of the country through a unique perspective. 
Eric further added that if he had more time before he had to leave, he would have sought out other activities to learn while in Colombia. Reminiscing on a day that he and I spent together in Medellin, he said, "If you remember that day we went over to the sports complex and spoke with the archery instructor, that would have been another learning activity I probably would have added if I'd had another couple months in Medellin.”

Marie-Anne's strategy for learning about three different European cultures included (1) traveling alone, so that she would be "more open" to meeting locals wherever she went, and (2) having "no real agenda," so that she could remain flexible in pursuing whatever called her attention. She explained:

My first truly solo trip was November of 2015. I went with no real agenda, only that I was going to go to Europe, my flight landed in Istanbul and then [I] went to Venice and my return flight would leave 12 days later out of Paris... Traveling alone was great! I got to see, eat, and do whatever I wanted. It also made me more open to meeting new people. I met people in restaurants, parks, museums, etc.

Daniel also mentioned that on one of his European trips, the learning strategy was to remain flexible and engage in activities that called his attention in the moment. $\mathrm{He}$ told the story of how he stopped at different locations to learn about them while he was driving from London through France and into Spain. It was the strategy that fit his personality and served his learning needs and goals. The following is the story that he told to me:

One of the most, I think, interesting trips that we did, as a matter of fact, was we had moved back to the States [from England]. I think about a year later we wanted to go visit friends of ours in London. We booked a flight to London, and we knew that we were going to spend, whatever, two days there. We knew where we were going to stay. We stayed in our old neighborhood; that was easy. We saw our friends. Then, we were getting on the Chunnel and going to Calais, which is the first stop in France, picking up a car. All we knew from there was, we had about four or five days to get ultimately where we were going, which was 
Sitges, which is a beach on the south coast of Spain, outside of Barcelona. That's where our ultimate stop was, and we just started driving.

We just went, “Oh my God! There's lavender fields, let's stop. There's a winery, let's stop." We're like, 'Okay, it's late in the day, we're getting hungry, we should probably think about where are we going to park our butts for the night and get some dinner." Look at the map, we're like, "Oh, how about Avignon? Great, let's go to Avignon." Didn't know anything about it. Beautiful, beautiful old city. We learned a lot. Then, we stayed in a cloister. It was a nunnery that had been converted into a hotel. We didn't know; we just found it.

It was amazing. Get up the next day, drive, drive, drive. We're like, "Okay, it's time to stop again, where are we going to stop?" We went to...oh shoot...it's a mustard name. Anyway, another town [possibly Dijon, France]. Beautiful town, didn't know anything about it. Again, amazing, learned so much, it was gorgeous. Then, on our way, we drove through the Pyrenees and got to the beach. We're just not afraid to do that.

Kamal, like Marie-Anne, also uses the learning strategy of traveling by himself.

He said that he prefers it, for multiple reasons, one of which being that he does not like being "influenced" by others, he prefers to "seek and gather knowledge" for himself. He explained with the following:

That's the thing, I like traveling with people too, but not all the time. There are some trips I want to take by myself. I want to go to the Himalayas. I've been to the Himalayas, but I want to go there again, by myself. Last time, I was with friends. I would definitely see it in a different light. I would probably be more involved in the culture and with the people and the community there if I'm traveling alone, which I cannot do when I'm traveling with someone.

Say, I'm in Egypt, but I'm looking to the Pyramid of Giza or whatever. The tour guide's telling me this and that, but its all just junk. To me, it doesn't mean anything because I already know the history because that's why I'm there but to actually experience it and see it and perceive it the way I want to and the way I built it in my head. He cannot do that for me. You have to do it for yourself. You need to seek and gather knowledge for yourself, but when you travel in groups, I feel you're really influenced by other people and how they're thinking. There's a saying, "If you hang out with a donkey long enough, you become a donkey." I prefer to travel by myself.

Darrell also enjoys traveling alone, but said that "when I'm traveling alone,

sometimes I have this moment, where it's like [expletive], I wish someone was here to 
witness this!” I asked Darrell about his strategy for learning through his travels. He explained that he always searches for his "wow" moment - a feeling of discovery through seeing or experiencing something new, also known as "enlightenment." He explained:

I always know that I feel a bit more powerful when I learn something new from a different place. Whenever I go to a place and I've absorbed something, not consciously going to absorb it, but hoping that every place is so different that I leave with something, I feel a bit more powerful. There are times when I go on a trip and I'm numb because I didn't learn anything new, or I didn't find that "wow" moment.

When I've had a "wow" moment, it could be a meal at a particular restaurant, in this place, a view of the sun, of a building, of people doing certain things. These are "wow" moments for me.

When I asked how he knew if he was having a "wow" moment or not, he explained, "I'm subconsciously evaluating it," and he said that later on he reflects on the experience. He alluded to the notion that in order to have a new experience, or a discovery moment, sometimes one must do something that they normally would not. For example, Darrell recounted a story of the time he decided to take a motorbike to Majorca, Spain - something he normally would not do, but it ended up becoming a deeply memorable experience. This was his story:

Let's see, when I was in Spain, I decided to go to Majorca, which is like a beach town, and I did something I wouldn't ordinarily do - I rented a motorbike that went on a ten-mile highway. The view, the whole experience, was completely different. But I went with the view that, okay, if I do a bike, moped, rather than take a car, it would have been cheaper, I had to bike the whole time, and the experience would have been different. But it's unlike it in any other city, that whole experience was different.

Ken's strategy for learning Spanish meant full immersion into a Spanish-speaking culture. In fact, he thought it best to immerse himself into two distinct cultures, on two separate continents. Ken began in Colombia, where he believed that he would have an 
easier time learning Spanish, as Colombians speak in a way that is "easier for foreigners to learn," according to him. After a year and a half, he would spend six months in Spain, for a second cultural immersion experience. He recounted:

I started in Medellin, Colombia. I chose Colombia because I wanted to learn Spanish and by most accounts from native Spanish speakers, the Colombian Spanish is credited with having a neutral dialect, being grammatically correct, and easier for foreigners to learn - in comparison to other dialects of Spanish. I've spent 1.5 years living in Colombia, one year in Medellin, and six months in Cali, and now I am wrapping up my time abroad by spending six months in Madrid, Spain.

Jorge admitted that even though he "always" travels with the purpose of learning or discovering new things, that his strategy for learning while traveling has changed somewhat since the time that he went to Greece and wanted to simply "sit on a balcony and watch the Mediterranean sea go by." He told me that he has refined his strategy for learning about local cultures, he said, "My philosophy has changed a bit since the time I took the trip to Greece. I still purposely try and discover new experiences, but a lot of my planning now revolves around trying local cuisines and visiting places where locals frequent rather than spending the majority of my time in tourist spots."

Eduardo also mentioned that he enjoys immersing himself into the local food culture when he travels, among other things. His strategy includes learning about exotic foods, local drinks, famous landmarks, the terrain, and the dating scene, of a foreign country. While discussing his learning goals and strategies, he said:

Specifically with the food, the drinks, normally when I go to a country, I want to immerse myself in the food. I'm a "foodie" by nature. I want to immerse myself with the drinks that are known there. If I'm lucky, if I'm single, if I meet a beautiful woman, yeah, I want to [meet] women, I'll be completely honest... I go to a country for the sake of getting to know the food, the landmarks, the topography, the people. 


\section{Evaluating Learning Outcomes}

In this study of self-directed learning, participants pursued learning activities and experiences not to pass some sort of test or receive a grade from a teacher, but to gain a pride in achievement, development of character, and personal enrichment. Knowles (1980) explained that adult learning, and specifically, evaluation of learning outcomes, indeed, has to do more with these things rather than a childlike need for validation in the form of a passing grade. He said:

Probably the crowning instance of incongruity between traditional educational practice and the adult's self-concept of self-directivity is the act of a teacher giving a grade to a student. Nothing makes an adult feel more childlike than being judged by another adult; it is the ultimate sign of disrespect and dependency, as the one who is being judged experiences it. (p. 49)

For this reason, adult education practice and self-directed learning prescribe a process of self-evaluation of learning outcomes. In this process, the learner has the responsibility of measuring performance, progress, and gains in competence, evaluating strengths and weaknesses of the learning experience, and revisiting their own initial learning needs and goals for the experience. Knowles (1980) called this revisiting of learning needs the "rediagnosis of learning needs" (p. 49). He referred to this process of returning back to the "learning needs" while "evaluating learning outcomes" as a cycle of learning, reinforcing the notion that learning is a continuing process (p. 49).

Another tenet of adult education is the acknowledgement that adults define themselves by their experience; they define who they are in terms of the accumulation of their unique sets of experience (Knowles, 1980). Part of this identity is based on what their achievements have been. Adults are what they have done, and because adults define themselves largely by their experience, they have a deep investment in its value 
(Knowles, 1980). Thus, the evaluation of learning outcomes, and equally important, asking oneself, "Was this worth my time?" are arguably inherent in adult learning experiences.

The chief purpose of reflecting on, and evaluating learning is to discover the meaning of experience, itself. It is a quest of the mind, which digs down to the roots of the preconceptions which formulate our conduct; a technique of learning for adults, which makes education connected to life and thus elevates living itself to the level of adventurous experiment (Gessner, 1956). The participants in this study did, in fact, mention that they had some form of evaluation process. This section will show, in participants' own words, the variety of ways in which evaluation of learning outcomes takes place.

When I asked Evelyn if she thought that she had been successful with her learning goals through travel, she said that she absolutely had been, and she explained the ways in which travel had brought her personal enrichment. Her response showed the evidence to this researcher that she had, in fact, thought about and evaluated her own learning outcomes. She compared her former self with her current self and used words like, "I learned more..." "I am more..." and "I think I'm successful..." Responding to "Do you feel like you were forever changed as a person through this experience; were you successful in reaching your goal," she said:

Absolutely. I learned more about myself in three months on the road in Colombia in 2013 than I did in the 30 years I spent in Australia. I am more spiritual, openminded, confident, patient, and have a stronger sense of humanity, to name just a few. Regarding "successful," I think you first have to define what success is, for me, it was setting up a business and working abroad, so it's a constant work in progress. In saying that though, I think I'm successful as I'm living the dream of traveling whilst trying to do so. 
For Evelyn, part of the evaluation process did, like Knowles (1980) said, include a rediagnosing of learning needs. In her evaluation, she said, "Regarding 'successful,' I think you first have to define what success is..." So, she went back to what she initially had in mind for "success," defined it, and evaluated her own progress toward it. This is the cycle of learning.

Gabrielle also admitted that she had evaluated her learning experiences with her travels to the U.S. and found that she had, in fact, been personally enriched through the journey, albeit in unexpected ways. She explained:

Another interesting fact I also realized about myself was that I was not as openminded as I thought I was. I always prided myself on being very open-minded and being open to other cultures because I grew up in a diverse neighborhood. But I realized that while it was diverse, we still had the French culture and language in common. Being around a different culture in a foreign country for an extended period of time made me realize that I could be intolerant and very judgmental of others. I had to reevaluate myself as well as my perceptions of others. I also became more appreciative of my culture and my heritage once it was not around anymore. Kind of like I took my culture for granted. I don't know if it makes sense.

Gabrielle used words like, "I also realized about myself...," "I had to reevaluate myself...," and "I also became more..." to express how she evaluated her learning outcomes.

Daniel had a particularly unique way of reflecting on his travel experiences and evaluating his learning outcomes through travel, in fact. When we started to discuss the notion of reflecting back on an experience and realizing things that one learns along the way, he looked at a book that was on his coffee table, told me to pick it up, and said, "Here is a book from every year from the last ten years of our travels." There were ten books there all together. He explained what they meant to him by saying: 
Some of them, we started off doing it when we were in London, and it was a means of sharing our experiences with our parents, who knew would never get there. Everywhere we went, we kind of told a story through the book, and that was their Christmas present.

We chronicled every year. When we've done big trips like this one on the cruise, that's solely about the cruise. The point is, every day those are sitting there. People come over, they ask what they are. We go through them. Every time I look through them, I notice something different. I certainly have a flash in memory. I look at something and go, "Oh my God, I totally forgot that Santorini is a caldera of a volcano." I know that when I look at that picture. I would say, in a slightly artistic, lazy, creative way, we do [reflect on the experiences and evaluate learning outcomes]. That's our way of doing it. We do it with photos from every single trip. We tell a story with it.

I enjoy. That to me is...I enjoy doing that, putting them together. The first piece of reflection is putting it together, right? You have to remember, it's like the Amazing Race. You have to remember where you went first to tell the story, right? Then, it's also - what are the critical pieces that were important to us? It may have been that sunset, or it might have been the piece of architecture, or whatever, or all of the above. We try and capture and I flip through that, I always see something different. It puts you back in the moment, but I also look at it and go, "Oh my God, I completely didn't see this," or forgotten we had done that, or whatever.

There is no particular rule, in fact, that says that reflection of an experience and subsequent evaluation of outcomes takes place immediately after the experience unfolds. Actually, it might happen long after an experience is over, and could happen many times after, in fact. For Daniel, every time that he looks at his picture books of memories, he sees something different and they remind him of something that he learned along the way. Those books spanned ten years of travel, and for Daniel, were priceless. They represented all of the experiences and lessons learned over the years, and for him, might have even represented part of his identity as a traveler and as a lifelong learner.

Eric, like Daniel, also mentioned that reflecting, for him, is a long-enduring process, rather than a "once-and-done" action step. He said, "I'm still reflecting on my 
experience, and probably will for a long time to come. I have noticed that as I reflect on my trip, I've begun to feel like I'd accomplished more than I'd felt I had right after leaving" [Colombia]. Reflecting on an experience, actually, is an enjoyable activity, and should not require any haste. In fact, the longer the reflection process, sometimes, the more one remembers.

Eric felt that his trip was such a valuable investment of time that he said that he was planning another trip back to Colombia this year. Eric pointed out that he felt like he had, in fact, made measured progress with his goals. He explained his process of evaluating learning outcomes with the following:

I do feel I was successful in meeting my learning goal, although I wish I'd made even more progress than I had. I also met my goal of seeing other parts of the country, although again, I wish I'd been more productive in that area as well. And I feel I met goals I hadn't explicitly defined, some of which I may not yet even be aware of. It's probably important to point out that I met goals which were set after I'd already arrived and had been living in Colombia, learning to paraglide, for example.

Ken, while evaluating his learning outcomes and the question, "Was this experience worth my time?" he said that he contemplated the affects of leaving a career for a couple of years to travel and then returning to the workforce. However, Ken felt that his time abroad had, in fact, brought him personal enrichment, in ways that balanced both: (1) the disadvantage of not having an income temporarily and (2) any questions or concerns that might arise by employers as to why there is a two-year gap in employment history on his resume. He explained:

At this point, I have six months left of a two-year travel abroad experience, and I have no regrets. My time abroad has been self-funded, but I'm not a trust-fund kid, so I now am beginning to think about how to reintegrate myself into the workforce. I'm not particularly worried about the two-year gap in my work history though, because I can clearly articulate why I've been away and any 
potential employer who doesn't see my time abroad as a valuable life experience most likely isn't someone that I would want to work for. One thing that I have definitely noticed is that I am even less quick now, not that I was quick before, to judge others who view the world differently than I do. I am also more patient when interacting with others who are not from the States.

Ken noticed that he had grown as a person, and his character had been enriched from his experiences; these were his learning outcomes. He used words that express measurement, like "I am even less quick now..." and "I am also more..." To this researcher, this shows evidence of an evaluation process occurring.

Logan also evaluated his learning outcomes after his trip to Venezuela. In fact, what he learned from the trip and gained as personal enrichment actually came as a surprise to him. He said that he was shocked at what he found in Venezuela and that the valuable lessons that he learned came as a result of what he did not expect to encounter there. He explained:

To be honest, I went into the whole thing pretty ignorant. I had no idea that Venezuela was falling apart. Turns out, it was one of the most devastated places on the planet - as you can see in the news everyday. I look back now and realize that when the director for Venezuela said, "No one from America has ever come to help our group," I know why now. Venezuela, next to Honduras, has the highest murder rate per capita in the world. Their current inflation is up at around $900 \%$. More than $80 \%$ of the population now lives on less than $\$ 40$ a month. It's incredibly sad, yet an incredible opportunity to be fearless, show love and compassion, and break down cultural barriers.

Knowing other cultures has transformed by ability to empathize in reality with real situations and real people - not just posting something on Facebook about some cause I support. It has allowed me to become something that I still can't explain today.

Marie-Anne also learned some unexpected lessons through travel, but felt that they had enriched her life and strengthened her character. In fact, she mentioned a story about her first international trip and a valuable lesson that she learned after having her 
things stolen from a tour bus. She learned resilience, namely. She said, "I grew so much on that trip; I learned how to take care of myself and to never be afraid of new places." She also learned how to take safety precautions while abroad, by blending in with her surroundings. She explained:

From that day forward, I travel like a local. As if I am from the place I am visiting. I don't do anything different from what locals do. I don't wear fanny packs or hide my wallet on a lanyard around my neck. I conduct myself as I would at home, just a little more mindful of my surroundings.

Marie-Anne routinely reflects on her travel experiences, it's her way of evaluating learning outcomes and knowing how to plan for future trips. She said, "Reflecting on the trips I take is what keeps me wanting and planning the next trip."

For Darrell, the process of evaluating learning outcomes has to do with whether or not he had his "wow" moment on a trip. For him, a "wow" moment is a discovery moment, an experience of learning or discovering something that he had not seen or known previously. Success with meeting his learning needs and accomplishing learning goals means experiencing something new - something that makes him say "wow." When I asked him if I were correct in assuming that "wow-ness" could be synonymous with “newness," he affirmed, "newness, or learning." He explained:

The one thing I noticed about me is that I can go to a place, have a great moment, experience that moment, and I'll come back home. I remember the place, but I could never replicate that moment. It was so unique, so special. But I don't even want to replicate it, I just want to remember that this was this at this time, and what I experience, and I don't have to replicate it, because I won't be able to. It was the first moment when I saw this, when I went to this place. You can't replicate it...I'm subconsciously evaluating it [in the moment], and I think that those are the times when I come back and then I reflect - I didn't have a wow moment, a learning experience. So, people would say, "Oh, you went to Guatemala, did you like it?” If I didn't have a wow moment, subconsciously myself is telling myself, I didn't enjoy the place, you didn't learn anything, because you didn't have a wow moment...There's multiple opportunities for wow 
moments. It must be a really bad learning experience, and it's rare that I don't have a wow moment from a new place.

Kamal also mentioned that he evaluated learning outcomes based on special moments that he had during his travels. For him, his greatest learning outcome is that which results in understanding himself and his world better, and this comes from a series of insightful moments. In his own words, he described this process of reflection and evaluation with the following:

You learn about yourself when you experience something. Then, you try to reflect on how you feel about it and how you think about it. That's when you actually grow. You know more about yourself. You know your feelings better because you see a piece of art. If it doesn't invoke something in you, then there's no point seeing it. When that feeling is invoked, you need to actually experience that feeling and think about that feeling and why you felt that way. That actually lets you understand yourself better.

What I tried to do when I reflect on it is I try to feel what I felt at that moment, which is not possible because it's a different moment, but you think about how you felt at that moment. Then, you try to understand why you felt that way and what about it made you feel that way. What about that art or that person or about that language or that word or that moment or the scenery or nature or whatever it is, made you feel that way. If you can understand that, it's like understanding yourself a little better.

When I asked Kamal if the process that he explained helps him in the future, he replied, "Without a doubt, because you're growing. The more you grow, the more capacity or ability to understand more things and more you're open to people."

Discussing the process of evaluating learning outcomes, Eduardo had a story that he used as an example to describe a time in which he evaluated his own learning outcomes from traveling abroad. The time that he was in Turkey, witnessing the fighting between two ethnic groups, Eduardo learned a valuable lesson. He explained:

When I was there, I was like, "these people are fighting and arguing for what?" For nothing. They look the same, yet they tell each other, "You're not one of us." 
That was interesting to me. That was more of an ego. For me, it was like two roosters, two cocky roosters just going at it, and that's it, no solution. That was interesting to me. That's when I really learned something that Mom always taught me, and that's when you're in someone's house, whether it's a country, it's their house, you respect the rules. You go there, you respect the rules, you learn, you have a good time, and then you come back to where you're at. Then you appreciate it or reflect on the moment.

\section{Identifying and Overcoming Challenges Along the Way}

Up to this point, this researcher has analyzed and explained the ways in which travelers use components of Knowles' (1980) SDL theory during the course of their learning experiences with foreign travel. Now, I want to add to this analysis an important process to learning that is not included in Knowles' theory, namely, identifying and overcoming challenges along the way. Knowles does, in fact, describe how adults are "problem-centered" in their approach to learning and that adults face "immediacy of learning" when strategizing ways to solve problems that arise. He explained:

Adults tend to have a perspective of immediacy of application toward most of their learning. They engage in learning largely in response to pressures they feel from their current life situation. To adults, education is a process of improving their ability to cope with life problems they face now. They tend, therefore, to enter an educational activity in a problem-centered or performance-centered frame of mind. (p. 53)

These concepts inspired my interest in questioning my participants about how

they have recognized, overcome, and learned from challenges along their travel journeys.

Lindstrom (2011), in his travel study, noted:

Travel situations that effectively placed participants outside of their comfort zone amplified senses and stimulated uninhibited self-awareness. Bravely confronting new stimuli and new challenges were reported as delivering a rejuvenating and renewing effect, a motivational paradigm shift that opened the gates of potential learning. Participants who immersed themselves in unfamiliar environments were more apt to experiment, experience, question, listen, absorb, try out new behaviors, reflect upon and write about the experience. (p. 229) 
As I highlighted in Chapter 2 of this study, under the section Travel as Personal Enrichment through its Challenges, a description of some of the ways in which travelers learn valuable lessons through challenges was presented, according to a review of relevant scholarly literature. This section presents a description of this process of recognizing, overcoming, and learning from challenges, in the words of the participants.

When I asked Evelyn if she had faced any challenges during her travels, and if so, how she overcame them and if she thought that they were a part of the learning process, she replied:

One-hundred percent! You face so many challenges along the way, life on the road never goes to plan and that's the beauty of it. Learning the local language to simply order your lunch, lost possessions, cancelled flights, local political situations to plan your route, diligence with safety - the list is endless, but each experience is something you take home and remember for life. The way in which you handle these situations can only be learned along the way and I think often times I was surprised at how calmly I dealt with them. I can't think of too many experiences that didn't end in a smile, at the end of the day, they pale in comparison to the great times you have whilst traveling.

I asked Gabrielle the same questions and she responded with her own explanation

of how she was able to identify, overcome, and learn from challenges that she faced when she came to the U.S. She explained:

Language was one of the biggest challenges. When I came, I did not speak the language, and that was the reason for me to come in the first place. I wanted to learn the language. I could not communicate very well. It was frustrating many times. Then I had an American roommate. I could not understand what she was saying as she was speaking so fast and to me it sounded like she had a strong accent, she was from New Orleans. For two weeks straight, she called me "Nikki," as she thought it was my name, quite the misunderstanding. But as my language skills improved, my experience became more interesting and my immersion easier. I could understand what was going on around me. The first time I could go to a movie and actually laugh at the jokes because I understood them was just priceless. Adapting to a different culture was also challenging. I had vague memories of my adaptation to German life, so I could not rely on that experience of traveling by myself to help me adapt to the American culture. Besides, I only spent two weeks in Germany, I was with my school and my 
teacher, so if I had an issue I could talk to somebody. Being in America felt different. Many times I found myself wanting to be around other French people and wanting to speak French and eat French food and see my family. I relied on them a lot. Moving due to unforeseen circumstances and finding myself with an American roommate helped facilitate my adaptation to the American culture and helped me reach my goals.

Ken mentioned that challenges have, indeed, been learning experiences for him.

Although he hasn't had the types of challenges that "derail" his plans, he has found that

"total immersion" into a foreign culture comes with many learning opportunities that one might not have been aware of ahead of time. He explained:

Of course one has the usual challenges, like creating and sticking to a budget. Other challenges are the unexpected events which may derail one's plans like the need to return home to care for a loved one or unexpected expenses. Luckily, for me, I haven't been faced with a challenge as of yet which has forced me to reconsider or completely abort my plan for travel full-time. However, I would say that any challenge that one encounters while abroad is definitely part of the learning process - and that would include everything from how to rent an apartment in another country to how the legal process works in another country. You will learn multiple new things every single day - this is what is meant by total immersion.

Jorge, Marie-Anne, Jean-Claude, and Kamal also mentioned that budgeting and expense management were challenges along the way. And this is understandable when one plans a large and costly international trip - figuring in currency exchange rates, local inflation rates, surcharges, fees, taxes, and not knowing the actual costs of things incountry, expenses can certainly run higher than initially expected. Jorge said that he funded his trip on a credit card, which for him, was worth the cost that he would face later. He said:

The only challenge I [see] in hindsight was paying for the trip. I used a credit card to pay for it and didn't necessarily have the funds, but I decided that I would gradually pay it off when I returned. I learned that sometimes in life, there are calculated risks to take that later in life you'll be glad you took. 
Marie-Anne mentioned that her travel challenge is to find cost-effective destinations, ones that allow her to experience what she is looking for, while staying within her budget. She said, "I choose my destinations based on whatever deals I find. There really isn't a place I wouldn't go.”

Jean-Claude also tries to travel within a specified budget, and he mentioned how he does this. He said, "I tend to travel simply, low-budget, trying to experience as much as possible of the local life where I am at, meaning, sleeping at some family's house, camping in the bush, eating at a street vendor, taking public transport - always to interact with local people."

When I asked Kamal about travel challenges, his first response was about how to fund the trip and any unexpected expenses that might come up. He said, "Money is always a big one." He continued:

Budgeting is big. Normally, what I try to do is I budget for travel every month respective if I'm traveling or not that month. I'll put \$200 in my travel budget every month no matter what - if I'm traveling or not. Then, if I am traveling and I don't have money, probably dip into savings account or not, but other issues I've faced while I'm traveling, it's like missed flights and missed trains, especially in third-world countries, it's not easy, like you're stuck.

Kamal then discussed another challenge that came to his mind during our interview and wanted to explain what he had learned from the outcome. Kamal admitted that he has the occasional feeling when he travels, including in the U.S., that some people stare at him with a judgmental curiosity. He said, 'I'm a brown guy in this country, with a beard...People assume that I'm Muslim for some reason, that happens quite a bit." He told me a story of a time that he was in Red Bank, New Jersey, sitting, waiting with a friend, when he felt as if an unknown woman was starring at him, with a frightened look. 
Wanting to break the ice, he greeted her and asked if she and her husband wanted to sit down in the two free seats next to him. She asked, "Where are you from?... What religion are you?" He replied, "India... and humanity." And after about a ten-minute conversation, he said they became friends. They invited him to their home for dinner. He would later find out that her husband's brother died in the September 11th terrorist attacks. Kamal said that she had "built up walls" in her mind, and that he was on the other side of that wall, because of his physical appearance. When I asked him if this challenge was part of his own learning process in some way, he said:

Yeah, because you understand those people. It's just [that] you understand why they do what they do. This lady, she did that because her husband's brother had passed away in the terrorist attack. She's built up walls against everybody because that one reason. That's the biggest problem, it's everybody's building all these walls. It's easy to build them. It's hard to break them down because once you build them, you start believing in them. Then, you're so convinced that this is what it is, you just shut yourself off from really understanding other people and experiencing the world.

I asked him if he was a better person because of these types of experiences. He said:

Yeah. I know her better. I understand why she did what she did. After having that conversation with me, she understood who I am, what I am and how completely different I am from those people. It's just - she didn't know me... It's about getting to know each other.

There are many things that will, inevitably, cause new and challenging experiences when one travels. For Daniel, one of his first challenges while traveling was exchanging currencies and learning to manage money, while doing it in a completely different money system. Recalling his first trip to London, he remembered how confused he was with the money, being that it was in different colors, sizes, and denominations to what he had been accustomed. This might sound trivial, but the challenge and stress of learning something new, like learning how to calculate value in a purchase while still 
thinking in terms of one's native currency, can be exhausting. However, being able to adapt to this new challenge is exactly what problem-centered self-directed learning, with an immediacy for learning is all about. Daniel recalled his experience with the following:

First trip to London in, let's call it 1990, let's say, the Euro didn't exist yet. The [British] Pound to the Dollar was crap, probably where it is now, again, maybe. Even though they spoke the language [English], that was a bit of a challenge, because, I don't know, that was my first experience with foreign money. The notes are bigger, you have these coins, and so...It's confusing. Particularly [if] you're in a restaurant...it was not insurmountable, but...I don't think I'd thought about that. I don't think I thought about it at all. I didn't know anybody really explained it to me. It was just like, "Oh wow, this isn't my money, what do I do?"

Eventually, though, Daniel figured out how to manage foreign money. This

problem was solved and challenge overcome. In fact, Daniel admitted that he feels like he has grown as a person through his travel challenges. He said:

I've always felt that [you learn and grow through challenges]. If you face a challenge, figure out a solution, you get over the fear, you learn more, you are [a better person]. I could move anywhere. I could probably live anywhere.

Beside money, differences in laws and regulations from country to country can

create confusing and challenging situations for the traveler. Darrell recounted the lessons that he has learned through the challenges with the following:

So, I've had lots of challenges. I've had challenges dealing with the regulatory stuff, and regulatory stuff is like immigration, people don't know who you are and why you're there. I'll give you two scenarios. The first one was as a young man not knowledgeable on world travel, and this is way back when I was in Spain and I was returning home one time, I arrived at an airport broke as [expletive] with all these luggages and stuff that I accumulated, and they refused to take me on the plane with all this luggage, I couldn't check them in because I couldn't afford to pay for it. The plane left me, I had to wait two days to take a flight back, I had to sleep in the airport because I didn't have money to take an earlier flight. So that's one.

Then I went to El Salvador, not realizing that I was using my Bahamas passport, and if you're from the Bahamas you need a visa to go to El Salvador. So I arrived 
there, ready to have a good time, I was told "nope," you [have to] get on the next flight the next morning to go back. I had people with guns in my face, who escorted me to my hotel, who came that next morning and picked me up to make sure I got on my flight. Those are the kinds of experiences.

When I asked Darrell if the challenges had been part of the learning process, he said, "It has been. The experiences I had, that were challenges, allowed me to learn more, that I'm not going to repeat this mistake or overlook this particular information anymore."

Jean-Claude discussed challenges that show up during travel adventures and called them, "a little bump on the way." He said that they can actually make life more enjoyable. He said, “As travelers know, it doesn't always go as planned - delays here, break down there, scam over there, thief over there - unavoidable things happen and I learned [to accept] situations that I can't change, it makes life a lot more enjoyable.” He went on to say, "Challenges are inevitable in life and so in travel; whatever 'problem' arise, I try to see it as a way to improve on myself - so I deal with it the better way that I can - without stressing too much, knowing that it's not going to last." Jean-Claude told a story about how he overcame a challenge while driving through South America. He recounted:

Once I was road tripping through South America with a van bought in Colombia. At the border to cross Ecuador, I got told by the Immigration that there was some issue with the van's registration. Then, that was the start of a 10 day patience test, dealing with the previous owner to get the papers right. At first, I felt a bit of anger toward the situation, but then I realized that I couldn't do anything about it, that I might as well - not necessarily be happy about it - but at least accept it. At the end, things on a trip, like in life, happen all the time, one can deal different ways about any given situation. I prefer to make the best out of all of them. That was another example for me to accept things I cannot change and deal the best that I can with the one I can change. Isn't it wonderful? 
When I asked Eduardo about travel challenges, he responded immediately with

"language." Communicating effectively in a foreign language is one of the biggest

challenges that travelers face, in fact. However, it is not an impossible challenge to

overcome, with the right resources. Eduardo explained:

The language. I would say, for example, not being able to communicate effectively when we were in Prague, that was a challenge, a big challenge. However, we were able to overcome, usually through being friendly, smiling big time. That seems to open more doors than anything in my life. Also, communicating through picture-grams, or to sound even cheesy, like iPhone... and stuff like that, or whatever it takes. Eventually, that ten-second sentence can last through us trying to communicate for five or ten minutes, but we get it. It's a temporary challenge.

I paraphrased his response with "You use recourses," and he replied, "Absolutely, absolutely, tools and resources, visual aids, whatever it takes."

The majority of participants in this study admitted that they did, in fact, encounter challenges along the way, and that they had faced them, overcome them, and learned valuable lessons from them. Insofar as they differed from person to person, challenges had been an important part of the learning journey through travel and for this reason I was compelled to include the topic in this study of self-directed learning.

\section{Travel is Enhanced by Having Learning Goals and Strategies}

Upon analysis of the data, this researcher feels strongly that foreign travel experiences are enhanced simply by including learning goals and strategies along the way. My interest in exploring learning methods that could be utilized while traveling led me to consider how Knowles' (1980) SDL theory might be applicable. This model is applicable even as a starting point for travelers to begin thinking about their own selfdirected process for learning and which - if not all - components to keep in mind as they 
travel. This study has extracted personal stories, experiences, and perspectives from travelers concerning how they knowingly or unknowingly apply some or all of the six components during their travel learning. This researcher also gave participants an opportunity to discuss the ways in which travel is, in fact, enhanced by having learning goals and strategies. This section shows the results of that discussion.

Evelyn admitted that she gains much more when she travels with the purpose of learning. For this reason, she formulates learning goals and strategies for herself to learn about people, places, cultures, and languages during her expeditions. When I asked her about her learning intentions through travel, she explained why, exactly, she travels with learning in mind. She explained:

Experiencing new cultures and people is by far the greatest driver for me. The way others live, work, and play gives you a fabulous perspective on your own life. A by-product of that is learning so much about yourself and becoming a lot more appreciative I believe. Language is also a big one. I truly believe your mind gains clarity when you are learning a new language. I love learning a new language, currently Spanish and Japanese are under my belt and there is no reason I should be stopping there. Most of all, particularly if you do the solo travel, you build a confidence I don't believe you can learn in any school. You have only yourself to rely on, however, it never feels as though you are alone - you meet so many wonderful locals and travelers - characters from all walks of life. That experience builds you as a person.

Jorge said that he felt as if he would be wasting his own time and money if he returned from a foreign trip without learning things about a place or culture. In fact, for Jorge, it is important to practice the "art of cultural exploration" when he travels and immerse himself in another culture to the point of feeling "like a local." He certainly has learning goals and strategies, and makes efficient use of his time while abroad. When I asked him, "How do you think your travel experience was enhanced by having the goal of learning something along the way?" He responded: 
Simple. If I don't venture out into the city and explore it, I waste thousands of dollars and more importantly, gain no new cultural experiences by being inept in the art of cultural exploration. Every time I was tired or sleepy or just wanted to relax, I reminded myself that life is short and I may never get a chance to return to this location so I better make the most of it. Therefore, pushing myself to reach my own goal of learning about a country's culture, not at a mediocre pace, but as close to feeling like a local as I could.

Jorge also mentioned a personal creed that he lives by, in reference to travel. It is important to note that his belief is that travel is about learning. He said, "I have always been curious about how others live on this earth; I believe strongly in the motto that travel is the highest form of education that one can attain through complete immersion of experiences."

Logan also exclaimed that he believes travel provides an advanced route toward learning, if learning experiences are what the traveler is searching for. He said, "It [travel] has allowed me to become something that I still can't explain today. Traveling is greater than any class you can take in school or any book or blog you can read."

For Jean-Claude, traveling is like a "school for life," there are always lessons to learn. He affirmed the notion that traveling is always better when learning happens because you return to your native country a better person. He said:

I see traveling like a school of life, it's an awesome way of learning about yourself, how you deal with day-to-day situations, your emotions. By witnessing and experiencing different realities, it opens your eyes and often changes your perceptions about the world, people, and even your convictions. I always go back to my native country a changed and better person.

Marie-Anne agreed that traveling is enhanced through inclusion of learning goals and strategies. She likes learning about how people live and interact in other countries. For her, traveling with learning goals and strategies allows her to focus her attention on those precise learning experiences that she is pursuing. She explained: 
When I travel, I am not necessarily looking for a new adventure, but more so a new experience. I want to learn about the people, how they live, and how their values or mindset may be different from us here in the States...Traveling with the desire of learning about how the people live and interact allows me to pay attention to the people and the normal way of life rather than the touristic hype.

Ken also admitted that having a learning goal while traveling was essential. His goal of learning Spanish mandated the learning strategies of choosing a destination and immersing himself completely in a particular culture. He expressed the importance of having a goal with the following:

For me, having a goal was essential. I'm in the group of people that normally enjoys having some sort of goal in which to aspire. Since my goal has been to learn Spanish - that goal has influenced many of my decisions, such as what countries to live in and what neighborhoods to live in, i.e. neighborhoods within close proximity to my Spanish school.

Daniel expressed his love for learning and used travel references to describe how travel, itself, is enhanced by having learning goals and strategies. Although at times Daniel does not give conscious thought to his specific learning goals, he has a sense that they are there, and guide his travels. He said:

I think that, yes, I have a personal desire to learn. I'm fascinated by certain things...I try to learn something new every day. Whenever I go somewhere, I learn something. That is a...maybe it's more conscious than I think. That is a goal, I guess.

Daniel tries to experience culture, language, and food when he travels, and see famous or historical architectural landmarks. These things are important to him; they make his travel experiences more valuable. He said, "Pretty much everywhere we've gone, there's some kind of landmark - be it historical, be it architectural, or whatever - we always look for that." Daniel also enjoys designing his own learning strategy, which he 
describes as assigning time for leisure activities and also for cultural activities. He said, "...there's pool time, or beach time, and then it's cultural - that is how we travel."

For Darrell, travel is enhanced by having an "open mind" toward things like people, culture, and food. In fact, his goal of having a "wow" moment during foreign travel can only be accomplished by having an open mind toward new experiences. He suggested, actually, that travel experiences are a waste of money if the strategy of having an open mind is not applied. He explained:

I'm always going to tell people - listen, going to Europe, these are the places, this is the kind of food they eat, be sure that's something that you can adapt to. Be sure that you could be around people from another culture, that you're going to embrace it. Be open minded about it. If you are closed minded, don't go... My view is, don't waste your money to go to a place if you're not going to be flexible enough to adapt to food, culture, and people.

When referring to people who travel without learning goals and strategies or willingness to be open minded and adapt to the local culture, Darrell said:

...They haven't done any pre-research, they don't know anything and the go there, "Oh, I don't eat this, I don't eat that." Then what the [expletive] are you here for? Why did you waste your money and come here? It's going to be a worse experience than if you didn't go.

Kamal also discussed this notion that travel is enhanced with learning goals and strategies. For him, travel is enriching because he has the learning strategy of immersing himself in interesting and engaging environments. This strategy helps him to gain original perspectives on his own life - perspectives that can give him a "mindset" to "tackle problems in a different way." He expressed his agreement that travel is enhanced with learning goals and strategies by contrasting a genuine learning experience that one might have in a foreign environment with a simple beach vacation in a foreign country. 
When I asked, "How do you think your travel experience was enhanced by having the goal of learning something along the way?" he responded:

Instead of just going to the beach for a week? The thing about going to the beach for a week is you come back to the same problems you had but if you actually travel to learn something, you come back and you look at your problems in a different way - but maybe you're just traveling for fun. It's different because you're not really learning anything. Your life really hasn't changed. Your outlook really hasn't changed. You went out. You sat on the beach. You had a few drinks. You're back, but are you a better person? No. You're still the same person. You can't really tackle your problems in a different way. I think Albert Einstein said this: "You cannot really solve the problems you created by the same mindset - your mindset has to change if you want to solve the problems that you created with your mindset."

Kamal believes that travel, itself, "opens the mind" to perceive more, and this is why learning goals and strategies are effective while traveling. He said:

Because what travel does is, it actually opens your mind, so you can perceive more. Every time you're in a place, you take in a lot more. You have the ability to take in a lot more than usual because your mind is clutter-free. Otherwise, there's all these thoughts and emotions, like that's actually cluttering your mind but travel actually takes it away because it takes your mind away from things.

From descriptions that participants gave, it appears that travel and learning have a reciprocal relationship, meaning that travel is enhanced with learning outcomes, just as learning is enhanced through travel. Participants admitted that their travel experiences were more rewarding because they had learning goals and strategies along the way. They also explained, within previous sections, that learning about themselves, others, the world, or life, had been dramatically increased through foreign travel. This relationship is not the focus of this study; however, it could be an interesting focus for future studies that will be recommended in the next chapter. 


\section{Summary}

This chapter presented an analysis of qualitative data and showed (1) how participants described their own personal enrichment through travel, (2) in what ways Knowles' (1980) SDL theory is applicable in foreign travel contexts, (3) how participants learned through the challenges of travel, and (4) how participants believed travel is enhanced by having learning goals and strategies. In the next chapter, the responses to the research questions and implications for research and practice are discussed. 


\section{CHAPTER V}

\section{DISCUSSION}

This chapter is divided into three main sections: (1) responses to the research questions, (2) implications for research and practice, and (3) recommendations for future research. Then, limitations of the study are given and a summary ends the chapter.

\section{Responses to the Research Questions}

The discussion begins with responses to the secondary research questions followed by the response to the primary research question to conclude the section. Secondary Research Question 1: How can Knowles' (1980) 6 components of self-directed learning be applied to learning and personal enrichment experiences in foreign travel contexts?

According to participant responses, Knowles' (1980) SDL theory is not only relevant, but also applicable, in foreign travel learning contexts. Participants reported personal examples of how each of the 6 components can be applied during foreign travel experiences. For example, in climate setting, participants admitted that they placed great importance on selection of travel destinations and learning sites. They had specific criteria in mind when it came to creating learning environments; some required safety and welcoming environments, some needed highly social settings, and others pursued adventure settings and thrills. They each set a climate for learning according to their personality and learning needs.

Next, in diagnosing learning needs, participants tried to answer the question, “Why am I traveling, what am I hoping to gain?” Knowles (1980) described this process 
of diagnosis as measuring a gap between present competencies and the desired level of competency. He said that learners will experience a feeling of dissatisfaction about the distance between where they are and where they would like to be, and so are able to identify specific directions of desirable growth - this self-induced dissatisfaction with present inadequacies, coupled with a clear sense of direction for self-improvement gives the learner the motivation to learn (Knowles, 1980, p. 48). Participants in this study seemed to understand their own learning needs; many of them reported their "why" for travel, and mentioned things like: a lifelong desire to learn a foreign language or experience another culture (which result in increased linguistic and cultural competencies), a need to see specific world landmarks (resulting in personal enrichment and sense of accomplishment), or a compulsion to visit new places where they have never been - which I explained as "wanderlust." The wanderlust concept can be described as a need for discovery and experience-seeking in which traveling to new places brings deep satisfaction to the individual.

In formulating learning goals, the majority of participants expressed that it was, in fact, important for them to have learning goals during their travels. In fact, many reported traveling for specific reasons and having defined objectives in mind. Others realized in hindsight that many of their travels were unknowingly directed by an internal desire to accomplish or gain something from their trips. They said things like, "Looking back...I guess that was a goal." Either way, participants' foreign expeditions were designed with some meaning behind their plans and purposes. This author explored the idea that participants were motivated by learning goals, or the desire to gain a measure of 
personal enrichment from their trips - an idea that was central among the criteria for participant selection. And from the data, this idea was overwhelmingly correct.

Participants explained how they identified human and material resources for learning by specifying the types of resources that they found useful for their learning. Travelers typically cite travel agents, tour guides, friends, family, or acquaintances, locals, or fellow travelers as human resources for learning. Material resources for learning, in this context, usually includes books, manuals, brochures, maps, guides, up-todate information found on official websites, and other helpful internet resources like suggestions for travel and tourism, statistics, warnings, weather, and resources for accommodation/transportation arrangements. Self-directed learners understand that help is often needed along the way, and participants did, in fact, admit that they utilized resources to make their learning experience easier. As a matter of fact, all participants mentioned at least one, if not many, resources that were helpful in their experience. The most frequently cited resources in this study were the Internet and locals.

Then, in choosing and implementing appropriate learning strategies, participants reported a variety of strategies that they used to accomplish their learning goals. They planned activities and pursued experiences that would allow them to engage in their learning environment and discovery ventures. Knowles (1980) called this stage "Implementation," or "Conducting learning experiences." Examples of learning strategies included: enrolling in a language class abroad; initiating dialogue with locals while abroad to gain new perspectives and practice foreign language skills; pursuing multiple interests while abroad for maximum learning in limited time (e.g. learning Spanish and learning to paraglide, or language practice with surf lessons). Some 
participants also mentioned that their strategy for maximum learning was to travel alone - in order to challenge themselves to interact more frequently with locals and with the environment. Others employed the strategy of remaining flexible and adaptive to events and opportunities that might arise during their trip - in order to feel more spontaneous and unconstrained with their time, instead of rigid and planned.

Finally, when it came to evaluating learning outcomes, participants said that they had, in fact, reflected on their experience and indicated that they had learned from it. Some admitted that the reflection process, for them, was long and enduring, and might go on for many years. This researcher agrees that these types of travel experiences, ones in which personal enrichment and learning happen, are unforgettable and will continue to be a source of reflection for the rest of the traveler's life. An important indication for me that participants did, in fact, evaluate their learning outcomes, came when I analyzed their choice of descriptions for measurement - they said things like, "I am more confident," "I am more patient," "I feel more independent," and "I am a better person," for example. Their experience had been more than a fun time - it had changed them. And that is the ultimate learning outcome - to be changed for the better.

Further, when adults evaluate the value of a lived experience, many times they ask themself, "Was this worth my time and money?" and "Would I do this over again?" As time and money are limited, these are valid questions to ponder. I should note here that none of the participants said that their experience was a waste of time or money. In fact, many participants mentioned budgeting as a primary concern or challenge, but that travel was always worth the cost - so much so that one participant said he took a trip to Greece by paying for it on a credit card - a purchase that he would be paying for in 
installments for some time. Most participants said that they plan on continuing to pursue travel into the future; one participant said that he plans on returning to the same country very soon. All participants admittedly evaluated their learning outcomes.

After analyzing the data from discussions with participants, this researcher was able to show examples of how each of the 6 components of Knowles (1980) SDL theory could be used to look at the essence of learning experiences through foreign travel. This researcher believes that the findings in this study make a case that Knowles' model for learning is applicable in travel contexts and could be used by anyone traveling abroad with the intention of learning from their trip.

Secondary Research Question 2: How does being self-directed as a learner in foreign travel contexts serve to enhance the experience of foreign travel?

In Chapter 4 of this study, findings were shown from participant responses to the question, "How do you think your travel experience was enhanced by having the goal of learning something along the way?" This researcher's analysis of the findings explored the ways in which travel is enhanced by having learning goals and strategies. Being a self-directed learner in foreign travel contexts means knowingly, or unknowingly, applying some or all of the components that Knowles (1980) mentioned in his SDL model, along with becoming increasingly self-directed in nature, valuing experience as a rich resource for learning, pursuing personal interests for the sake of learning, selfdiagnosing learning needs, formulating learning goals, applying learning strategies, being reflective of outcomes, and overcoming challenges along the way. I believe that one can become a better traveler, then, by improving his or her own self-directed qualities and behaviors. Brookfield (1986) asserted, "the most complete form of self-directed learning 
occurs when processes and reflection are married in the adult's pursuit of meaning" ( $p$. 38). Foreign travel experiences can be richer and more meaningful as the traveler applies this concept of self-directedness.

One theme that emerged from participant data concerning this idea that travel is enhanced by having self-directed learning goals and strategies was a belief that one gains more from travel experiences when learning happens - therefore, designing a trip with learning goals and applicable learning strategies could result in more rewarding experiences. Boyatzis (1995) said, "people learn most effectively when they are in control of the learning process and can choose developmental activities best suited to their personal situation" (p. 51). In essence, having learning goals and strategies helps to enrich the experience. Most of the participants alluded to this point by giving examples and personal accounts of how they felt more enriched by being able to travel for learning's sake. Some even mentioned that if learning had not happened, time and money would have been wasted.

For some participants in this study, travel, itself, is about learning and personal growth - because travel has a way of putting the individual in unique situations in which an open mind is necessary to be able to adapt to new things. No two countries are the same and international travel will always force the traveler to confront something different, exotic, or strange. This is why travel is about learning - one must learn to adapt, albeit if only for a short time.

Another theme that emerged was the concept that learning through travel is unlike learning in a class or from a book. The experience gives the traveler a quick route to full immersion into an interactive environment - by requiring attention from all the senses: 
sight, sound, smell, touch, and taste. Travel, Bodger (1998) said, "provides an immediate and personal experience of an event, place, or issue that cannot be duplicated" (p. 28). Knowing this, I believed that Knowles' (1980) SDL model would be an ideal theoretical lens to view this study of learning through travel. It includes all of the most important steps that one must go through, from the beginning to the end, of a learning experience and is quite different from learning in-class or from a book. One participant said, "If you do the solo travel, you build a confidence I don't believe you can learn in any school," another exclaimed, "Travel is the highest form of education that one can attain," and another participant declared, "Traveling is greater than any class you can take in school or any book or blog you can read."

Since travel has to do with learning, and learning through travel is different from learning through a class or book, this researcher believes that providing this study to the existing literature gives an applicable model for travelers to use so as to improve their travel experiences and enhance their learning outcomes.

Primary Question: What is the essence of being a self-directed learner in foreign travel contexts?

The phenomenological framework of this study directed the conclusion toward finding the essence of the shared and common experience of the participants. The essence of being a self-directed learner in foreign travel contexts is described by its defining characteristics, according to this study, which are: placing value on the education gained through foreign travel; wanting to be enriched through its experiences; expecting a learning outcome; designing travel with learning goals and expectations; being resourceful in finding help along the way; developing resilience in overcoming 
unexpected challenges; being open-minded toward new experiences and adaptable to the moment; finding enjoyment in being involved and engaged in unique environments; becoming contemplative of the value of experience; and believing that travel is more fulfilling when learning takes place.

I believe that these characteristics describe the essence of the self-directed learner in his or her learning environment while traveling. This is exactly what Guglielmino (2008) was referencing when she said that self-directed learning offers a path to increased life satisfaction. Developing any one (or more) of these qualities as a self-directed learner in travel contexts can help the individual to become a more independent and effective learner in any self-directed pursuit, which is the goal of self-directed learning theory and andragogy.

Merriam, et al. (2007) said that the goal of self-directed learning is to enhance the ability of adults to be self-directed in their learning, whether it be in formal or informal learning settings, the workplace, pursuing interests or leisure activities, or in our everyday lives. Knowles (1983), describing andragogy as "the art and science of helping adults learn," said that "as a person matures, his or her self-concept moves from that of a dependent personality toward one of a self-directing human being” (p. 44-45). Knowles (1970) explained that adults have a psychological need to be self-directing and to be seen as self-directing, independent, and responsible in their own lives. He said:

Their self-concept becomes that of a self-directing personality. They see themselves as being able to make their own decisions and face the consequences, to manage their own lives. In fact, the psychological definition of adulthood is the point at which individuals perceive themselves to be essentially self-directing. At this point people also develop a deep psychological need to be seen by others as being self-directing. (Knowles, 1970, p. 45-46) 
Lindstrom (2011) concluded, "those who engage in a more self-directed and reflective approach to travel will gain insight into their personal limitations as well as their tremendous potential for tremendous growth and independence" (p. 238). This researcher believes that the thirteen participants have not only been enriched by their experiences of travel, as they described, but have also developed the skills of selfdirection that have made them more independent, responsible, and thoughtful as adult learners.

\section{Theoretical and Practical Implications}

This study has implications for the development of self-directed learning theory and the field of adult education. The findings relating to how travelers can engage in self-directed learning support the argument that Knowles' (1980) model is applicable in foreign travel contexts. Further, it is a model that can help adult learners to create travel experiences that are more meaningful, enriching, and educational.

An implication of this study is that travelers might consciously apply some or all of the components of Knowles' (1980) model to enhance their learning experiences while abroad. Learning, sometimes, is a side effect of the activities one undertakes (Simons, 2000); this researcher is implying that learning should not be a side effect of other activities, rather, a deliberate goal. I am recommending that adults actively pursue development of the characteristics that I described as the essence of being a self-directed learner in travel contexts. Pursuing the development of these qualities should increase reflection and understanding of learning experiences in any endeavor. Guglielmino (2008) suggested that the process of meaning-making is one of the most important types of self-directed learning adults engage in. She explained: 
By confronting and reflecting on the learning moments in their lives, they are able to arrive at new understandings. Based on those understandings, they may decide to rewrite their stories. Adults' reflections on their lives often lead to the visualization of a new future and the actualization of it. (Guglielmino, 2008, p. 8)

Further, the applicability of this study has relevant importance for adult learners who travel for the purpose of gaining or improving skills that can enhance their job competitiveness. In fact, traveling to acquire or improve language and/or cross-cultural skills, among others, can lead to career growth potential. Today, job seekers are pursuing experiences that can enhance their competitiveness in a global market. Employers, as well, recognize the value in international experiences and are showing greater interest in candidates that can demonstrate what is being learned through their foreign travels.

Orahood, Kruze, and Pearson (2004) found that these types of learners, due to the skills that they acquired while abroad, are the types of professionals that employers seek for international assignments and even for domestic assignments that require a degree of cross-cultural competency. It is as important for adult learners to be able to identify and explain the learning lessons that they gained in a foreign environment, as it is to have experienced them.

The findings in this study show a unique application of self-directed learning theory, which is one of the most important topics to be discussed in the field of adult education. Guglielmino (2008) suggested, "As researchers, it is our responsibility to learn all we can about the process of self-directed learning and the best ways to facilitate the skills and attitudes of self-direction in learning" (p. 10). Accordingly, this study adds to the existing adult education literature and provides an exploration of a practical application of self-directed learning. 
Merriam, et al. (2007) argued that "research and theory building in self-directed learning is in need of fresh questions" (p. 127), one of which being, "To what extent is self-directed learning situational or cultural?" The findings of this study answer a "fresh" question, and show how self-directed learning is applicable in the situational context of foreign travel, specifically, "What is the essence of being a self-directed learner in foreign travel contexts?"

This study provides a new angle for theory building in andragogy, which is the "art and science of helping adults learn" (Knowles, 1983, p. 55), and contributes a construct with which adult education researchers and practitioners can help adults to learn. The results of this study suggest that it is important to explore new angles to learning models and pursue unique applications of theories to continue to innovate and improve methods of learning. Adult education practitioners have a duty to continually improve the facilitation of learning for their students. Merriam, et al. (2007), concerning the goal of self-directed learning to help adults learn, said, "Within this goal, the assumption is that part of the job of educators of adults is to help learners, whether they are learning on their own or in formal learning programs, to be able to plan, carry out, and evaluate their own learning" (p. 107).

The importance of this study could also affect disciplines outside of adult education, for example, travel and tourism, hospitality services, and international/ intercultural education, among others. The value of this study in other fields is that it continues the research on self-directed learning, which is a learning process that is used in almost every academic discipline. 


\section{Limitations of the Study}

The findings of this phenomenological study must be considered in the context of potential limitations. First, participants in this study admitted that they experienced a measure of learning and personal enrichment through foreign travel. Because of this, I interviewed them to discover an essence to learning through travel, and to see if components of Knowles' (1980) SDL model could be applicable in this context. Subsequently, I found that their processes for learning did, in fact, align with the model. However, this is not to say that all who travel apply self-directed learning strategies. I would assume that many who travel, say for business or on military mission, do not have the time nor inclination to consciously plan learning goals, activities, and strategies. Therefore, findings from this study's sample of participants do not extend to a larger population described as "all who travel;" however, future research to include participants who travel for various reasons could show how SDL is applied in different ways.

Second, this study did not include college study-abroad participants nor accounts of study-abroad experiences. The reason for this was that I did not want to examine learning experiences that were designed and/or led by a professor or academic program. Self-directed learning emphasizes the role of the individual in his or her own learning goals, strategies, and evaluations. This was a study of lifelong learning, not learning for academic credit. Lifelong learning refers to the notion that adults can continue to pursue learning experiences on their own time and terms and is an expression that is commonly heard in the adult education field. In lifelong learning education, adults continue the process of further learning and continuous self-education throughout their lives. Lifelong learning also implies that learning occurs in many different settings and recognizes that 
many important learning influences are found outside the formal education system. Further, the ultimate goal of SDL is to transition the responsibility of learning from the teacher to the learner, allowing the learner to assume control and establish independence in setting learning goals and monitoring their progress.

There have been a number of academic studies done on the learning outcomes of college study abroad programs (Couper, 2001; Kelly, 2010; Sanders \& Morgan, 2001; Swords \& Kiely, 2010; Tarrant \& Lyons, 2012; Tarrant \& Sessions, 2008), therefore I chose not to include study abroad experiences in this study.

\section{Recommendations for Future Research}

Guglielmino (2008), while discussing studies and applications of self-directed learning, said, "there is much that remains to be discovered" (p. 10). This researcher agrees. In fact, future research on self-directed learning can build on the findings of this study. The findings in this study are by no means exhaustive but reflect the experiences

of the 13 international travelers in this study. Therefore, future research may include the following.

First, an investigation to review and compare the findings from studies that used the theories of experiential learning, transformative learning, and self-directed learning to further explore the concept of learning through travel.

Second, an exploration of the relationship between self-direction in learning through adventure seeking, and risk-taking behaviors. My study showed how travelers pursued personal enrichment through travel adventures that satisfied a curiosity or brought them a sense of discovery from learning new things, however, even though their 
adventures were full of risk, daring, and danger, the participants did not discuss deeply any of these themes. A study like this could prove fascinating.

Third, studies that might include participants who were excluded from this one would broaden the scope of exploring self-directed learning through travel. That is to say that looking at those who travel for reasons other than learning, like those on military deployment, vocational relocation, retirement abroad (expats), or even due to reasons of asylum-seeking or other forced travel circumstances, would extend our understanding of self-directed learning in foreign travel contexts. Likewise, looking at how SDL is utilized in college study abroad programs could show us how students are learning through their own explorative behaviors and personal interests while away from their professor or classmates.

\section{Summary}

Chapter 5 concluded the study with the responses to the research questions, implications for research and practice, and recommendations for future research. The purpose of this phenomenological study was to understand the role of self-directed learning as a learning process that adults use to design and pursue learning and personal enrichment experiences in foreign travel contexts. The aim of the study was to answer the three research questions, which were: (1) What is the essence of being a self-directed learner in foreign travel contexts? (2) How can Knowles' (1980) 6 components of selfdirected learning be applied to learning and personal enrichment experiences in foreign travel contexts? and (3) How does being self-directed as a learner in foreign travel contexts serve to enhance the experience of foreign travel? 
The discussion section of this study answered those questions, along with providing evidence for the arguments that Knowles' (1980) SDL model is applicable in foreign travel contexts and that traveling with learning goals and strategies enhances the experience. This study provided implications for theory building in SDL and andragogy, and practical implications for the adult learner and adult education practitioner. This section also provided recommendations for future research that may extend the findings of this study.

This study gives readers a better understanding of how self-directed learners learn through foreign travel experiences and how they can become personally enriched in the process. Furthermore, it provides readers with an applicable construct with which to do so. 


\section{REFERENCES}

Ainoda, N., Onishi, H., \& Yasuda, Y. (2005). Definitions and goals of" self-directed learning" in contemporary medical education literature. Annals-Academy of Medicine Singapore, 34(8), 515.

Airey, D. (2001). Journal of teaching in travel and tourism. Tourism and Hospitality Research, 3, 185-186.

Arsenault, N. L. (1998). A study of educational-travel and older adult learners: Participant types and program choices. (Doctoral Dissertation: McGill University).

Arsenault, N., \& Anderson, G. (1998). New learning horizons for older adults. Journal of Physical Education, Recreation \& Dance, 69(3), 27-31.

Association of American Residents Overseas. (2013). Retrieved from www.aaro.org

Belyavina, R., \& Bhandari, R. (2012). U.S. students in overseas degree programs: Key destinations and fields of study. Institute of International Education.

Berlitz. (2013). Global Language Learning \& Cultural Training. Retrieved from www.berlitz.us

Bochner, S. (Ed.). (1982). Cultures in contact: Studies in cross-cultural interaction. Oxford, UK: Pergamon Press.

Bodger, D. (1998). Leisure, learning, and travel. Journal of Physical Education, Recreation \& Dance, 69(4), 28-31.

Bogdan, R. C., \& Biklen, S. K. (2007). Research for education: An introduction to theories and methods. New York, NY: Pearson.

Bolton, N. (1979). Phenomenology and education. British Journal of Educational Studies, 27, 245-258.

Boyatzis, R. E. (1995). Cornerstones of change: Building the path for self-directed learning. In R. E. Boyatzis, S. S. Cowen, \& D. A. Kolb (Eds.), Innovation in professional education (pp. 50-91). San Francisco, CA: Jossey-Bass.

Boyle, D. P., Nackerud, L., \& Kilpatrick, A. (1999). The road less traveled Crosscultural, International experiential learning. International Social Work, 42, 201-214. 
Brenner, A. A. (2014). Transformative learning through education abroad: A case study of a community college program. (Doctoral Dissertation: Temple University).

Brockett, R. G., \& Hiemstra, R. (1991). Self-direction in adult learning: Perspectives on theory, research, and practice. Routledge Series on Theory and Practice of Adult Education in North America. New York: Routledge

Brodsky-Porges, E. (1981). The grand tour travel as an educational device 1600-1800. Annals of Tourism Research, 8, 171-186.

Brookfield, S. D. (1984). Self-directed adult learning: A critical paradigm. Adult Education Quarterly, 36, 226-234.

Brookfield, S. (1985). Self-directed learning: A critical review of research. New Directions for Adult and Continuing Education, 1985(25), 5-16.

Brookfield, S. (1984). Self-directed adult learning: A critical paradigm. Adult Education Quarterly, 35, 59-71.

Brookfield, S. (1986). Understanding and facilitating adult learning: A comprehensive analysis of principles and effective practices. Milton Keynes: Open University Press.

Bulik, R. J., \& Romero, C. M. (2000). The elusive concept of self-directed learning. In H.B. Long \& Associates (Eds.), Principles of self-directed learning. Schaumburg, IL: Motorola University Press.

Caffarella, R. S. (1993). Self-directed learning. New Directions for Adult and Continuing Education, 1993(57), 25-35.

Campbell, J, \& Kudler, D. (2004). Pathways to bliss. San Francisco, CA: New WorldLibrary.

Cavaliere, L. A. (1992). The Wright brother's odyssey: Their flight of learning. New Directions for Adult and Continuing Education, 1992(53), 51-59.

Chene, A. (1983). The concept of autonomy in adult education: A philosophical discussion. Adult Education Quarterly, 34, 38-47.

Chieh-Wen, S., Ming-Jian, S., \& Ming-Chia, C. (2008). Special interest tour preferences and voluntary simplicity lifestyle. International Journal of Culture, Tourism and Hospitality Research, 2, 389-409. 
Collins, M. (1988, May). Self-directed learning or an emancipatory practice of adult education: Re-thinking the role of the adult educator. In Proceedings of the 29th Annual Adult Education Research Conference (pp. 61-66).

Conceição, S. C., \& Skibba, K. A. (2008). Experiential learning activities for leisure and enrichment travel education: A situative perspective. Journal of Teaching in Travel \& Tourism, 7(4), 17-35.

Cooper, C. (1993). An analysis of the relationship between industry and education in travel and tourism. Teoros International, 1(1), 67-69.

Cousineau, P. (1998). The art of pilgrimage: The seeker's guide to making travel sacred. Berkeley, CA: Conari Press.

Creswell, J. (1998). Qualitative inquiry and research design: Choosing among five traditions. Thousand Oaks, CA: Sage.

Crompton, J. L. (1979). Motivations for pleasure vacation. Annals of Tourism Research, $6,408-424$.

Damarin, S. (1993). Schooling and situated knowledge: Travel or tourism. Educational Technology, 33(3), 27-32.

Dent, K. (1975). Travel as education: the English landed classes in the eighteenth century. Educational Studies, 1, 171-180.

Douglas, N., \& Derrett, R. (2001). Special interest tourism. John Wiley and Sons Australia, Ltd.

Falk, J. H., Ballantyne, R., Packer, J., \& Benckendorff, P. (2012). Travel and learning: A neglected tourism research area. Annals of Tourism Research, 39, 908-927.

Formica, S., \& Uysal, M. (1996) The revitalization of Italy as a tourist destination. Tourism Management, 17, 323-331.

Fussel, P. (Ed.). (1987). Norton book of travel. New York, NY: Norton.

Garrison, D. R. (1992). Critical thinking and self-directed learning in adult education: An analysis of responsibility and control issues. Adult Education Quarterly, 42, $136-148$.

Garrison, D. R. (1997). Self-directed learning: Toward a comprehensive model. Adult Education Quarterly, 48, 18-33.

Gessner, R. (ed). (1956). The democratic man: Selected writings of Eduard C. Lindeman. Boston, MA: Beacon Press. 
Getz, D. (1991) Festivals, special events and tourism. Van Nostrand Reinhold, New York.

Glaser, B. G., \& Strauss, A. (1967). The discovery of grounded theory: Strategies for qualitative research. New York: Aldine Publishing Company.

Guglielmino, L. M. (2008). Why self-directed learning. International Journal of Selfdirected learning, 5(1), 1-14.

Guglielmino, L. M. (1977). Development of the self-directed learning readiness scale. Unpublished doctoral dissertation, University of Georgia.

Guglielmino, L. M. (1997). Contributions of the self-directed learning readiness scale (SDLRS) and the learning preference assessment (LPA) to the definition and measurement of self-direction in learning. Paper presented at the First World Conference on Self-Directed Learning, Montreal, Canada.

Hansman, C. A. (2001). Context-based adult learning. New Directions for Adult and Continuing Education, 2001(89), 43-52.

Hansman, C. A. \& Mott, V.W. (2010). Adult Learners. In C. E. Kasworm, A. D. Rose, \& J. M. Ross-Gordon (Eds.), Handbook of adult and continuing education (pp. 13-23). Los Angeles: SAGE Publications.

Herr, E. L. (1990). Employment counseling in a global economy. Journal of Employment Counseling, 27, 147-159.

Hiemstra, R. (1994). Self-directed learning. The sourcebook for self-directed learning (pp. 9-20). Amherst, MA: HD Press.

Hirschorn, S., \& Hefferon, K. (2013). Leaving it all behind to travel venturing uncertainty as a means to personal growth and authenticity. Journal of Humanistic Psychology, 53, 283-306.

Holdnak, A., \& Holland, S. M. (1996). Edu-tourism: Vacationing to learn. Parks and Recreation, 31(9), 72-75.

Houle, C. O. (1961). The inquiring mind. Madison: University of Wisconsin Press.

Inkson, K., \& Myers, B. A. (2003). "The big OE": Self-directed travel and career development. Career Development International, 8, 170-181. 
Institute of International Education. (2013). Open Doors 2013: International Students in the United States and Study Abroad by American Students Are at All-Time High. Institute of International Education.

International House World Organization. (2012). Learn a Language with International House. www.ihworld.com

Jarvis, P. (2004). Adult education and lifelong learning: Theory and practice. New York: Routledge.

Jenkins, R. L. (2010). International travel with an academic purpose - A necessity for business education. American Journal of Business, 25(2), 7-8.

John, W. S., \& Johnson, P. (2000). The pros and cons of data analysis software for qualitative research. Journal of Nursing Scholarship, 32, 393-397.

Johnson, B., \& Christensen, L. (2008). Educational research: Quantitative, qualitative, and mixed approaches. Thousand Oaks, CA: Sage.

Kanter, R. "Globalism/Localism." Harvard Business Review, 69, 9-10.

Kerka, S. (1993). Career education for a global economy. ERIC Clearinghouse on Adult Career and Vocational Education.

King, K. (2010). Informal learning in a virtual era. In C. E. Kasworm, A. D. Rose, \& J. M. Ross-Gordon (Eds.), Handbook of adult and continuing education (pp. 421-429). Los Angeles: SAGE Publications.

Knowles, M. S. (1983). Andragogy: An emerging technology for adult learning. In M. Tight (ed.), Adult learning and education. London: Croom Helm.

Knowles, M.S. (1980). The modern practice of adult education: From pedagogy to androgogy ( $2^{\text {nd }}$ ed.). New York: Cambridge Books.

Knowles, M. (1975). Self-directed learning: A guide for learners and teachers. NY: Association Press.

Knowles, M. (1984). The adult learner: A neglected species. (4 ed.). Houston: Gulf Pub.

Knowles, M. S. (1970). The modern practice of adult education (Vol. 41). New York: New York Association Press.

Knowles, M. S., Swanson, R. A., \& Holton, E. F. (2011). The adult learner: The definitive classic in adult education and human resource development. (7th ed.) Burlington, MA: Elsevier. 
Kolb, D. A. (1984). Experiential learning: Experience as the source of learning and development (Vol. 1). Englewood Cliffs, NJ: Prentice-Hall.

Kolb, D. A., Boyatzis, R. E., \& Mainemelis, C. (2001). Experiential learning theory: Previous research and new directions. Perspectives on thinking, learning, and cognitive styles, 1, 227-247.

Larsen, K., Martin, J. P. \& Morris, R. (2002), Trade in educational services: Trends and emerging issues. World Economy, 25, 849-868.

Lindstrom, S. K. (2011). Travel and adult transformative learning. (Doctoral Dissertation: Capella University).

Litman, J. A., \& Spielberger, C. D. (2003). Measuring epistemic curiosity and its diversive and specific components. Journal of Personality Assessment, 80, 75-86.

Lundberg, D. E. (1971). Why tourists travel. Cornell Hotel and Restaurant Administration Quarterly, 11(4), 75-81.

Lyons, J. L. (2010). Autonomous cross-cultural hardship travel (ACHT) as a medium for growth, learning, and a deepened sense of self. World Futures, 66, 286-302.

MacNeil, R. D. (1998). Leisure, lifelong learning, and older adults: A conceptual overview. Journal of Physical Education, Recreation \& Dance, 69(2), 26-28.

McKercher, B. (2002). The future of tourism education: An Australian scenario? Tourism and Hospitality Research, 3, 199-210.

Maslow, A.H. (1970). Motivation and personality ( $2^{\text {nd }}$ ed.). New York: HarperCollins.

Merriam, S. B., Caffarella, R. S., \& Baumgartner, L. M. (2007). Learning in adulthood: A comprehensive guide. San Francisco, CA: John Wiley \& Sons.

Merriam, S. B. (2001). Andragogy and self-directed learning: Pillars of adult learning theory. New Directions for Adult and Continuing Education, 2001(89), 3-14.

Mezirow, J. (1985). A critical theory of self-directed learning. New Directions for Adult and Continuing Education, 1985(25), 17-30.

Mitchell, R. D. (1998). Learning through play and pleasure travel: using play literature to enhance research into touristic learning. Current Issues in Tourism, 1, 176-188.

Morse, Janice M. (1994). Designing funded qualitative research. In N. K. Denzin \& Y. S. Lincoln (Eds.), Handbook of qualitative research (2nd ed., pp. 220-35). Thousand Oaks, CA: Sage. 
Mott, V.W. (2000). Adult and continuing education: A political-economic enterprise. In D.A. Gabbard (Ed.), Knowledge and power in the global economy: Politics and the rhetoric of school reform (pp. 335-342). Hillside, NJ: Lawrence Erlbaum.

Mousakas, C. (1994). Phenomenological research methods. Thousand Oaks, CA: Sage Publications.

Murray, D. (1999). The challenges of the future work environment: What corporations want from tomorrow's graduates in international education. In K. Theile and C. Ó Hógartaigh (Eds.), Partnership.

Ng, K. Y., Van Dyne, L., \& Ang, S. (2009). From experience to experiential learning: Cultural intelligence as a learning capability for global leader development. Academy of Management Learning \& Education, 8, 511-526.

Office of Travel and Tourism Industries. (2013). U.S. Citizen Travel to Overseas Regions. Monthly Departures to International Destinations.

Opdal, P. M. (2001). Curiosity, wonder and education seen as perspective development. Studies in philosophy and education, 20, 331-344.

Open Doors Data: U.S Study Abroad Duration of Study Abroad. Institute of International Education.

Orahood, T., Kruze, L., \& Pearson, D. E. (2004). The impact of study abroad on business students' career goals. Frontiers: The Interdisciplinary Journal Of Study Abroad, 10, 117-130.

Packer, J. (2006). Learning for fun. Curator: The Museum Journal, 49, 329-44.

Peace Corps. (2012). Retrieved from http://www.peacecorps.gov/

Pearce, P. L., \& Foster, F. (2007). A “University of travel”: Backpacker learning. Tourism Management, 28, 1285-1298.

Penland, P. (1979). Self-initiated learning. Adult Education Quarterly, 29, 170-179.

Pritchard, J. L. (2000). Travel enhances education. American Biology Teacher, 62, 421-423. doi: http://dx.doi.org/10.1043/00027685(2000)062(0421:TEE)2.0.CO;2

Razzano, E. (1996). The overseas route to multicultural and international education. The Clearing House, 69(5), 268.

Reio, T. G., Jr. (2013). Adult curiosity dimensionality. From COERC 2008, 123. 
Reio, T. G., Jr. (2012). Curiosity and exploration. In Encyclopedia of the Sciences of Learning (pp. 894-896). New York: Springer US.

Reio, T. G., Jr. (2004). Prior knowledge, self-directed learning readiness, and curiosity: Antecedents to classroom learning performance. International Journal of Selfdirected learning, 1(1), 18-25.

Reio, T. G., Jr., Petrosko, J. M., Wiswell, A. K., \& Thongsukmag, J. (2006). The measurement and conceptualization of curiosity. The Journal of Genetic Psychology, 167, 117-35.

Rhinesmith, S. "Global mindsets for global managers." Training and Development, 46, no. 10 (October 1992), 63-68.

Roberson, D. N., Jr. (2005). Lifelong learning in the county: A context of nature, community, and simplicity. The Rural Educator, 27, 29-40.

Roberson, D. N., \& Merriam, S. B. (2005). The self-directed learning process of older, rural adults. Adult Education Quarterly, 55, 269-287.

Rojek, C., \& Urry, J. (Eds.). (1997). Touring cultures: Transformations of travel and theory. London: Routledge.

Rubin, H. J., \& Rubin, I. S. (2011). Qualitative interviewing: The art of hearing data. Thousand Oaks, CA: Sage.

Rubenson, K. (1998). The great challenge for BC: lifelong learning for all. Learning Quarterly, Centre for Curriculum, Transfer \& Technology, 2(3), 13-18.

Sahakian, W.S. (1984). Introduction to the psychology of learning ( $2^{\text {nd }}$ ed.). Itasca, IL: Peacock.

Sakkal, A. (2013). The culture of home away from home: Embracing the travel experience for learning and development. (Doctoral Dissertation: University of California, Davis).

Schlager, F., Lengfelder, J., \& Groves, D. (1999). An exploration of experimental education as an instructional methodology for travel and tourism. EDUCATIONINDIANAPOLIS, 119, 480-489.

Shokar, G. S., Shokar, N. K., Romero, C. M., \& Bulik, R. J. (2002). Self-directed learning: Looking at outcomes with medical students. FAMILY MEDICINEKANSAS CITY, 34, 197-200. 
Sigala, M., \& Baum, T. (2003). Trends and issues in tourism and hospitality higher education: Visioning the future. Tourism and Hospitality Research, 4, 367-376.

Simons, P. R. J. (2000). Towards a constructivistic theory of self-directed learning. In G.A. Straka (Ed.), Conceptions of self-directed learning: Theoretical and conceptional considerations (pp. 155-169). Munster, Germany: Waxmann.

Smith, S. L., \& Godbey, G. C. (1991). Leisure, recreation and tourism. Annals of Tourism Research, 18, 85-100.

Stein, K. L. (2012). Getting away from it all: Constructing identity on vacation. Symbolic Interaction, 34, 290-308.

Taylor, S. (2006). Theorizing educational tourism: Practices, impacts, and regulation in Ecuador. (Order No. 3213606, Columbia University). ProQuest Dissertations and Theses.

Tennant, M., \& Pogson, P. (1995). Learning and change in the adult years: A developmental perspective. Jossey-Bass Higher and Adult Education Series. Jossey-Bass Social and Behavioral Service Series. San Francisco, CA: JosseyBass.

Thomas, D. C., \& Inkson, K. C. (2009). Cultural intelligence: Living and working globally. Berrett-Koehler Publishers.

Tough, A. (1971). The adult's learning projects: A fresh approach to theory and practice in adult learning. Toronto: Ontario Institute for Studies in Education.

Tough, A. M. (1967). Learning without a teacher (No. 3). Ontario Institute for Studies in Education.

Trauer, B. (2006). Conceptualizing special interest tourism-frameworks for analysis. Tourism Management, 27, 183-200.

Trooboff, S., Vande Berg, M., \& Rayman, J. (2008). Employer attitudes toward study abroad. Frontiers: The Interdisciplinary Journal of Study Abroad, 15, 17-33.

UNWTO (1995). Technical manual: Collection of tourism expenditure statistics. World Tourism Organization. p. 10.

Valente, J. S. (2005). The role of self-directed learning in older adults' health care (Doctoral dissertation, University of Georgia).

Van Winkle, C. M., \& Lagay, K. (2012). Learning during tourism: The experience of learning from the tourist's perspective. Studies in Continuing Education, 34, 339-355. 
Vance, C. M. (2005). The personal quest for building global competence: a taxonomy of self-initiating career path strategies for gaining business experience abroad. Journal of World Business, 40, 374-385.

Vance, C. M., Sibeck, G., McNulty, Y., \& Hogenauer, A. (2011). Building global competencies through experiential coursework in international travel and tourism. Journal of International Education in Business, 4, 30-41.

Watts, Jacqueline H. (2008). Integrity in qualitative research. In: Given, Lisa M. ed. The Sage encyclopedia of qualitative research methods, Volume 1 (pp. 440-441). Thousand Oaks, CA: Sage Publications.

Wood, B. J. G., Tapsall, S. M., \& Soutar, G. N. (2005). Borderless education: Some implications for management. The International Journal of Educational Management, 19, 428-436.

WTTC. Report. World Travel \& Tourism Council, 2013. www.wttc.org

Yeoman, I., Robertson, M., Ali-Knight, J., Drummond, S., \& McMahon-Beattie, U. (Eds.). (2011). Festival and events management. New York, NY: Routledge. 


\section{APPENDIX A}

\section{SEMI-STRUCTURED INTERVIEW GUIDE}

Travel Education: A Phenomenological Study On Self-Directed Learning And Personal Enrichment Through Foreign Travel Experiences

Your travels have given you something very important to show for the time and energy that you put into leaving your comfort zone and venturing out to a foreign country. They have given you a story to tell others, a story about how travel enriches your life. The purpose of this interview is to draw out that story. Please think of a learning or lifeenriching experience that you have had through foreign travel.

\section{Interview Questions}

Let's start at the beginning.

Where did you go?

Why did you travel to where you went?

What sparked your interest in going to this place?

Did you feel that you were called to some sort of adventure or to discover something new through travel?

Was something happening in your life that became a trigger to travel?

How did the opportunity for travel come up?

Did you feel that there was some need to travel? Was it simply a curiosity to be satisfied or more of a lifelong dream? Please explain. 
Did you purposely intend to learn something about yourself, others, the world, or a life lesson in general? For example, did you intend on learning something about:

- A certain place or landmark

○ A part of world history

- The arts

- People, cultures, languages

- A famous or popular location

○ The experience of international travel, itself

- Your own personality, self-reliance, sense of adventure, explorative nature, etc.

- Technical or business practices in another country

○ Other

Can you see how this experience enriched your life in some way? How so?

What challenges came up along the way? How did you face them? Would you say that they were a part of the learning process?

What resources (or people) did you find to help you? For example, were any of the following helpful to you along the way?

○ Travel agent

○ Tour guides

- Friends, family, or acquaintance who had personal knowledge of the location/culture

○ Teachers

- Medical professionals

○ Suggestions, directions, help from locals or fellow travelers

- Books, manuals, brochures, maps

○ Internet resources (webpages) for information

○ Personal intuition

O Other, like what? 
Did you travel with the purpose of learning or discovering new things? Did you make travel plans with those intentions in mind? How so?

How do you think your travel experience was enhanced by having the goal of learning something along the way?

How did you plan on achieving your goal?

How did you feel about your experience once you reflected upon it later on?

Did you realize some things later on that you learned that you didn't notice during the experience?

Travel has a way of changing us. Do you feel like you were forever changed as a person through this experience? How so?

Were you successful in reaching your learning goal?

What would failure have looked like, for you? 
APPENDIX B

\section{LIST OF CODES}

Themes, Codes, and Subcodes

\section{PERSONAL ENRICHMENT}

TRAVEL CHANGED ME, PERSONAL DEVELOPMENT THROUGH TRAVEL, BUILDING CHARACTER, PERSPECTIVE CHANGE, ALTERED WORLDVIEW, MORE UNDERSTANDING OF THE WORLD AND/OR OTHERS, I NOW DO SOMETHING DIFFERENTLY, MY LIFE PATH CHANGED, I NOW TRAVEL MORE, I WANT TO SEE THE WORLD, GLOBAL CITIZEN

\section{PARTICIPANT PERSONAL HISTORY}

TRAVEL DESTINATION

MY BACKGROUND

CLIMATE SETTING,

DIAGNOSING LEARNING NEEDS, BUCKET LIST (\&SENSE OF URGENCY) CURIOSITY; TRAVEL AS SEEKING (WANDERLUST)

FORMULATING LEARNING GOALS, IDENTIFYING HUMAN AND MATERIAL RESOURCES FOR LEARNING, HUMAN RESOURCE; MATERIAL RESOURCE; LOCALS AS RESOURCE CHOOSING AND IMPLEMENTING APPROPRIATE LEARNING STRATEGIES

EVALUATING LEARNING OUTCOMES?

REFLECTION

FAILURE

TRAVEL IS ENHANCED BY HAVING LEARNING GOALS 
OTHER IDEAS/CONCEPTS THAT ARE BROUGHT UP BY INTERVIEWEE

WITHOUT HELP

TRAVEL CHALLENGES

OVERCOMING CHALLENGE

BUDGET AS CHALLENGE

LONE TRAVEL

TRAVEL SPEEDS UP EXPERIENCES 


\section{ADULT CONSENT TO PARTICIPATE IN A RESEARCH STUDY}

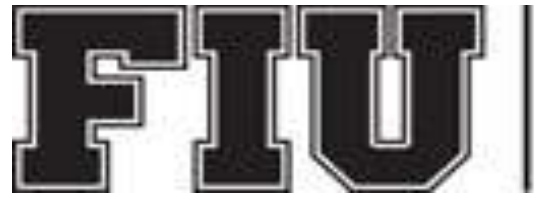

\section{FLORIDA \\ INTERNATIONAL UNIVERSITY}

\section{Title: Travel Education: A Phenomenological Study On Self-Directed Learning And Personal Enrichment Through Foreign Travel Experiences}

\section{PURPOSE OF THE STUDY}

You are being asked to be in a research study. The purpose of this study is to understand the role of self-directed learning as a learning process that adults use to design and pursue learning and personal enrichment experiences in foreign travel contexts. This is about understanding the ways in which adults find joy in travel through creating their own learning environments.

\section{NUMBER OF STUDY PARTICIPANTS}

If you decide to be in this study, you will be one of 10-15 people in this research study.

\section{DURATION OF THE STUDY}

Your participation will require approximately 1-2 hours of your time, not including follow-up emails or phone calls, if necessary.

\section{PROCEDURES}

If you agree to be in the study, we will ask you to do the following things:

Answer interview questions honestly and with detail about your travel experiences.

Interviews will be audio recorded for transcription. No one will ever hear your voice, therefore there is no need to be nervous or speak in any way other than normal conversation. The final research findings and conclusions will be in written form only. If you prefer not to be recorded, you have the option of answering the interview questions in writing. 


\section{RISKS AND/OR DISCOMFORTS}

The following risks may be associated with your participation in this study:

There are no known risks to you for participating in this study.

\section{BENEFITS}

The following benefits may be associated with your participation in this study: Your interview will give you an opportunity to reflect on your travel experience and your own learning process. This might allow you to learn something about yourself, bring you greater awareness about your own learning preferences, and benefit you in future travel experiences.

This study will benefit society as it adds important, practical, and applicable information to research already done on self-directed learning and how people learn through travel. Future readers of this study might find greater understanding about themselves as they read about others' travel experiences. This study could provide future readers with concepts, ideas, and suggestions on how to design their own self-directed learning experiences while traveling.

And finally, understanding another aspect of why people travel at all could help those in the Travel \& Tourism industry to improve their travel products/ services/ resources to meet the needs and preferences of travelers.

\section{ALTERNATIVES}

There are no known alternatives available to you other than not taking part in this study. However, any significant new findings developed during the course of the research which may relate to your willingness to continue participation will be provided to you.

\section{CONFIDENTIALITY}

The records of this study will be kept private and will be protected to the fullest extent provided by law. In any sort of report we might publish, we will not include any information that will make it possible to identify a subject. Research records will be stored securely and only the researcher team will have access to the records. However, your records may be reviewed for audit purposes by authorized University or other agents who will be bound by the same provisions of confidentiality.

\section{COMPENSATION \& COSTS}

You will not receive payment for your participation. You will not be responsible for any costs to participate in this study. 


\section{RIGHT TO DECLINE OR WITHDRAW}

Your participation in this study is voluntary. You are free to participate in the study or withdraw your consent at any time during the study. Your withdrawal or lack of participation will not affect any benefits to which you are otherwise entitled. The investigator reserves the right to remove you without your consent at such time that they feel it is in the best interest.

\section{RESEARCHER CONTACT INFORMATION}

If you have any questions about the purpose, procedures, or any other issues relating to this research study you may contact [CONTACT INFORMATION BLOCKED FROM FINAL EDITION]

\section{IRB CONTACT INFORMATION}

If you would like to talk with someone about your rights of being a subject in this research study or about ethical issues with this research study, you may contact the FIU Office of Research Integrity by phone at 305-348-2494 or by email at ori@fiu.edu.

\section{PARTICIPANT AGREEMENT}

I have read the information in this consent form and agree to participate in this study. I have had a chance to ask any questions I have about this study, and they have been answered for me. I understand that I will be given a copy of this form for my records.

Printed Name of Participant 


\section{APPENDIX D}

\section{RESEARCHER JOURNAL \& FIELD NOTES}

This collection of thoughts is meant to document the researcher's own understandings and personal judgments about the project. It is a collection of reflections.

\section{Dissertation coursework}

From 2012 until 2015 I was enrolled in doctoral level coursework; I took classes at night and on the weekends, while I held a full-time professional position at FIU. It really kept me busy, but thankfully I had an amazing boss who allowed me many days free to work on my coursework. Reflecting back now, I realize that she understood the importance and magnitude of completing the degree, because she had done so as well. I am thankful that so much of the coursework was designed to help doc. students to succeed, like having us take courses on writing a dissertation, how to do research, how to publish your work, etc.

\section{Thinking of a subject to research}

In one of my first courses, I was asked to think of a subject to base my dissertation research on. I actually think that it was my first class! And honestly, I was taken aback by the assignment. I thought that I would take many more courses before I was to think about my dissertation. But no, it does not work like that. The coursework is designed to help you work on the dissertation, but you should have an idea of what it is you want to study even before you go into a doc. program. So, I thought of an idea; actually, the idea came about from one of my lifelong passions: travel. I would do a dissertation on travel. But, what? There are so many things that can be said about travel! For that class, I submitted a paper on traveling with Peace Corps. But the dissertation ideas would come and go over the next couple of years, until finally I would decide on a topic, based on Adult Education tenets: Andragogy and Self-Directed Learning. The topic would be "Travel Education: A Phenomenological Study On Self-Directed Learning And Personal Enrichment Through Foreign Travel Experiences."

\section{Pilot study}

During the final year of coursework, I took all of my research methods classes.

Quantitative methods $1 \& 2$ were challenging, but I had an amazing professor who understood the difficulties that students have with those courses. I got through it, and learned a lot. It was in the qualitative research methods classes that I shined. I had known for quite a while that I would write my report based on qualitative methods 
(interviews). So, I did a pilot study of the subject in which I was interested; it was a required work for the qualitative methods class. I interviewed an undergraduate student on her experience with traveling and studying abroad. It was the first time that I had been an interviewer, utilizing a recording device, transcribing and coding data. Honestly, it was a great experience because the professor was right there every step of the way for help and direction.

\section{Comprehensive exam}

Fortunately enough, the option to submit chapters 1-3 of my dissertation was available as a choice for examination. I saw this as a huge push forward toward producing a final work. Instead of sitting down and answering questions, examination style, on what I have learned during 17 courses in the program, I could submit my dissertation ideas for review from my chair. I thought this was not only very helpful, but a really great idea for any research-centered doctoral program to incorporate. See, within the 3 chapters, I needed to demonstrate understanding of the principles and tenets that make up the field of Adult Education. By showing an advanced level of knowledge and the ability to perform high-level academic research, I suppose my potential to complete the degree was proven. Thus, proudly enough, I advanced on to doctoral candidacy - and moved abroad to write.

\section{Proposal defense}

After preparing a presentation to be given to my chair and committee, I arrived to Miami and FIU for our discussion. The proposal defense was an official and serious matter, yet our conversation seemed to flow in a casual and collegial way. Since I am so interested in my research subject, I suppose others could feel my passion. Everyone chimed in and asked questions. Each member of the committee even shared anecdotal stories and helpful suggestions. Everyone seemed sincerely interested in what my conclusions would turn out to be. It was an absolute success and I felt like a million bucks. With the defense done and approved, and the IRB approval process wrapping up, I could move onward toward data collection.

\section{Data collection field notes}

Data collection, in this phenomenological study would be in the form of interviews. In fact, once discussed with the committee, it was decided that 10 would be sufficient for data saturation, with my topic in mind. Among the interviews I would have a close look at what the "essence" of the data says. Because some of the participants were traveling and abroad during my data collection phase, they were fine with answering questions on a written questionnaire. The questions were the same as if I were interviewing them in person and they all provided rich detail and description of their experiences. They were open-ended questions and were answered in narrative-style responses, which provided 
plenty of data and themes that pointed to commonalities of experience among participants. The following field notes depict the thoughts and judgments that I had either at the time of interviewing participants or while reviewing and coding the written responses.

\section{Participant 1: Darrell}

Darrell's interview was done while I was in Miami for a few days on travel. Interviewing Darrell was fun. I knew it would be an interesting conversation because he is an avid traveler. Being from the Bahamas and living in the US, I assumed that he would have a unique perspective on foreign travel, and he did. He explained that he had always had an interest in foreign travel, languages, cultures, seeing differences among people. This might be a recurring theme among participants: that of having an interest in exploring other countries/ cultures goes back to childhood. Although Darrell has been to many places with his job, he has a special personal interest with Europe, especially Spain. His self-directed learning pursuits across the country were the focus of this interview. He talked about having a "wow" moment during his travels; that is what he tries to experience when he is abroad. I didn't quite understand at first, but I had him explain further. For him, this represents newness, or seeing/ experiencing something newhaving a new experience in life. I thought that maybe the concept would be a common theme among other participants. For me, this is indeed something that I feel as well. As a traveler, I am looking for experiences that help me to see my world in a new way. This for me is how I perceive personal enrichment.

As I interviewed, I pointed my questions toward the stages of Knowles' SDL theory, looking to see if Darrell, in fact, went through any of them during his travels. I tried to make the conversation flow, I used probes and dialogue inducers like "tell me more" and “oh, how so?" I paraphrased him to make sure I was understanding what he explained. Darrell honestly wanted to go on and on, which was excellent for me as he was full of stories. This might be another recurring find among participants: they have travel stories and want to share them. While I was coding Darrell's transcripts, I was able to encounter "emergent" themes, codes that I would use to label topics that did not have to do with Knowles' stages of SDL. This list of codes would be used to compare against other participants' responses as I worked through them.

Interviewing Darrell seemed more like a casual conversation between two friends. And honestly, that is what it was. My approach was to make him feel as comfortable as possible and take him, mentally, back to his travel adventures. Darrell was more than happy to invite me into his home and talk about these things while we recorded. 


\section{Participant 2: Daniel}

Daniel lived in New York City (Brooklyn) when I interviewed him. We arranged a meeting weeks in advance, and it happened that the day after the interview he was to move to Ft. Lauderdale with his partner, so the entire apartment was full of boxes. He was gracious to allow me the time to interview him with such limited time. He welcomed me into his apartment, granted the recorded interview, showed me all of the photo albums that he professionally prepared which logged all of his international travels, and we went out for lunch afterward. It seemed that he enjoyed the experience of reliving his travel adventures as much as I enjoyed the conversation myself.

Daniel wanted to begin the interview by explaining that he was from a small town (USA) and his first travel experience was going to "South of the Border," the tourist trap on the border of North and South Carolina. We both found it ironic that years later he would travel to the real "south of the border," Mexico, and explore the ancient Mayan ruins, beaches, and town. He narrated his travel stories with excitement and also discussed his living in England for a number of years and venturing throughout Europe. He mentioned his interests in architecture, history, cultures, and international cuisine. I probed for depth and detail. He explained the ways that travel has personally enriched him and I found the information to be very important and pertinent to the research focus. $\mathrm{He}$ discussed challenges that he met along the way, like being confused with currency exchanges and what to do when electricity would go out on a daily basis. I could relate to these things and figured that I would create new codes for "travel challenges" because surely this would come up again and again with participants. In fact, I thought that "challenges" or "overcoming challenges" could be a great contribution to the literature, as it relates to Knowles' stages of SDL.

\section{Participant 3: Jorge}

While I was preparing further interviews, I received my first written responses from participants that either preferred to answer my interview questions in writing or lived in a foreign country or were currently traveling abroad. Jorge sent me his responses in writing. These notes document my thought process as I read, analyzed, and coded the responses.

At first review, I felt that Jorge's responses were somewhat brief. However, I noticed that he did not go off topic but answered the questions directly and with contemplation. The recorded interviews that I conducted and transcribed did have many moments when the participant would stray off topic until I refocused their attention. These written responses, however, provided substantial data and hit the themes that I wanted to explore. 
To be honest, it was Jorge's second submission that I accepted. His first one consisted of discussing his first study abroad experience. I had to tell him that this study excludes study abroad programs done for college credit. Once he understood this, he resubmitted his responses, which directed toward other international travel experiences that he has had in his adulthood.

Jorge discussed his trip to Greece. He explained that he used a travel agent as a resource for learning more about the destination. He also mentioned that finance, or budgeting, was a challenge during this adventure. This would be a new code for this study: "budget as challenge." Because for many people, I assume, costs factor heavily on travel planning and the types of experiences that one can pursue.

\section{Participant 4: Kamal}

Kamal's interview was done in a public library in Philadelphia. I arrived first and tried to arrange a private conference room, but to no avail. The staff was not overly helpful, at first, to accommodate a private room on a Saturday morning. However, after a few minutes of sitting and thinking about what I was going to do, I got up and walked around until I found an open room in the basement. It looked more like a staff kitchen/ break room than a conference room, but it had a table and chairs, which served me just fine. After explaining to a library staff member that I would need it for about an hour or hour and a half, she granted Kamal and me access.

I basically started recording right away because I knew that he would have very interesting stories to tell. Kamal is from India and spent much of his youth in United Arab Emirates before coming to Miami for college. He talked about taking trains throughout India, traveling to Sri Lanka, and what it was like for him living in Miami. After graduate school Kamal moved to the Philadelphia/ South Jersey area for work. He explained what he sometimes feels like as a "brown guy" in this country. Not that it is out of the ordinary, but that he feels as if he is looked at as a Muslim, a threat. He has a beard, he has an accent, he feels like people treat him differently. I affirmed that when you look different from most of the local people when you travel, that you indeed get stared at a lot. That is how I felt in Colombia. People were curious about me, but at times the staring was a bit extreme.

Kamal had interesting travel stories, some of them I could use for this study, and others would not be used, as they related more to his childhood. He talked about his plans for upcoming trips, to Australia and New Zealand. And later, when I was coding his transcripts, I realized that "wanderlust" would be a recurring theme. I describe it as having the desire to continue traveling internationally once a foreign trip is over. It is that personal interest to keep seeing more and more of the planet. I am noticing that 
travelers have certain things in common, and this is one of them. You see, I know people that do not like to travel. In fact, they are content with staying home and never venturing out. But travelers, it's as if they want to keep adding more places to their list of adventures. Or so it is my opinion.

At any rate, Kamal's interview gave a unique perspective to the data of this study. I, as the writer, am seeing the world as an American traveling throughout it. Kamal is experiencing America as an Indian traveling throughout it. I was grateful to have been able to record his thoughts and opinions. Albeit he went off topic a bit and went to some deep, metaphysical places that had less to do with travel themes, it was an interesting conversation nonetheless. His whole expression of thought gave greater understanding of how he conceptualizes the world in general. By this point, I was getting better at the art of bringing people back on subject and Kamal ended up giving me solid data to use in my discussion.

\section{Participant 5: Evelyn}

I received Evelyn's responses via email because she was traveling at the time between Australia, Colombia, and Mexico. I knew that Evelyn's perspective on travel would also add to a varied range of experiences among my participants because of her being a traveling Aussie (Australian). Born and raised in Australia, she had the courage to venture across the world to the Americas to see what awaited her. Her first travel experience was at age 17 when she was awarded a scholarship to visit Mallorca, Spain. Since then, she said that she was bitten by the travel bug. This I code as "Wanderlust" once again.

Evelyn ended up studying International Business in college and was interested in emerging markets. This interest brought her to Colombia, South America. Eventually, she knew that she wanted to perfect her Spanish and work in a travel-related industry to sustain her "wanderlust" lifestyle. She discussed some of the travel challenges along the way and how she overcame them. She also talked about resources that she used to help design her learning experiences. Resources, both material and human, are a big part of Knowles' stages in SDL. One seeks out those people and things that can help them to arrive at their learning goals, you see.

I asked Evelyn if she felt like travel had changed her, forever, for good. Her response was: "Absolutely. I learned more about myself in three months on the road in Colombia in 2013 than I did in the 30 years I spent in Australia." From this, and comments made by other participants, along with my own personal feelings, I created the code "Travel speeds up experiences." I believe that what you experience during international travel can equate to a condensed, fast-paced version of "real life." What I mean is that your 
senses tend to be overloaded with sights, sounds, smells, tastes, personal encounters, and cognitive hyper-speed during your trip abroad, much more than how life is when you are back home working and doing "normal," daily things. This might be why people say that their experiences abroad changed them or altered their perspective of the world. Sometimes, it only takes a couple of days in a foreign culture to have this happen. It is incredible, it is what the theories of experiential learning and transformative learning are all about. And this concept will certainly be discussed in the write-up of the study.

\section{Participant 6: Ken}

Ken also sent me his written responses via email as he was in Spain at the time that I was doing data collection. I met Ken in Colombia and we hit it off right away. Ken and I have a lot in common as travelers. He had decided to take a two-year stint away from work to travel and improve his Spanish. See, Ken is a medical doctor, who just began a new job with a company in the health fields, and decided that not only would improving his Spanish serve him, but it was an excellent time to fulfill a dream of living abroad. So he set off to Colombia for a year and a half, then to Spain for the remaining six months. Ken's responses to my pointed questions were well-written and thoughtful and provided rich experiences to use in my research.

One theme that Ken discussed was his desire to travel and study Spanish. He said that he felt it was the right time in his life to take on an adventure (he is 45), and he had always wanted to live abroad. Further, the death of a high school friend put life into perspective a bit; he realized that the time is now to make a dream come true. This theme falls into Knowles' SDL stages of "climate setting" and "diagnosing learning need." I would create two new codes based on his testimony and the themes brought up by other participants. They would be known as "Sense of urgency" and "Bucket list." For Ken, this was part of his life's bucket list of things to accomplish and he had a sense of urgency to fulfill his dream.

Ken's responses were very direct and actually gave me the data points that I was looking for, such as providing personal accounts with the stages of Knowles' SDL model and how travel has brought him personal enrichment.

What I felt like I had in common most with Ken is that we both took time off from a professional career path to pursue lifelong dreams of travel and adventure. For me, they are one in the same. And it goes to show how important travel is for those who dream of it. I suppose that both Ken and I see the same value in the experiences that one can have through it and how it enriches ones life and career in the end. 


\section{Participant 7: Eduardo}

Eduardo talked to me about many of his travel experiences; he was full of engaging stories, actually. He began by explaining how he has always been fascinated with languages and cultures since childhood and being raised by a Puerto Rican family. Growing up, he realized that not everyone had the same cultural idiosyncrasies that he had, and he became deeply interested in learning about others. Eduardo has had the opportunity to see many places due to being sent abroad serving in the Air Force. And once he was able to see different places and experience other cultures, he decided time and time again to continue his travels (on his own) in a more self-directed learning manner. Eduardo spoke a lot about the places that he had been and interesting and unique cultural aspects that he noticed abroad, but I tried to prompt him to speak about the learning process that he employed with his lone travels. This opened him up a little. He was excited to talk about his learning goals, designs, and strategies. He discussed how much he was interested in people, cultures, languages, and history, as well as different foods and architecture, and how he made his travel plans with these things in mind.

Eduardo mentioned that he has a bucket list for travel, and this, of course, I code as "bucket list" under the stage Diagnosing learning need, because his need to travel and learn about the world comes from his need to check off his travel accomplishments. He said that he always keeps in mind that he, like everyone, is going to die one day. His sense of urgency to travel and to fulfill his travel goals is what motivates him to plan and execute his travel designs. Eduardo admitted that he has an adventurous personality, extroverted rather than introverted. And I believe that most travelers would, in fact, lean more toward extroversion, although I do not have any research statistics to back that up.

Eduardo's learning strategies focused on cultural immersion. He is a planner, like me, so he tended to do his due diligent pre-travel research, and used as many resources that he could to gather important information. And because of this, he was able to reach all of his learning goals successfully. Eduardo also talked about how travel has brought him personal enrichment and made him a better person. With that prompt, he went on to explain that he has become more humble, he has realized that you must work hard in life for what you want, and that it is important to not hold grudges. His enriching lessons I code, of course, as "personal enrichment" and "travel is enhanced by having learning goals." These areas, although not specifically identified in Knowles' stages of SDL, will be elaborated upon in my discussion. It is my focus to explain how exactly travel is enhanced by having learning goals along the way. 


\section{Participant 8: Gabrielle}

Gabrielle had always shown interest in this study, not only to participate, but to understand other participants' responses to the research questions as well. She and I both have a curiosity to understand what it is, exactly, that we get from traveling. And although we have very different backgrounds, it doesn't really matter (is my opinion). The true essence that I am looking for in this study has to do with the life lessons, personal enrichment, and the process for learning that lie in travel contexts. We each have a story to tell, and to live, but I believe that there is something in common between us travelers that we can each relate to. I believe that many travelers could relate to Gabrielle's story.

Gabrielle's responses to my questions provided an account of what it was like for someone from France to journey to the United States for a unique living/ learning experience. Gabrielle discussed how she wanted to really become proficient in English and didn't want to simply go to the United Kingdom like so many Europeans do. She was drawn to the American culture from movies that she watched growing up. She mentioned that she felt a sense of urgency to see the US from the moment that she saw the Twin Towers come down on Sept. 11. She had an uneasy feeling that if she didn't go to the US, that it might all disappear. This I would code as "sense of urgency" to travel, under the stage of climate setting.

Gabrielle's learning goal was not only to become proficient in English, she wanted to become an English teacher, in the US! She talked about some of the challenges with the language and understanding people (like roommates) with different accents (like New Orleans). But she also spoke about how she overcame many of those challenges with time. Her strategy was to surround herself with English-speaking people, and it appeared to be a strategy that would serve her well. The challenges that she spoke of, once I recognized them in the data analysis stage, I would code as "travel challenges" and "overcoming challenges." I could relate to Gabrielle's struggles as a traveler. Immersing in a Spanish-speaking country, I was able to communicate. But once I stepped foot into a French-speaking culture, I was totally lost. I could not imagine saying to myself that one day I would become a French teacher, in a French-speaking region of the world. It is not only unimaginable, it is highly respectable to have such a challenging personal goal to accomplish.

I knew that Gabrielle would have interesting stories to tell and a perspective on travel and how it brings personal enrichment. She said that she felt successful in reaching her learning goals. And she also was able to reflect on what failure would have looked like with her learning goals. That would have meant returning home and not being able to 
communicate with fluency in English. So for her, it was a dream come true and a learning experience accomplished.

\section{Participant 9: Logan}

I met Logan while I was living in Colombia, and we had a lot in common, not the least of which was our love for travel. And as a fellow traveler, I wondered what it was, exactly, that he was gaining, personally, from his experience in South America. So, I asked him, and we became friends. Not long after meeting, he headed to Peru, then back to the US. He was planning his next trip to Argentina when I asked him to tell me about some of his travel experiences for this study. I was surprised when he chose to talk about his Venezuela adventure.

Logan had an interesting travel story to tell me: it was the time that he went to Venezuela to learn how to surf and at the same time volunteer for a Christian organization abroad. I felt that this story was exactly what self-directed learning is all about_-having a learning goal, looking for resources, making a plan, executing the plan, immersing yourself in the learning experience, and evaluating your own level of learning. For Logan, it was learning a new skill. Unfortunately for him, he came to understand why there were no other Americans traveling to Venezuela - the country has been devastated politically and economically, with inflation reaching upwards of $900 \%$ and large populations living in extreme poverty. I actually am not sure how Logan didn't realize these things before planning his trip, but it turned out to be an opportunity for him, as he explained. He described the location as terribly sad, but at the same time it was an opportunity for him to be "fearless, show love and compassion, and break down cultural barriers." Talk about having a good attitude for travel!

When I analyzed his travel story later, I pulled out and coded themes that touched on Knowles' stages of SDL. And I started to feel that the more experience that I get with data analysis, the better I become at it. I actually started to feel like a professional researcher; this doctoral preparation has been quite enriching for me actually. I felt like I could take anyone's story and pull out themes to write a discussion about. And I suppose that is the purpose of being trained to do qualitative research, to build the skills that would be important to the life of a researcher. This has been my own self-directed learning experience, in many ways actually.

At any rate, Logan ends his story with how it had made him a better person and transformed him forever. It had made him independent and confident. In fact, he relates his experiences to living a "self-help book." One can read a self-help book, but it is quite different when you live an experience that brings you personal development. Logan exclaimed that "travel is greater than any class that you can take in school, or any book or 
blog that you can read." And that to me is the essence of self-directed learning in travel - getting out there, on your own, and experiencing that which cannot be lived by reading a book.

\section{Participant 10: Viktorya}

I met Viktorya a couple of years ago when we lived in the same building in Miami. I was impressed that such a young person would be on the other side of the world doing an optional professional internship at a hotel in Miami, being that she was from Romania. Fast forward a couple of years and I asked her to answer some of my questions concerning this study. Viktorya is currently living and working in Dubai, so she answered them via email. Her answers were brief, but English is not her first, nor her second language, so I will work with what I have for data mining. She discussed her experience in Miami as her travel-learning-experience. She talked about her learning goals, how the experience enriched her, and her reflection of success/failure with her learning outcomes. She actually said that it was one of the greatest experiences of her life.

When it came to answering the question about any challenges that came up and how she faced them, she could not think of any particular one. Instead, she said that it was easy for her to adapt and connect with people. At first I thought that she might be reflecting with rose-colored glasses, I thought "come on, no challenges?" But I have learned through this process not to judge what people say about their experiences nor ask them to say what I want them to say. I have tried to practice non-judgment, as I believe that people construct their own reality by putting meaning to their own experiences; and it becomes their truth. And although I am looking for the essence of commonality among participants, it is fine if some of them have different opinions. I hope that people do, in fact, differ in opinion about certain things. It makes their story unique.

I was happy to have Viktorya participate in this study because she brings a unique perspective as someone who if from Eastern Europe, speaks 5 languages, traveled to the US for a learning opportunity and chose Miami (which is very different from the rest of the US), and did so to add to her professional development. This is what self-directed learning is all about and in the world of international travel, this is what it looks like.

\section{Participant 11: Marie-Anne}

I met Marie-Anne several years ago and knew that she was a traveler. However, it wasn't until we became Facebook friends that I was able to see all of her posts and pictures of her international travels. After that, I was impressed, actually, by all of her solo adventures throughout Europe. So, I asked her to participate in this study; I thought that her input would be very insightful as it relates to self-directed learning and foreign travel. 
Marie-Anne explained that her first foreign experience was in high school, but that later on, at 25 , she would return to Europe alone, to venture through a number of locations.

Marie-Anne, like Viktorya, said that she didn't really see any challenges while she was traveling. She said, "I don't take commercial tours, I am on my own agenda, and go with what feels right." And for her, that is what works. For me, it sounded like Knowles' $5^{\text {th }}$ stage (choosing and implementing learning strategy). But I actually coded it as "travel challenges (none)" to mention later that some participants could not think of any challenges that came up along the way. She explains how she looks for new travel experiences: searches online websites, looks at her preferred airline websites, and compares travel industry deals with her own travel budget until she makes a match. This to me sounded like "budget as challenge" and coded it so.

When she discussed the concept of success/failure with learning outcomes, she actually had an example of failure with previous trips, specifically, her Panama trip. She felt like the country offered less for her to see than what she had expected. Failure to her means that she "feels nothing" for a certain location. I am discovering, actually, that many travelers make decisions and take action according to their feelings and intuition (gut feelings). Maybe we are traveling, in general, for the feelings that it brings us.

\section{Participant 12: Eric}

I met Eric while I was living in Colombia; he was actually my neighbor in a building with a mix of Colombians and a few foreign travelers and expats (American and European). Eric was an interesting guy and genuinely interested in his own learning experience. See, Eric was in Colombia to learn Spanish and learn to paraglide. Colombia was the perfect place for him with great weather, very friendly local people, a "neutral" Spanish pronunciation, and Andes Mountains. A few times a week Eric would jump off of those Andes cliffs with a group and paraglide down to Earth. He loved it.

One day Eric and I had a very in-depth conversation about my dissertation study and he was immediately fascinated. I told him that I would like to interview him and he was completely on-board. Eric's responses to my questions were insightful and thoughtful. He really provided rich detail about his experience in Colombia, his learning plans, outcomes, and his thought process in general regarding how travel enriches your life.

Eric's story touched on all stages of Knowles' SDL theory and gave me rich data to show how people, in fact, use the model for learning. It is my argument that although travelers might not consciously think about any of the stages of learning that they go through, that they do, indeed, go through them. I am just wondering, however, what will be the best way to discuss this argument in my chapters 4 and 5. I'm quite sure that I will break each stage down and show that participants passed through each stage individually, but 
stories like Eric's I would like to keep whole and show that embedded in his travel story (and others) that all stages are present. Well, it should be interesting.

\section{Participant 13: Jean Claude}

I met Jean Claude when I arrived to Quebec; he was the brother of the owner of the house where I was staying. It turned out that he was an avid traveler, having been to most parts of the world. In fact, Jean Claude only stayed in Montreal about 3-4 months per year, just enough time to work and save enough money to live abroad the rest of the year. I thought his story was fascinating and wondered if he was traveling to actually learn things about the world or just to get away. He told me all about things that he tries to learn from different cultures and languages while traveling, and some of the challenges that he has had along the way. I was happy to have Jean Claude participate in this study, and he was too. French is the predominant language in Quebec and Jean Claude's English was good, however he struggled at times. I hoped that his accounts would come across clear in the interview process. He was quite clear, and had valuable contributions to make to my data.

While I was finishing up this project, in Montreal, Jean Claude had left to go work a job for about 10 weeks in Nova Scotia. It was bitter sweet to see him leave, but such is the life of a traveler. We feel most alive when we are moving and traveling. We wished each other well and safe travels.

\section{Chapter 4: Writing the findings}

This part of the process, for me, was one of the most enjoyable. Sifting through the data to pull out direct quotes and stories from the participants to emphasize themes that I wanted to write about was actually exciting. Seeing participants' words, common phrases, common stories and anecdotes helped me to see the underlying essence of the study. As I sat in a public library in Montreal, Canada with French all around me, I was able to relate to all of their stories of travel and learning about different cultures. Each day I sat down and worked on this chapter, and I felt able to focus and be very productive. This chapter had more to do with revealing what participants had said in response to my questions. Discovering that travelers do, in fact, utilize components of Knowles' SDL model was exciting for me. It made me feel like I was about to make a valuable contribution to the literature by showing a unique application to the model: SDL in travel contexts.

\section{Chapter 5: The discussion}

I was excited when I reached chapter 5 in my project, it had meant that I was close to the end - I hoped. The discussion gave me a chance to revisit the literature review in a way 
that would combine the thoughts of previously cited authors with my data analysis conclusions. It also gave me the opportunity to answer the research questions with clear evidence. Working on chapter 5 made me reflect deeply on my own travel experiences over the past year and a half and realize the things that I, myself, had learned. I found myself agreeing a lot with what my participants had expressed, albeit, I had my own unique experiences. I felt that chapter 5 would be a chance for me to show my best work in this project, by synthesizing what I knew, what I had learned, what I had experienced, and how I had grown in this research adventure. I was excited that my words would be embodied forever in a book that I enjoyed writing so much. Implications and recommendations for future research would be a chance for me to talk to future researchers and help direct them a bit with what direction I thought this concept should take, just like I took suggestions from previous authors on this subject. In that way, chapter 5 creates a dialogue between this author and those to come. It was a real adventure and enriching experience.

\section{Presentation of the final work}

I submitted my dissertation for review, which in the end was around 150-160 pages, and after a few rounds of corrections and editing, it was approved by my dissertation chair. It was exciting, actually, that my chair found no major flaws in my write-up. The next step would be to present it to all of my professors. So, I flew in to Miami once again and met with then on a Friday morning at $10 \mathrm{am}$. I had a Power Point presentation ready to go and a few notes with which I would discuss my research. The dissertation defense lasted about an hour and a half and thankfully everyone signed the approval forms. Actually, my professors had great suggestions for what I could add to the final draft, and they genuinely showed interest in the topic and support for my research. Now, as I finish this journal, I will submit the final edition of my work to the graduate school at FIU next week, and will have the doctor of education degree conferred by next month. This concludes a journey that took me five years and living in foreign countries - essentially, my Ernest Hemingway experience. What an adventure it has been. 
VITA

\section{RICHARD JASON DAPKO}

Born, Easton, Pennsylvania

B.A., International Studies

University of South Florida

Tampa, Florida

2010

M.S., Higher Education Administration

Florida International University

Miami, Florida

2010-2015

Senior Academic Advisor

Instructor

Florida International University

Miami, Florida

2015-2016

Doctoral Candidate

Adult Education \& Human Resource Development

Florida International University

Miami, Florida 